\title{
West Virginia Education Information System users' concerns as measured by the Stages of Concern Questionnaire
}

Toni Lynne DeVore

West Virginia University

Follow this and additional works at: https://researchrepository.wvu.edu/etd

\section{Recommended Citation}

DeVore, Toni Lynne, "West Virginia Education Information System users' concerns as measured by the Stages of Concern Questionnaire" (1999). Graduate Theses, Dissertations, and Problem Reports. 3128. https://researchrepository.wvu.edu/etd/3128

This Dissertation is protected by copyright and/or related rights. It has been brought to you by the The Research Repository @ WVU with permission from the rights-holder(s). You are free to use this Dissertation in any way that is permitted by the copyright and related rights legislation that applies to your use. For other uses you must obtain permission from the rights-holder(s) directly, unless additional rights are indicated by a Creative Commons license in the record and/ or on the work itself. This Dissertation has been accepted for inclusion in WVU Graduate Theses, Dissertations, and Problem Reports collection by an authorized administrator of The Research Repository @ WVU.

For more information, please contact researchrepository@mail.wvu.edu. 
West Virginia Education Information System Users' Concerns as Measured by the Stages of Concern Questionnaire

\title{
Toni Lynne DeVore
}

Dissertation submitted to the College of Human Resources and Education at West Virginia University in partial fulfillment of the requirements for the degree of

\author{
Doctor of Education \\ in \\ Advanced Educational Studies
}

Phyllis C. Durden, Ed.D., Chair

Martha D. Dean, Ed.D.

Van O. Dempsey, Ph.D.

W. Michael Reed, Ph.D.

Frieda M. Owen, Ph.D.

Department of Advanced Educational Studies

1999

Morgantown, West Virginia

Keywords: Concerns Based Adoption Model, Mandated Change, Information Systems

Copyright 1999 Toni Lynne DeVore 


\begin{abstract}
West Virginia Education

Information System Users'

Concerns as Measured by the

Stages of Concern Questionnaire
\end{abstract}

by

Toni Lynne DeVore

The purpose of this study was to determine if there are significant differences in users' concerns related to the West Virginia Education Information System based on position, county size, length of use, and attendance at the WVEIS Data Conference. Using the Stages of Concern Questionnaire from the Concerns Based Adoption Model, 118 WVEIS users were surveyed first in June 1998. A post conference survey was mailed to the same population five months later with 80 responses being returned. Analysis of the data was done using StatView software to run an analysis of variance, unpaired, and paired t-tests. Profile graphs were completed using Excel. Additionally, nine participants from the post conference survey were interviewed to provide a more in-depth look at users' concerns.

The data suggest there is a significant difference between users' concerns and position. It also suggests there is not a significant difference among users' concerns based on county size. Overall, the data suggest a non-significant difference when examining time as a factor influencing users' concerns. A significant difference was noted in Stages 3, 5, and 6 on the pre-conference survey when comparing those attending and those not attending the conference. Paired t-tests were run on the results from Stages 3,5, and 6 comparing attended pre/post and did not attend pre/post. A non-significant difference was seen in the paired t-tests run on the post conference survey.

Using both quantitative and qualitative methods the innovation WVEIS was studied. Although it was a mandated change, its use has been incorporated into the culture of the school. Principals are key users and have used the system in new and innovative ways. The desire to collaborate with others concerning WVEIS is strong, especially in principals. WVEIS is being used, principals are a key to the success, and staff development should focus on best practices and be position specific. 
Chapter 1................................................................................................................................................. 1

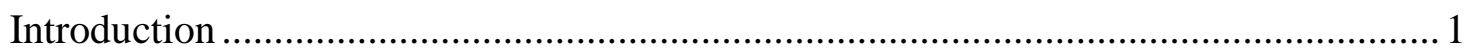

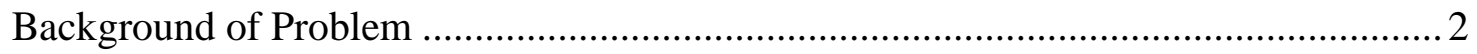

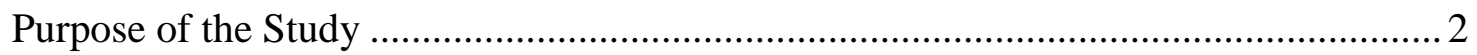

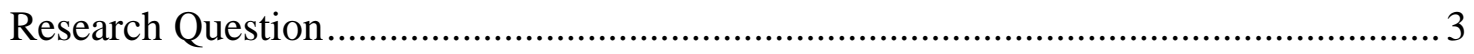

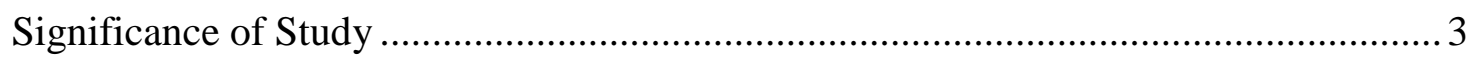

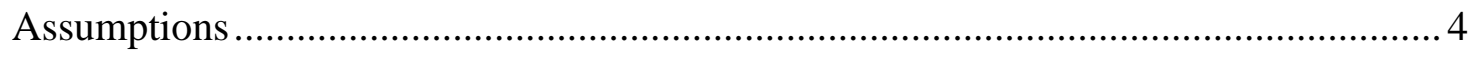

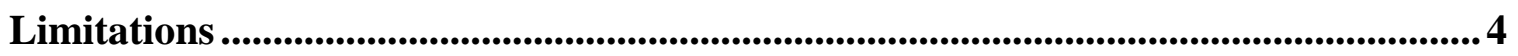

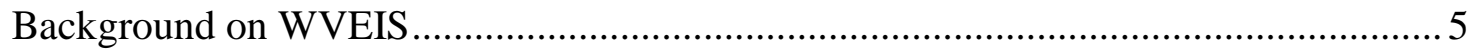

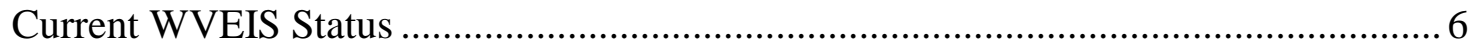

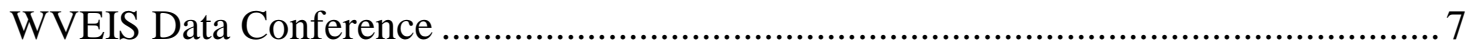

Concerns Based Adoption Model/Stages of Concern Questionnaire.............................. 7

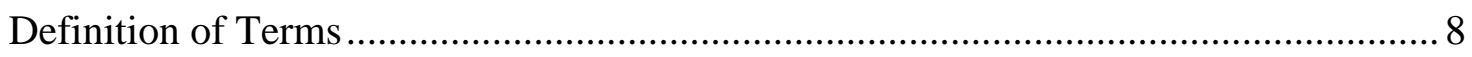

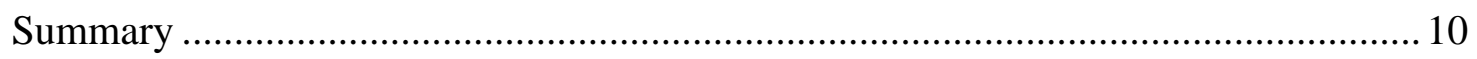

Chapter 2................................................................................................................................................ 12

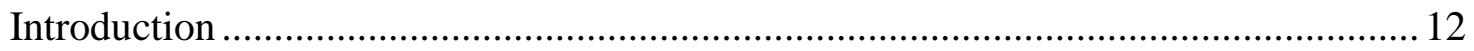

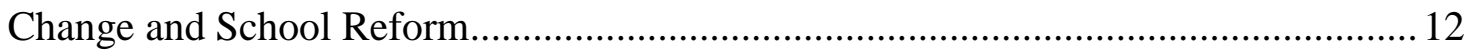

Staff Development........................................................................................ 15

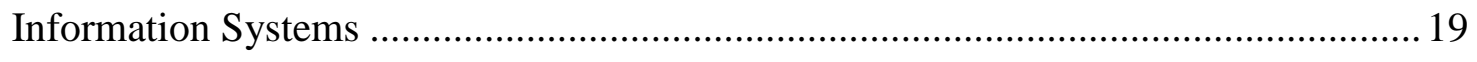

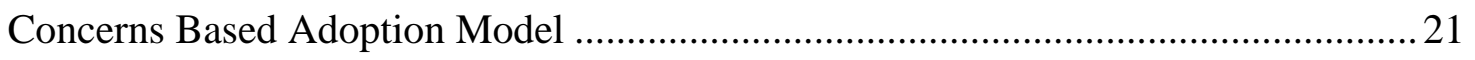

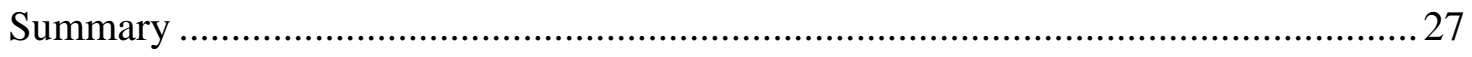

Chapter 3............................................................................................................................................... 29

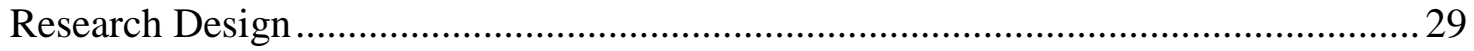

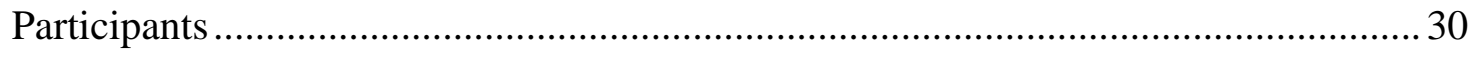

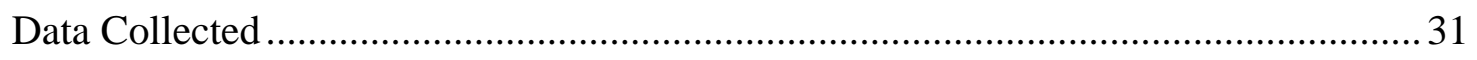

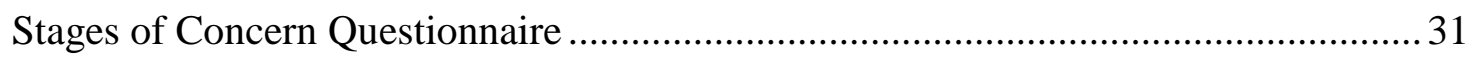


Statistical Treatment of Quantitative Data .............................................................. 32

Internal Reliability of the Stages of Concern Questionnaire.......................................33

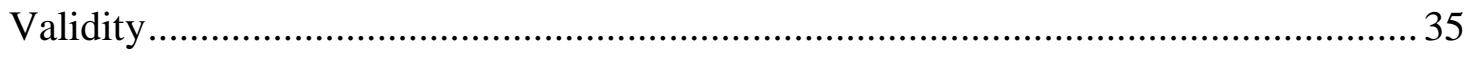

Reliability and Validity of Qualitative Research (Interview) .................................. 37

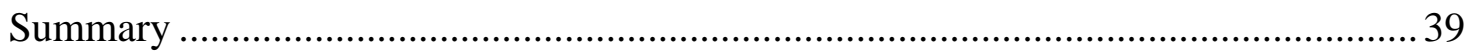

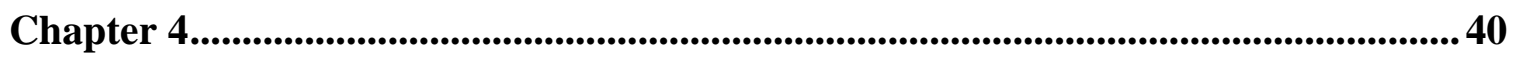

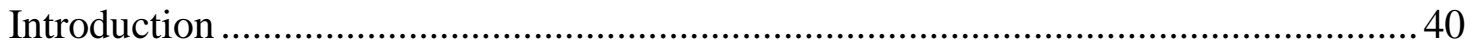

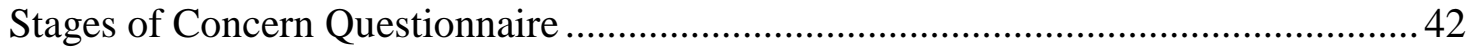

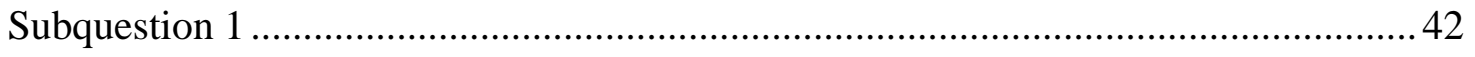

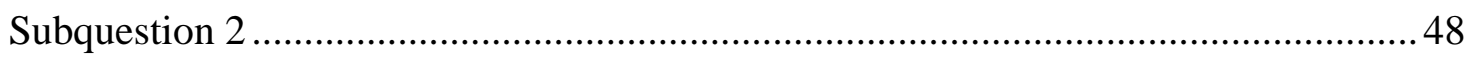

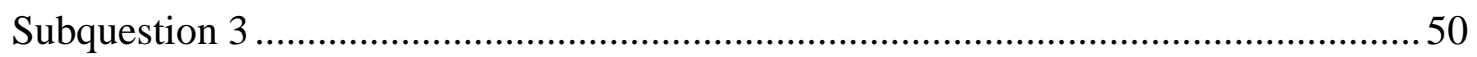

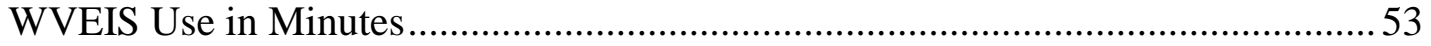

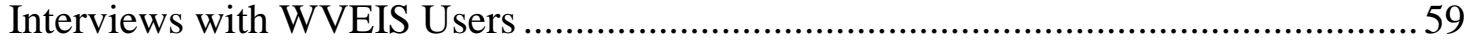

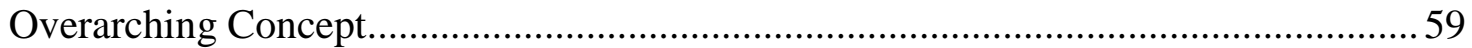

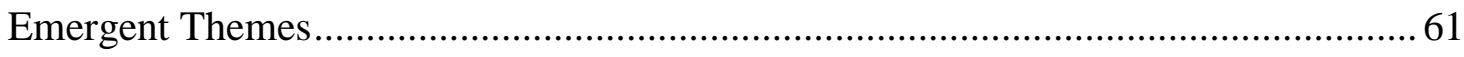

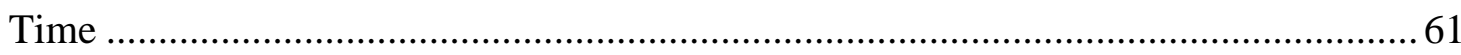

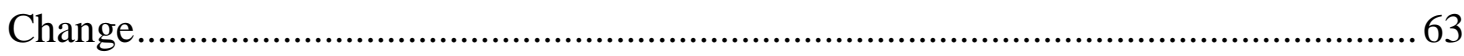

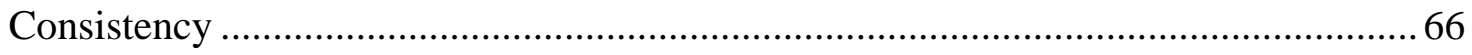

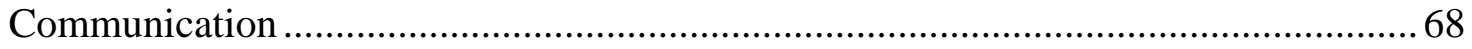

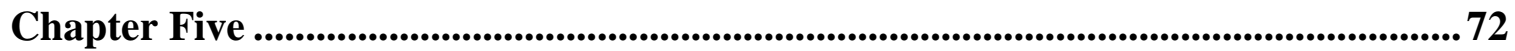

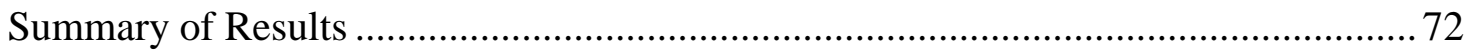

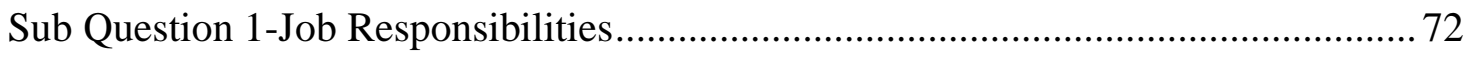

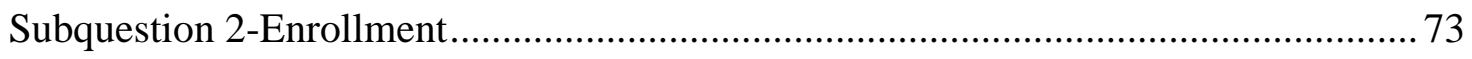

Subquestion 3-Amount of Time (Years and Daily Use) ....................................... 74

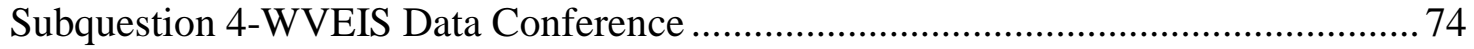

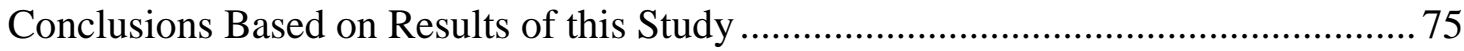

Recommendations for Further Study .......................................................... 78

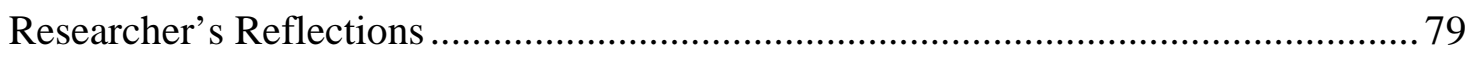

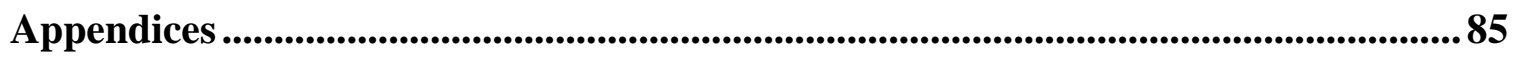




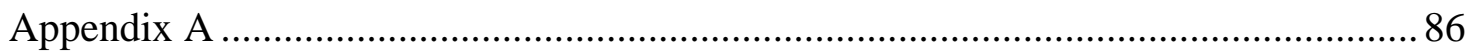

School Law Quote Regarding WVEIS................................................................ 86

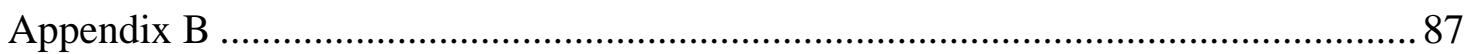

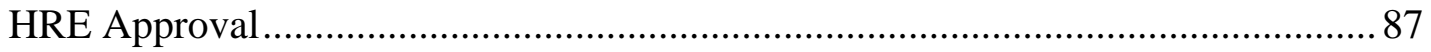

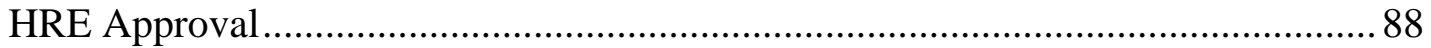

Stages of Concern Questionnaire ...................................................................... 89

Essentials of Best Practice in Professional Development for Sustained Change...... 91

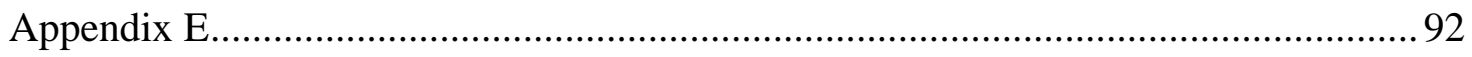

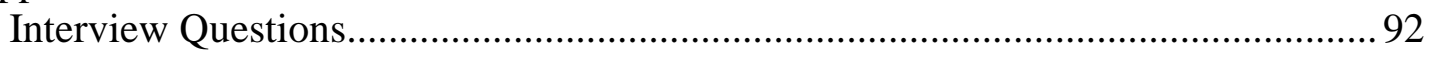

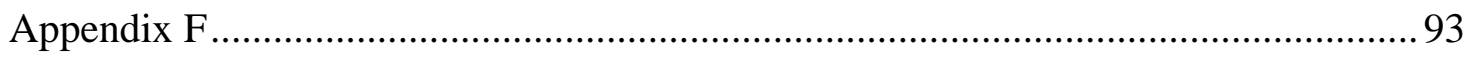

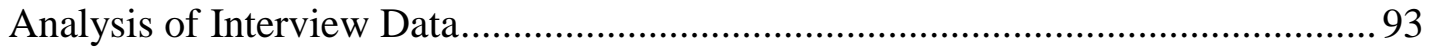

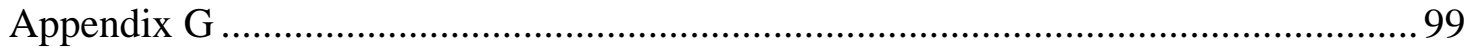

SoCQ Normed Percentiles ............................................................................... 99

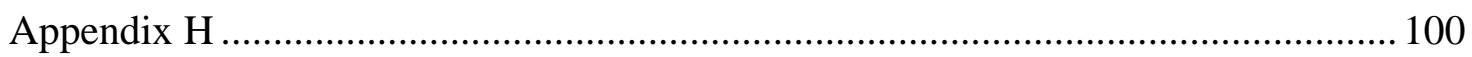

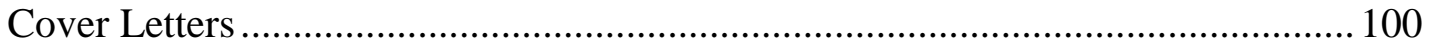

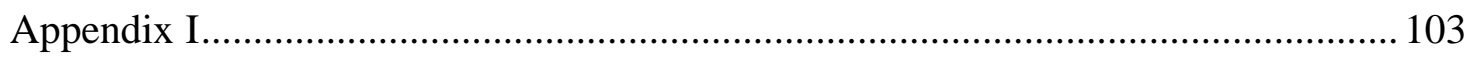

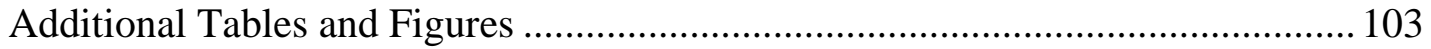

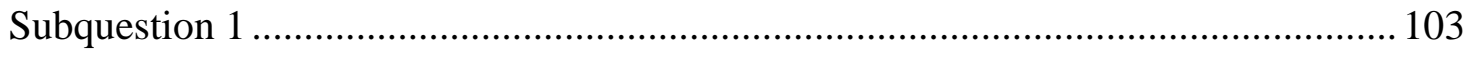

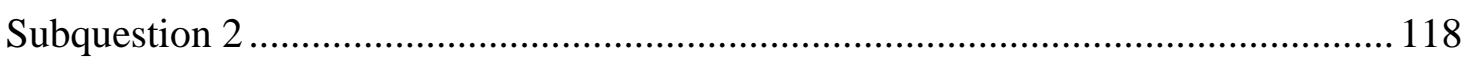

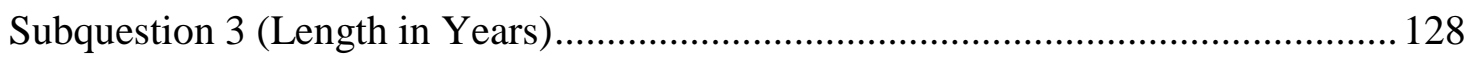

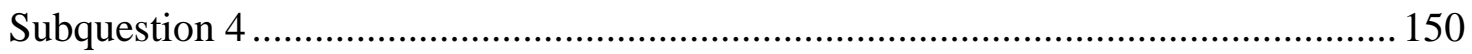




\section{LIST OF FIGURES AND TABLES}

Figure 2.1

Figure 2.2

Table 3.1

Table 3.2

Table 3.3

Table 3.4

Table 4.1

Figure 4.1

Table 4.2

Table 4.3

Figure 4.2

Table 4.4

Table 4.5

Figure 4.3

Table 4.6

Table 4.7

Figure 4.4

Table 4.8

Table 4.9

Figure 4.5

Table 4.10

Figure 4.6

Figure 4.7
Stages of Concern 24

SoCQ Arranged by Stages......................................... 25

Coefficients of Internal Reliability.............................. 34

Coefficients of Internal Reliability.............................. 35

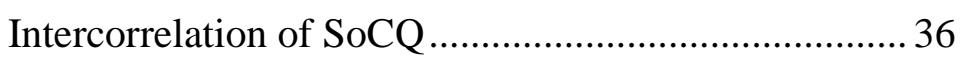

Correlation of Peak Stage.............................................. 37

Mean Scores Based on Position ................................... 43

Normed Percentile Scores Based on Position .............. 45

P-Values for Subquestion 1 ....................................... 47

Mean Scores Based on County Size............................ 48

Normed Percentiles Based on County Size ................. 49

P-Values for Subquestion 2 ....................................... 50

Mean Scores Based on Amount of Time in Years .......51

Normed Percentiles Based on WVEIS Use Years ....... 52

P-Values for Subquestion 3 (Years)............................53

Mean Scores Based on Amount of Time in Minutes ... 54

Normed Percentiles Based on Time in Minutes........... 55

P-Values for Subquestion 3 (Minutes/Day) ................. 55

Mean Scores by Stage ................................................. 57

Normed Percentiles Based on WVEIS Conference ..... 58

Pre/Post Mean Differences......................................... 58

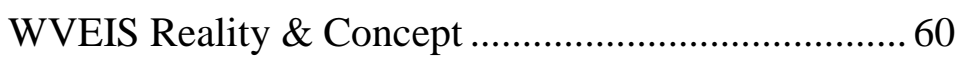

Emergent Themes................................................... 71

Subquestion 1

Stage 0

Table I.1

Anova . 103 
Table I.2

Means

103

Figure I.1

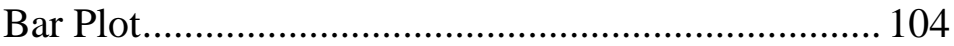

Table I.3

Fisher's PLSD 105

Stage 1

Table I.4

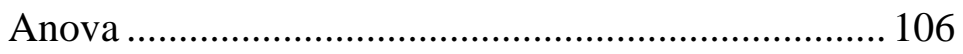

Table I.5

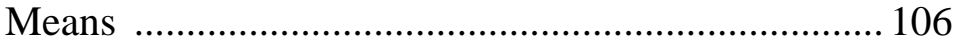

Figure I.2

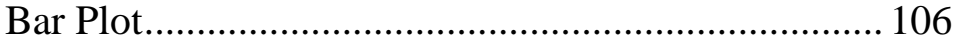

Table I.6

Fisher's PLSD

107

Stage 2

Table I.7

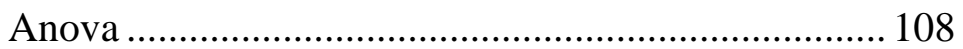

Table I.8

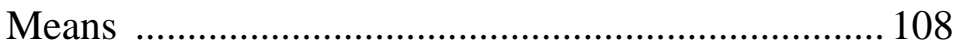

Figure I.3

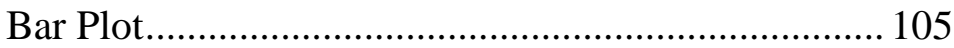

Table I.9

Fisher's PLSD

109

Stage 3

Table I.10

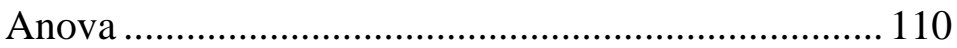

Table I.11

Means .................................................................... 110

Figure I.4 Bar Plot............................................................... 110

Table I.12 Fisher's PLSD ..................................................... 111

Stage 4

Table I.13

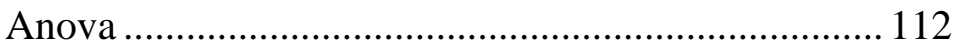

Table I.14

Means …................................................................... 112

Figure I.5

Bar Plot.............................................................. 112

Table I.15

Fisher's PLSD ..................................................... 113

Stage 5

Table I.16

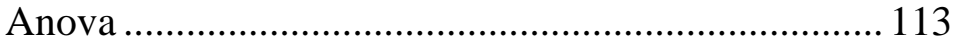

Table I.17

Means 114

Figure I.6

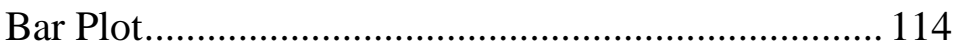

Table I.18

Fisher's PLSD 
Stage 6

Table I.19

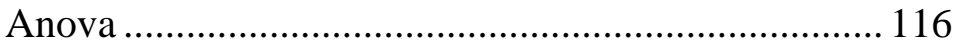

Table I.20

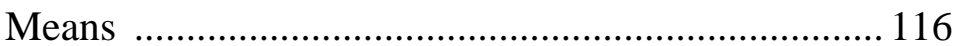

Figure I.7

Bar Plot............................................................... 116

Table I.21

Fisher's PLSD

Subquestion 2

Stage 0

Table I.22

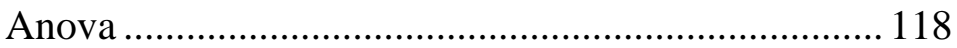

Table I.23

Means .................................................................... 118

Figure I.9 Bar Plot........................................................... 118

Table I.24 Fisher's PLSD ................................................. 119

Stage 1

Table I.25.

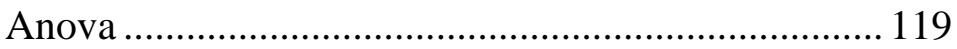

Table I.26

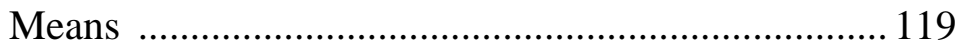

Figure I.10

Bar Plot............................................................. 120

Table I.27

Fisher's PLSD ........................................................... 120

Stage 2

Table I.28

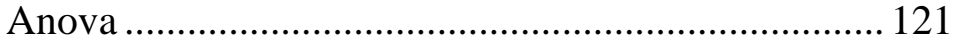

Table I.29

Means 121

Figure I.11

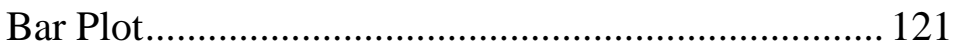

Table I.30

Fisher's PLSD . 122

Stage 3

Table I.31

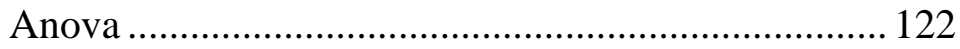

Table I.32

Means 122

Figure I.12

Bar Plot 123

Table I.33

Fisher's PLSD 123

Stage 4

Table I.34

Anova 124

Table I.35

Means 124 
Figure I.13 Bar Plot................................................................ 124

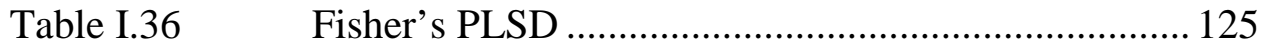

Stage 5

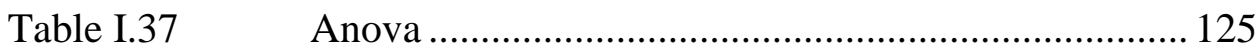

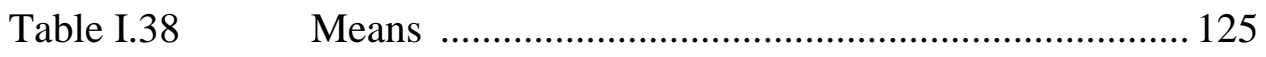

Figure I.13 Bar Plot................................................................... 126

Table I.39 Fisher's PLSD …………………………………........ 126

Stage 6

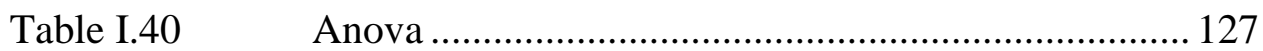

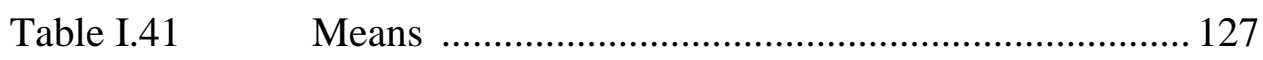

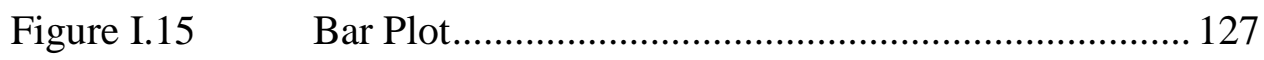

Table I.42 Fisher's PLSD …………………………................ 128

Subquestion 3 (Years)

Stage 0

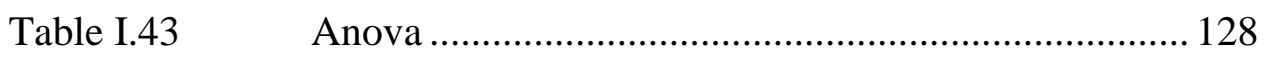

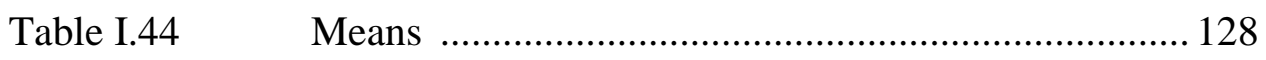

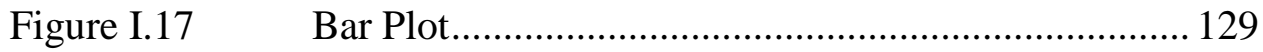

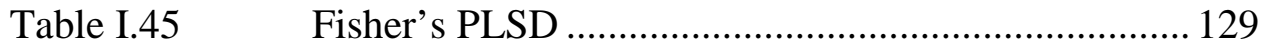

Stage 1

Table I.46 Anova ………………………………................... 130

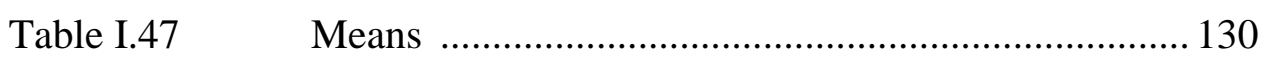

Figure I.18 Bar Plot.............................................................. 130

Table I.48 Fisher's PLSD …………………………………..... 131

Stage 2

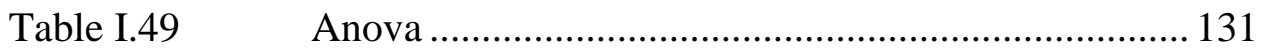

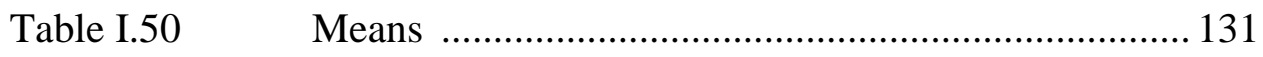

Figure I.19 Bar Plot.............................................................. 132

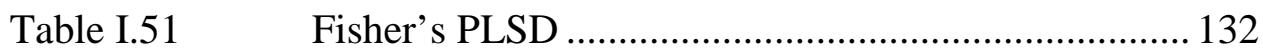


Stage 3

Table I.52

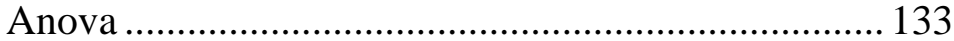

Table I.53

Means 133

Figure I.20

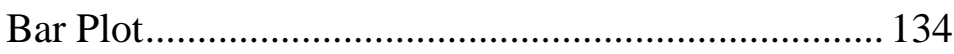

Table I.54

Fisher's PLSD 134

Stage 4

Table I.55

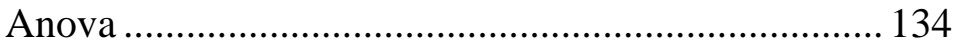

Table I.56

Means 135

Figure I.21

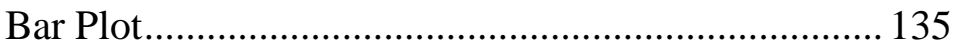

Table I.57

Fisher's PLSD 136

Stage 5

Table I.58

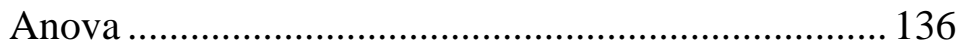

Table I.59

Means 137

Figure I.22

Bar Plot 137

Table I.60

Fisher's PLSD 138

Stage 6

Table I.61

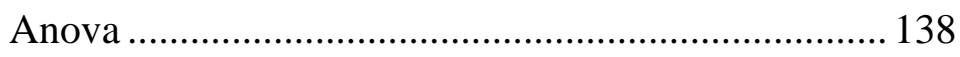

Table I.62

Means 139

Figure I.23

Bar Plot 139

Table I.63

Fisher's PLSD 140

Subquestion 3 (Minutes/Day)

Stage 0

Table I.64

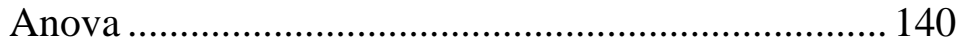

Table I.65

Means 141

Figure I.24

Bar Plot 141

Table I.66

Fisher's PLSD

Stage 1

Table I.67

Anova 142

Table I.68

Means 142 


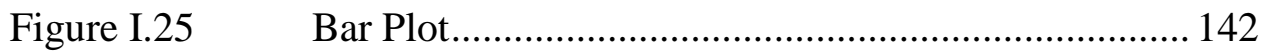

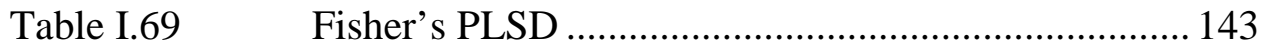

Stage 2

Table I.70

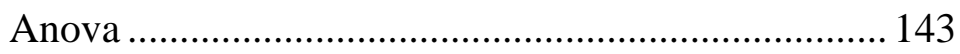

Table I.71

Means …………………………………………..... 143

Figure I.26 Bar Plot................................................................. 144

Table I.72 Fisher's PLSD ...................................................... 144

Stage 3

Table I.73

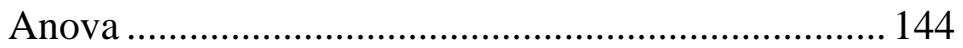

Table I.74

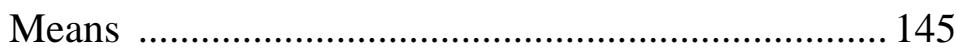

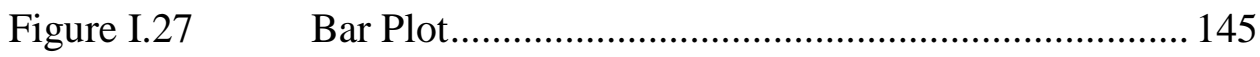

Table I.75 Fisher's PLSD …………………………………....... 145

Stage 4

Table I.76

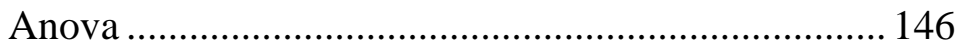

Table I.77

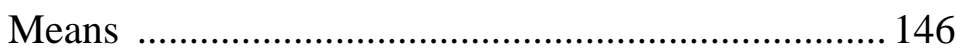

Figure I.28

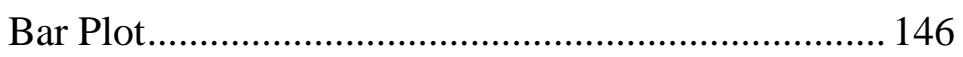

Table I.78

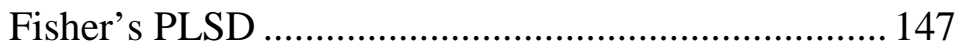

Stage 5

Table I.79

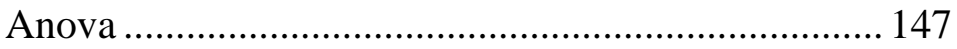

Table I.80

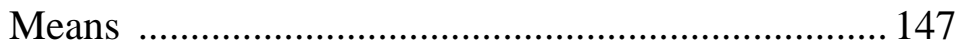

Figure I.29

Bar Plot................................................................... 148

Table I.81

Fisher's PLSD ………………………………….... 148

Stage 6

Table I.82

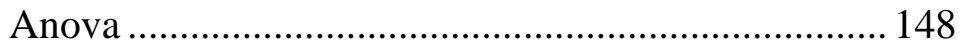

Table I.83 Means ................................................................... 149

Figure I.30 Bar Plot................................................................ 149

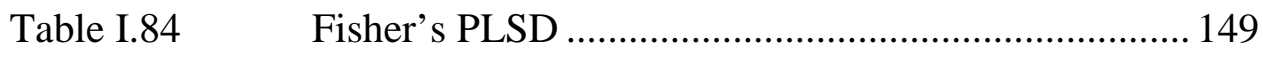


Subquestion 4

Stage 0

Table I.85

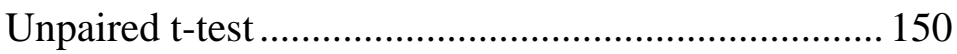

Table I.86

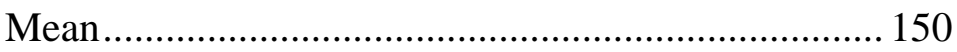

Stage 1

Table I.87

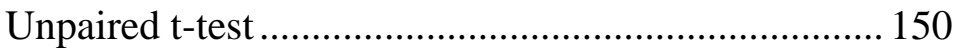

Table I.88

Mean

Stage 2

Table I.89

Unpaired t-test

Table I.90

Mean.....

Stage 3

Table I.91

Unpaired t-test

Table I.92

Mean

Stage 4

Table I.93

Unpaired t-test

Table I.94

Mean.

Stage 5

Table I.95

Unpaired t-test 152

Table I.96

Mean

Stage 6

Table I.97

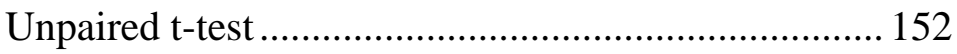

Table I.98

Mean 152

Table I.99

Paired t-test Stage 3 Attended 152

Table I.100

Paired t-test Stage 3 Did Not Attend 153

Table I.101

Paired t-test Stage 5 Attended 153

Table I.102

Paired t-test Stage 5 Did Not Attend 153

Table I.103

Paired t-test Stage 6 Attended 153

Table I.104

Paired t-test Stage 6 Did Not Attend 153 
Stage 0

Table I.105 Unpaired T-test.................................................... 154

Table I.106 Unpaired T-test....................................................... 154

Stage1

Table I.107 Unpaired t-test .................................................... 154

Table I.108 Mean............................................................... 154

Stage 2

Table I.109 Unpaired t-test ................................................... 155

Table I.110 Mean.................................................................... 155

Stage 3

Table I.111 Unpaired t-test ................................................... 155

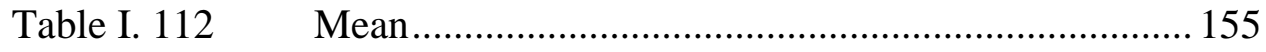

Stage 4

Table I.113 Unpaired t-test ...................................................... 156

Table I.114 Mean..................................................................... 156

Stage 5

Table I.115 Unpaired t-test ....................................................... 156

TableI.116 Mean....................................................................... 156

Stage 6

Table I.117 Unpaired t-test ...................................................... 157

Table I.118 Mean.................................................................... 157 


\section{ACKNOWLEDGMENTS}

To my family, thank you for giving me the gift of time, for your patience, your love, and your confidence in my abilities. To Joe, my husband, who offered his strength and understanding when I needed it. To my daughter, Sararose, who encouraged me to study and ran interference so I would not be disturbed as I wrote. She is truly a gift from God; her smile lights my world. To my mother, Sara, thank you for believing in me and being such a wonderful role model. I could not have completed this without your encouragement.

To April Belle Nichols, my friend, reviewer, and sounding board, thank you for your time, expertise, and sassafras tea.

To all participants who filled out the surveys, were interviewed, or reviewed the material, with out you this project would not have been possible.

To my committee: Dr Phyllis Durden, Dr. Martha Dean, Dr. Van Dempsey, Dr, W. Michael Reed, and Dr. Frieda Owen, each of you came with unique talents and individual gifts, thank you for sharing them with me and guiding me throughout my work.

As a member of Cohort II, I want to extend my thanks again to Dr. Durden for her support and guidance and to the other members of the cohort for their help and assistance in completing the program and the dissertation. 


\section{Chapter 1}

\section{Introduction}

In education today, individuals in leadership roles are expected to make decisions and set policies that have positive impacts on the schools, staff, and students they represent. Many of these decisions and policies result in some form of change or innovation. As educational leaders move schools toward the twenty-first century, changes or innovations may reflect a different school calendar, a new method of assessment, or a change in data acquisition and use. How are changes or innovations introduced into school settings? Hall and Rutherford (1978), Cuban (1988), and Fullan (1991) report the process of change as a component of educational issues.

These changes or innovations can address all levels: the classroom, the school, the district, or the state. In many cases, staff development occurs for administrators, teachers, and staff that help guide the change or innovation. The Office of Technology Assessment (1995) and the United States Department of Education (1994) cite professional development and the use of technology as two important components of school change and reform. Guskey (1994) also identified professional development as a prime factor in the change process.

How can the implementation of changes or innovations be monitored? Linda DarlingHammond, co-director of the National Center for Restructuring Education, Schools, and Teaching, discusses the use of various indicators while another method, the Stages of Concern Questionnaire, as used by Hall and Rutherford (1978), indicates the depth of implementation and identifies individuals' concerns. If the individual's concerns are addressed, then implementation of the innovation may be more accepted by the individual involved and ultimately more successful.

One of the changes experienced by schools is the acquisition, storage, and analysis of student, employee, and financial data. In West Virginia, the West Virginia Education Information System (WVEIS), a data management system, was mandated by legislative 
action. The pilot implementation of WVEIS occurred in 1989. Since then, new users have been added as counties expand their implementation, state requirements for using components of WVEIS increase, and/or personnel change at the county or school level.

\section{Background of Problem}

WVEIS is being used in some form in all 55 West Virginia county school systems. Since the pilot study and subsequent implementation of WVEIS, users include superintendents, central office personnel, building level administrators, teachers, secretaries, and other professional and service personnel. During implementation, many Regional Education Service Agencies (RESA) and counties offered various types of staff development. The WVEIS Data Conference is a statewide opportunity for staff development on WVEIS provided by the West Virginia Department of Education.

However, there have been no studies done to show the level of use or depth of knowledge users have acquired related to WVEIS. Nor have users' concerns, as defined by the Concerns Based Adoption Model, been identified. Hord, Rutherford, HulingAustin, and Hall (1987) indicate "where concerns are more (or less) intense will vary as the implementation of change progresses." Gauging the users' concerns related to WVEIS may suggest how fully the innovation WVEIS has been adopted and, consequently, how the WVEIS Data Conference impacts users' concerns

The individual is a critical factor in change. At the beginning of an innovation, Hall (1979) reports individuals usually have high personal levels of concern. As the innovation is implemented the levels of concern shift.

\section{Purpose of the Study}

The purposes of this study were to determine if there are significant differences in users' concerns related to the innovation WVEIS; to explore the impact of the WVEIS Data Conference as a staff development opportunity on users' concerns; and to study the impact of the mandated implementation of technology-WVEIS. 


\section{Research Question}

This study addressed the following question: Are there significant differences in users' Stages of Concerns about the innovation WVEIS? Subquestions included:

1. Is there a significant difference between users' concerns based on job responsibility?

2. Is there a significant difference between users' concerns based on county size as determined by student population?

3. Is there a significant difference in users' concerns based on the amount of time (years and time used during a regular workday)?

4. Is there a significant difference in pre and post-test users' concerns based on those attending the 1998 WVEIS Data conference?

\section{Significance of Study}

The intent of the West Virginia Department of Education and the West Virginia Legislature was for WVEIS to become institutionalized into the culture of school districts. The implementation of a data management system on a statewide basis constituted a challenge for the state, county school systems, individual schools, and end users. As implementation continues, users adapt to the changes in the software and hardware. Identification of users' concerns about the innovation WVEIS, as done in this study, can be used to guide decisions by the legislature and the West Virginia Department of Education about present and future efforts related to information management systems.

This research represents baseline data collected about WVEIS users in 1998. By focusing on the users' concerns about WVEIS, as identified by the Stages of Concern Questionnaire and through interviews, the depth of involvement based on concerns of those surveyed can be suggested. The analysis of data collected suggests whether the variables of position, county size, time, and attendance at the WVEIS Data conference have a significant or non-significant impact on WVEIS users' concerns as identified by the Stages of Concern Questionnaire. 
Along with the analysis of the survey results and emergent themes from interviews, the conclusions and the recommendations from this study are available to those in decision-making positions related to WVEIS. The results and recommendations can be used to tailor future decisions regarding WVEIS, the Data Conference, or other staff development offerings. The data can serve as a benchmark for continued study of users' concerns as additional requirements and refinements to WVEIS are introduced.

\section{Assumptions}

In conducting this research the following assumptions were made:

1. All schools have similar administrative tasks and the same required state level reporting.

2. The expectation and legislative mandate are to use WVEIS in accomplishing those tasks.

3. The use of WVEIS as a management information system appears to have firm backing from the West Virginia Department of Education and its use is expected to continue.

4. Not all counties have implemented WVEIS in the same fashion or time frame.

5. The staff development for all users was not the same.

6. WVEIS users want to become more proficient and learn about features and/or functions found in WVEIS that they do not currently use.

\section{Limitations}

This research focused on users' concerns related to the innovation WVEIS. The following limitations need to be considered when examining the results obtained:

1. The results obtained by the use of the Stages of Concern Questionnaire can only be as valid as the respondent was conscientious in completing the SoCQ and the interpreter was in developing subquestions (Hall, Rutherford, and George, 1986). 
2. Inherent in the design of the SoCQ, Stage Four: Consequences, deals with the impact of the innovation on the student. WVEIS does not directly impact the student in the curriculum area. It is assumed that this stage would be low consistently throughout those surveyed.

3. Only surveys from county employees will be included in the study.

4. This study was conducted in West Virginia only.

5. Only WVEIS users were included in the population.

6. This study utilized a limited sample of WVEIS users.

\section{Background on WVEIS}

In the mid to late 1980s, the West Virginia Department of Education began a search for a way to provide consistent and accurate data about West Virginia schools. When requests for student and employee information came from the legislature, difficulties arose in compiling and reporting that information in a consistent and timely fashion (Burdette, 1998). At that time, county school systems across West Virginia used a variety of methods to maintain student, employee, and financial records. Some of the larger counties had their own computer systems and data management personnel to deal with finances. Other counties took part in a variety of methods. One method included an early version of the SIMS software used in WVEIS today. Some counties generated report cards with the computer while others hand recorded grades. Due in part to this lack of uniformity, the effort to gain a global picture of education in West Virginia faced many challenges. A solution to provide timely, consistent, and summative data about students, employees, and finances became a priority.

Working with educators first and then individuals responsible for data processing in education, the West Virginia Department of Education developed a request for proposal for a data management system to encompass all West Virginia schools. In 1989, efforts in the West Virginia Department of Education, the West Virginia legislature, and in Governor Gaston Caperton's office resulted in three West Virginia county school systems 
piloting a management information system. This system passed into West Virginia state code in 1990 (School Laws of West Virginia, 1995). Officially designated the West Virginia Education Information System (WVEIS), state code required compliance by January 1991. The requirement for WVEIS implementation is outlined in West Virginia code18-2-26 found in Appendix A.

As WVEIS implementation progressed, the impact of this data management system infiltrated day-to-day routines in schools from methods of communication and reporting to financial statements.

\section{Current WVEIS Status}

In its current configuration, WVEIS is a wide area network based on West Virginia's eight Regional Education Service Agencies (RESA). At each RESA, an AS400 computer is configured as a server. Connected, at a minimum, to $56 \mathrm{~KB}$ telephone lines, sites in each county and the West Virginia Department of Education communicate within and across RESAs. Sites may include schools, central offices, bus garages, or warehouses. At these sites, computers hold software programs that allow the remote computers to communicate with the server. The nine servers provide the central data processing for the WVEIS network.

Software resides on the servers that cover four major components of data management. Student management system (SMS) features scheduling, attendance, grades, and student demographic data. The financial management system (FMS) is a general ledger component that handles purchase orders, warehousing, and accounts payable. Payroll, located in the employee management system (EMS) integrates with the human resources management system (HMS) in a variety of tasks. Some counties use an automated substitute calling system that pulls information from EMS and HMS. The four management systems comprise a relational database used in West Virginia schools.

Each WVEIS user is assigned a unique user name, password, and level of security.

When users log on, menu driven screens provide a path to access different components of WVEIS. The component, OfficeVision, is an added email feature. The user name also 
serves as an address that permits users to send and receive email throughout the WVEIS system. This email system, used by the West Virginia Department of Education and other WVEIS users, can be interfaced with the Internet.

WVEIS provides principals, counselors, central office, and state department personnel access to information. For example, a school principal may call up a student or teacher schedule; at the central office, budgets are reviewed. The state department cannot "see" individual records but receives specified summative reports electronically through WVEIS. Samples of reports generated include a second month report on enrollment (SMS), a certified list of teachers (EMS), and a year-end financial statement (FMS). As a uniform approach to information systems, WVEIS provided all counties with the same tools.

\section{WVEIS Data Conference}

Organized by the West Virginia Department of Education, the WVEIS Data Conference is held each year in June. In 1998, notification of the meeting was sent out to county contacts and other users in the spring with a request for presenters and needed session topics. A tentative agenda was sent which included eight concurrent sessions and two general sessions. Posting the tentative agenda via email, those interested registered through OfficeVision. The conference was held June 22-24, 1998.

\section{Concerns Based Adoption Model/Stages of Concern Questionnaire}

The Concerns Based Adoption Model (CBAM) articulated by Hall and Loucks (1978) is based on research by Frances Fuller. CBAM measures concerns toward change. Only through changes in individuals can systemic change in schools be achieved (Fuller 1969). In 1979, Hall reported that at the beginning of an innovation, individuals have high levels of concern at Stages 0-Awareness, Stage 1-Informational, and Stage 2Personal. First, individuals are concerned about becoming more knowledgeable about the innovation and how it affects them personally. As individuals use the innovation and become more knowledgeable, then Stage 3-Management concerns are more evident. With more experience and skill, the individual's concerns with the innovation move 
toward Stage 4-Consequence, Stage 5-Collaboration, and Stage 6-Refocusing. Ownership of the innovation and commitment to its use are reflected in the higher stages. Based on Concerns Theory (Hall, 1979) a pattern to the intensity of different stages of concerns can be linked to the change process as implementation of an innovation occurs. Chapter 2 provides additional information about CBAM and the SoCQ.

\section{Definition of Terms}

The following definitions and acronyms are submitted for clarification of terms used in this study:

Administrators-those individuals charged with the operation of schools at the local, county and state level.

\section{CBAM-see Concerns Based Adoption Model.}

Concern-defined by CBAM as the concept to describe the perceptions, feelings, motivations, frustrations, and satisfactions of each individual who is approaching a change, initially implementing an innovation, or developing skill in using an innovation. Concerns appear to move through stages and can be measured by the Stages of Concern Questionnaire.

\section{Concerns Based Adoption Model (CBAM)-a model that focuses on measuring an} individual's concerns toward an innovation. Developed by Gene Hall and Susan Loucks in 1978; it is based on the research of Frances Fuller.

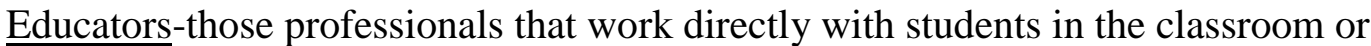
guidance office - teachers and counselors.

EMS-employee management system, a component of WVEIS.

FMS-financial management system, a component of WVEIS.

Faculty Senate Day-half-day a school month is mandated for site based faculty meetings. Many counties tie a half-day of staff development to these meetings. 
HMS-human resource management system, a component of WVEIS.

Infrastructure-the wiring needed to connect computers to a network.

Information system-all informal and formal, manual, computer-supported, and verbal activities directed at collecting, distributing, and processing all kinds of data within an organization (Visscher, 1996).

Innovation-the term used to refer to the specific change that is being examined; in this dissertation, the innovation is WVEIS.

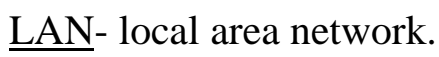

Management Information System-an organized method of providing past, present, and projected information related to the operation of the system from a unique set of data entries (MIS).

$\underline{\text { Regional Education Service Agency- in West Virginia, one of eight regional centers }}$ charged with responsibilities for WVEIS and other educational programs.

RESA- Regional Education Service Agency.

SBA-School Building Authority.

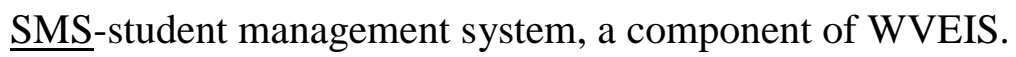

SoCQ-Stages of Concern Questionnaire is a 35-item questionnaire with a seven-point scale response format, a component of the Concerns Based Adoption Model.

Student management system-a unique set of data entries that carries standard information about a student including vital statistics, test data, and scheduling information.

User-an individual with an account and password used to access WVEIS.

WAN-wide area network.

WVDE-West Virginia Department of Education. 
WVEIS-West Virginia Education Information System.

\section{Summary}

Change and school reform occur at all levels. One change experienced by schools is the acquisition and analysis of data. School systems from around the world have implemented different methods for dealing with data. West Virginia addressed this issue through the West Virginia Education Information System. This change affected every county. Responding to the need by legislators for accurate and up to date information about schools as they address K-12 educational issues, WVEIS was mandated. Through its adoption and use, WVEIS infiltrates the day-to-day routines in schools from methods of communication within counties and the state to the electronic submission of state required reports.

As the responsibility for change is examined, most authors identify the importance of the individual in promoting sustained change (Fullan, 1996).

The staff development that accompanies school reform is a factor in changing the attitudes, culture, and actions of individuals involved in the change or innovation. Staff development is needed not only to address the process but individuals' concerns. Different views on what staff development should look like exist. Conferences, workshops, and after-school sessions are all examples. The constructivists believe learners should create their own knowledge structures while others with a good base of understanding may benefit from fewer hands-on methods. Regardless of the approach, staff development is a vehicle to implement reform.

For WVEIS, different models of staff development existed at the county, RESA, and state level. One avenue for state wide staff development is the WVEIS Data Conference.

Using the SoCQ, WVEIS users' concerns are identified and examined in relation to position, county size, and length of use. The impact of the WVEIS Data Conference on users' concerns was also examined. As WVEIS evolves adaptations, further uses, and 
additional requirements will impact users and affect users' concerns. It is imperative that these concerns are identified and addressed in order to better implement the innovation.

The importance of this dissertation for educational leadership is two-fold. First, information systems permeate education, in West Virginia it is WVEIS. In order to acquire the needed information to make appropriate decisions, leaders need access to and an understanding of the data. Secondly, leaders must be able to identify the concerns of those involved in a change or innovation to provide opportunities to address not just process skills but individual needs.

As innovations are introduced or mandated, educational leaders must respond to the needs and concerns of those implementing the innovation. When opportunities are provided that address individual needs, in addition to process skills, the opportunity for greater depth of implementation increases.

A review of the literature is found in Chapter 2 with strands covering change, information systems, professional development, and the Concerns Based Adoption Model. Chapter 3 describes the study's methodology that includes data collected through the SoCQ and nine interviews. The results generated from the analysis of variance, unpaired, and paired t-tests of the questionnaires are reported in Chapter 4. An analysis of the interview questions with the four themes that emerged is also in Chapter 4. Summary, conclusions and discussions based on the study's findings are in Chapter 5 along with recommendations for future study. 


\section{Chapter 2}

\section{Review of Literature}

\section{Introduction}

Reviewing the educational literature, four strands were considered; change and school reform, staff development, information systems, and the Concerns Based Adoption Model. Change and school reform are relevant topics in educational literature. This topic was identified as the first literature strand and was examined through articles by Linda Darling-Hammond, Michael Fullan, and others. The second strand, staff development, is identified as an essential component to change. Speck, Sparks and Hirsh, and DarlingHammond are a few of the authors reviewed in the staff development strand. Visscher and Telem are contributors to the strand on information systems. The Concerns Based Adoption Model developed by Hall and Loucks is the last strand of literature reviewed. From CBAM, the SoCQ was the instrument used in quantitative data collection. Bringing these four strands together allow for a more complete picture of change, technology, and staff development, as they relate to the innovation WVEIS, to develop. The review of the literature also highlights the theoretical views and ideas related to the four strands and to research done in those areas.

\section{Change and School Reform}

The topic of change and school reform is easily found in educational literature and in the day to day efforts in schools and school systems. Schools are inundated with change efforts. Some efforts are directed at teaching and learning at the classroom level, grade configurations in middle schools, and block scheduling for high school students. Goals 2000, Schools To Work, site based management, effective schools, and systemic school initiatives (SSI) are just a few of the changes experienced in educational environments. Identified as school reform, these efforts are experienced at all levels and locales in education. In order to build a system to meet world class standards schools are expected to restructure (Osborne, 1993). 
In reflecting on twenty-first century schools, Darling-Hammond (1994) identifies three major themes of school reform. The first theme is creating learner-centered schools, followed closely by teacher professionalism. Included in teacher professionalism is mentoring, collaboration in planning, and individual professional development. With accountability as the third theme, a method for gauging the effectiveness of the reform is a component for the student, teacher, and administrator. In order to accomplish the goals Darling-Hammond (1994) recommends "a shift in our approach to school reform, from pursuing top-down standardized solutions to acknowledging the need for local energy, local ideas, and flexibility." She remarks (Darling-Hammond, 1997) that the "agenda for change is an ambitious one" and encourages a "genuine right to learn."

In a discussion of school reform, Fullan (1996) characterizes the efforts thus far as piecemeal and not likely to make a difference. He identifies two sets of strategies as the keys to change; “(a) those pertaining to teacher preparation and teacher development throughout the career, and (b) those related to school development" (Fullan, 1996). In order to examine the complexity of the change process Fullan identifies eight lessons of change. They are "inevitably, empirically, and theoretically nonlinear." The eight lessons are:

1. You cannot mandate what matters. When change is mandated, policies are likely to receive only superficial compliance. Ultimatums often prove ineffective.

2. Change is a journey not a blueprint. No one can anticipate and predict every effect a change may cause. This is another metaphor for Chaos Theory.

3. Problems are our friends. Problems are inevitable and no matter how well planned, growth occurs when problems are solved.

4. Visions and strategic plans come later. You cannot create a vision by talk. It must be demonstrated not just written down. 
5. Individualism and collectivism must have equal power. We walk a careful path between teacher isolationism and group think.

6. Neither centralization nor decentralization works on its own. Some combination of bottom-up, top-down is needed.

7. Connection with the wider environment is critical for success. Schools must be collaborative within their environment but maintain connections to the outside.

8. Every person is a change agent. Each of us has the capacity to deal with change and can affect the system (Fullan, 1996).

Fullan expresses concern over fragmentation, overload, and incoherence of too many different innovations.

The phrase, as the pendulum swings, characterizes Cuban's (1988) concerns over why some reforms seem to be adopted repeatedly. He attributes some of these changes and reforms to reflect larger socioeconomic and political issues. Schools are continually trying to come to grips with external demands and competing values.

Hall and Hord (1987) suggest educational reforms have not been successful in accomplishing the goals of the innovation. Too often the innovators have failed to examine the attitudes, values, needs, and concerns of those implementing the change (Hall and Hord, 1987; Fullan and Miles, 1992; and Vaughan, 1997).

Vaughan (1997) reconfirms the intense personal concerns teachers exhibited in research about SchoolNet technology. Only knowing that they would have to implement the technology effort, teachers were not initially concerned about managing the technology or how it would impact students. Teachers were more concerned about how it would impact them. 
Improving schools must include a focus on the educational culture (Osborne, 1993). In order to focus on the culture, attention must be paid to the individual and his/her concerns.

Change can become effective and more successful if the concerns of those implementing the change are considered (Hall and Hord, 1987). The perceptions and feelings of those involved in the reform will determine whether change actually occurred.

\section{Staff Development}

The mechanism used in most educational settings to introduce change is staff development (Fullan and Miles, 1992). As new curriculums, innovations, and procedures are adopted, mandated, or implemented, those involved must incorporate new skills, attitudes, and techniques. In order to accomplish these and other changes staff development becomes a component in educational circles and in reform efforts. Tiede (1992) describes the essential nature of staff development especially when technology is the innovation or change.

Darling-Hammond and McLaughlin (1995) emphasize the importance of life-long learning as it relates to educators. To incorporate new ideas, skills, and concepts educators may find staff development the opportunity to form "learning networks" (Fullan, (1996). When staff development addresses educators needs in an appropriate fashion, it can become one vehicle for life long learning in the educational community.

Sparks and Hirsch (1997), The Office of Technology Assessment and Speck (1996) identify staff development at the center of education reform strategies and necessary for bringing about successful reform. Anne Lieberman, Linda Darling-Hammond, and Milbrey McLaughlin are quoted by Sparks and Hirsch (1997) as calling for new forms of

professional development. Teachers are expected to engage students in the classroom and should have the same opportunity themselves in staff development sessions. Staff development must provide teachers opportunities to discuss, think about, try out, and hone new practices. This is not a two-or three-day event in the school calendar. This is a change in the culture of staff development. 
Three ideas are currently altering the shape of schools and staff development (Sparks and Hirsch, 1997). These ideas are results-driven education, system thinking, and constructivism. In results-driven education teachers and administrators acquire new instructional knowledge and skills.

Sparks and Hirsh (1997) incorporate ideas by Senge, as they characterize "systems thinking as a framework for seeking interrelationships rather than things, for seeing patterns of change rather than static snapshots." Other aspects of systems thinking is that change is continuous and the application of well-focused actions and leverage can sometimes produce significant improvements.

Constructivism is the third element causing changes in staff development. Believing that learners create their own knowledge structures, constructivists apply the terms thinker, creator and constructor to the learner (Sparks and Hirsh 1997). This type of staff development "will include activities such as action research, conversations with peers about the beliefs and assumptions that guide instruction, and reflective practices such as journal keeping" (Sparks and Hirsh, 1997).

As found in the effective schools reform, best practices have also been identified for staff development. Speck (1996) identifies twenty essentials of best practice that incorporate many of the previous concepts. These practices were identified in a federally funded staff development project undertaken by the Cupertino Union School District, California. "The evaluation looked at elements of professional development that contributed to sustained change" (Speck, 1996). The following four practices relate to this study:

1. Professional development is a multiple, diverse, and ongoing process, not a oneshot approach.

2. The principal is the key.

3. School districts must provide resources.

4. Coaching and systemic support are required for the efforts to grow professionally. 
The complete list of essential practices as identified by Speck (1996) is found in Appendix D.

Staff development is one vehicle to implement sustained change (Sparks and Hirsch, 1997; Darling-Hammond and McLaughlin, 1995). It must focus on the needs of the participant and address not just procedures but concerns generated by the reform (Hall and Hord, 1987). In the literature Fullan, Cuban, Osborne, and Speck address the need and importance of staff development. The challenge for those scheduling and conducting staff development is to move beyond the knowledge level of providing information and include changing the concerns, skills, and practices of those attending (Hall and Hord, 1987)

Educators are required in West Virginia Education Policy 2510 to attend eighteen hours of staff development each school year. In West Virginia Education Policy 5500, the required staff development must address one of the following topics:

1. educational priorities for West Virginia but not limited to implementation of regulations, trends, and issues at local, regional, state, national, and international levels

2. the areas of study in which you are currently teaching

3. teaching strategies appropriate to those areas of study

4. classroom management skills

5. techniques appropriate for learners with various exceptionalities and learning styles

6. alignment of instructional goals and objectives with effective strategies, methods and/or techniques

7. student and program evaluation methods and instruments 
This is a minimum and cannot possibly cover all aspects of change encompassed in schools. In some instances, the staff development is organized from the state level; it may be county wide; or school directed. It also may come as part of a legislated mandate. Some avenues for acquiring these hours may include attendance at conferences, workshops, or sessions offered outside the school day. Other sessions are provided during regular work hours in association with days students do not attend. These days without students may be at the beginning of the school year, in conjunction with faculty senate days, or at the end of school term. Some educators attend activities during the school day with professional leave and others take part in summer activities. In 1998, the West Virginia legislature, in House Bill 4306, created a state and eight regional staff development councils to compliment the local staff development council. The role of these additional councils continues to evolve. A companion to the recent legislation is the adoption of staff development goals by the West Virginia Board of Education. In September 1998, the state board adopted the following staff development goals:

1. Enhance instructional effectiveness through use of the Instructional Goals and Objectives (IGOs) and best practices

2. Use assessment and performance data to improve student achievement

3. Prepare students for the transition from school to post-secondary education and the world of work by implementing a system of comprehensive career development with career clusters and majors, career guidance and work-based learning

4. Ensure a physically, socially and emotionally safe environment

5. Integrate and apply technology to teaching and learning

6. Connect parents and the community to the educational process

7. For principals to become leaders of instructional leaders

Each of the above policies and goals of the state board of education demonstrate the requirement and importance of staff development for educators in West Virginia. 
As WVEIS implementation began, RESAs and counties employed various methods of staff development. The one common opportunity open to WVEIS users statewide is the WVEIS Data Conference held each year. Attendance and participation in this conference addresses implementation of state regulations, Policy 5500, goal 1.

\section{Information Systems}

One change experienced in education settings is the implementation of information systems. "The concept can be used in a very broad sense referring to the information system of an organization which encompasses all formal and informal manual, computersupported, and verbal activities directed at collecting, distributing, and processing all kinds of data within an organization" (Visscher, 1996). A few examples include the classroom use of the Internet to research a science assignment, scheduling students for the next school year, and report cards. Visscher (1992) provides a more refined and limiting definition for information systems. "An information system is based on one or more computers, consisting of a database and one or more computer applications, enabling the user to record, process, retrieve, output, and distribute data." This research focused on the more narrow definition; especially tasks more commonly associated with administrative duties and data collection. The appearances of information systems have changed as educational needs and uses have expanded. There is no standard configuration or scale. Some information systems cover single schools; others encompass districts, states, or nations. In some cases, use of these systems is voluntary in others use is mandated. As the technology changes, the contents and concept of information systems also under go change. For West Virginia the information system, WVEIS, is a mandated statewide effort that evolves continuously.

Implementation of an information system is a challenge for any organization; schools are no exception. Telem (1996) identifies the benefits of introducing an information system to school systems as a contribution to improving performance and strengthening educational leadership. Visscher (1996) correlates the support provided by an information system to the number and type of computer applications included. Examples of common 
features could include student registration, financial planning, attendance, registration, and educational evaluation.

In a short history on information systems, Visscher (1996) identifies teachers as the first to create "amateurish school administrative programmes." Software vendors in the United States entered the market during the 1960s with the first business applications that included financial and payroll packages. Hong Kong, the United Kingdom, the United States, and the Netherlands had initial school administrative computer applications by the late 1970s.

From 1970-1980, the expansion stage saw several non-integrated clerical and administrative applications used. Because these packages lacked integration, the relationships among data were difficult to extrapolate. Even with the lack of integration, the goal of software development was to improve the efficiency of school office activities (Visscher, 1996).

The integration stage beginning in a few countries in the 1980s was characterized by management information systems and integration of modules. The stabilization stage according to Visscher (1996) "is still a dream since it requires the accomplishment of the full potential of computer-assistance, complete with system refinement and maintenance."

A variety of information system solutions can be found in educational arenas. The SCHOLIS system in the Netherlands; SAMS in Hong Kong; MUSAC in New Zealand; SIMS in Montgomery County, Maryland; DISC in the Austin Independent School District; EDT in Connecticut; and WVEIS in West Virginia are all examples of information systems found in K-12 settings around the world. There is no common path to the implementation of these information systems. Participation in some systems is voluntary, others mandatory. There are differences and similarities in all of these systems.

Two common threads surfaced in the literature on information systems. One is the desire to share information and to make available data needed in decision making. In 
research conducted in Israel during 1997, Telem (1998) discusses work done by Avidon who examined the role of the school computer-administrator. The school computer administration position was created to work exclusively with student management systems. The SCA is charged with maintaining and sharing information gleaned from the database (Telem, 1998). Another thread refers to the gains made when a critical mass is achieved (Visscher, 1996; Maughan, 1997). In each instance the importance of staff development for the user to enter, retrieve, and utilize data was highlighted. Many approaches to developing and managing information systems exist. The need to organize, analyze, and utilize data continues to play an important role in education. As technology hardware and software advance and the skills of the user become more sophisticated, the role of information systems will also need to adapt to fill future needs.

\section{Concerns Based Adoption Model}

During the late 1960s, concerns theory was developed through the work of Frances Fuller and associates at the University of Texas at Austin. Four major cluster concerns were identified: self-concern, task concerns, impact on students, and improvement concerns. Additional research suggested that these stages exist in a developmental sequence (Fuller and Brown, 1975).

Building on the work of Fuller and others, the Concerns Based Adoption Model (CBAM) emphasizes the individual and the innovation as the focus. Osborne (1993) identifies CBAM as one of three models that can develop a systems approach to educational reform because the CBAM model focuses on the user in the change process. By providing information to leaders of change Osborne (1993) notes:

To consider modifying the dynamic components of an organization, the social scientist must understand more than the awesome potency of its culture. Also vital is an understanding of human nature when confronted with the concept of change. Only by understanding that real change also involves dealing with members' deep-seated motivation can the organizational architect form a cast to mold and shape a strong, unified culture. 
Based upon work with educational innovations Hall and Hord (1986) derived the following assumptions from their experience on innovation adoption:

1. Understanding the point of view of the participants in the change process is critical.

2. Change is a process, not an event.

3. It is possible to anticipate much that will occur during a change process.

4. Innovations come in all sizes and shapes.

5. Innovation and implementation are two sides of the change process.

6. To change something, someone has to change.

7. Everyone can be a change facilitator.

The process of change is a personal experience. As an individual approaches change or implements an innovation certain perceptions, feelings, and frustrations about the innovation and the change process can be identified. The response to change is a concern; concern is described as:

The composite representation of the feelings, preoccupation, thought, and consideration given to a particular issue or task is called concern. All in all, the mental activity composed of questioning, analyzing, and re-analyzing, considering alternative actions and reactions and anticipating consequences is concern.

An aroused state of personal feelings and thought about a demand as it is perceived is concern.

To be concerned means to be in a mentally aroused state about something. The intensity of the arousal will depend on the person's past experiences, and associations with the subject of the arousal, as well as how close to the person and how immediate the issue is perceived as being. Close personal involvement is likely to mean more intense (i.e. more highly aroused) concern which will be reflected in greatly increased mental activity, thought, worry, analysis, and anticipation. Through all this, it is the person's perceptions that 
stimulate concerns, not necessarily the reality of the situation (Hall, George, and Rutherford, 1986).

Three diagnostic dimensions to assess the stages of concern about an innovation were developed (Hall and Hord, 1986). The Stages of Concern Questionnaire, Levels of Use, and Innovation Configuration represent methods for measuring aspects of the change process as experienced by the user. The seven stages of concern can be found in Figure 2.1. Briefly, the seven stages begin with self-concerns, and then task concerns which address logistics regarding the use of the innovation and end with impact concerns, which deal with increasing the effectiveness of the innovation. This study used the SoCQ to gather data on the concerns of WVEIS users. 


\section{Stages of Concern about the Innovation}

\section{IMPACT}

6 REFOCUSING: There are more universal benefits from the innovation, including the possibility of major changes or replacement with a more powerful alternative. Individual has definite ideas about alternatives to the proposed or existing form of the innovation.

5 COLLABORATION: The focus is on coordination and cooperation with others regarding use of the innovation.

4 CONSEQUENCES: Attention focuses on the impact of the innovation on the student. The focus is on relevance of the innovation for student, evaluation of student outcomes, including performance and competencies, and changes needed to increase student outcomes.

\section{TASK}

3 MANAGEMENT: Attention is focused on the processes and tasks of using the innovation. Issues related to efficiency, organizing, managing, scheduling, and time demands are of utmost importance.

SELF

2 PERSONAL: Individual is uncertain about the demands of the innovation, his/her adequacy to meet those demands, and his/her role with the innovation. This includes analysis of his/her role in relation to the reward, structure of the organization, decision making and consideration of potential conflicts with existing structures or personal commitment. Financial or status implications of the program for self and colleagues may also be reflected.

1 INFORMATIONAL: A general awareness of the innovation and interest in learning more detail about it is indicated. The person seems to be unworried about him/herself in relation to the innovation. He/she is interested in substantive aspects of the innovation in a selfless manner such as general characteristics, effects, and requirements for use.

\section{UNRELATED}

0 AWARENESS: Little concern about or involvement with the innovation is indicated.

Source: Hall, G. and Hord, S. (1987). Change in Schools:

Facilitating the Process.

Figure 2.1 
The Stages of Concern questionnaire is a 35-item instrument based on seven stages of concern. Associated with each stage are five questions. In Figure 2.2, the statements from the SoCQ are organized by stage. The survey instrument including demographic data is in Appendix C.

Statements on the Stages of Concern Questionnaire

Arranged According to Stages

Item Number Statement

Stage 0

3 I don't even know what the innovation is.

12 I am not concerned about the innovation.

21 I am completely occupied with other things.

23 Although I don't know about the innovation, I am concerned about things in the area.

30 At this time, I am not interested in learning about this innovation.

\section{Stage 1}

6 I have a very limited knowledge about the innovation.

14 I would like to discuss the possibility of using the innovation.

15 I would like to know what resources are available if we decide to adopt the innovation.

26 I would like to know what the use of the innovation will require in the immediate future.

35 I would like to know how the innovation is better than what we have now.

Stage 2

7 I would like to know the effect of reorganization on my professional status.

13 I would like to know who will make the decisions in the new system.

17 I would like to know how my teaching or administration is supposed to change.

28 I would like to have more information on time and energy commitments required by the innovation.

33 I would like to know how my role will change when I am using the innovation.

Stage 3

4 I am concerned about not having enough time to organize myself each day.

8 I am concerned about conflict between my interests and my responsibilities.

16 I am concerned about my ability to manage all that the innovation requires. 
25 I am concerned about time spent working with non-academic problems related to the innovation.

34 Coordination of tasks and people is taking too much of my time.

Stage 4

1 I am concerned about students' attitude toward the innovation.

11 I am concerned about how the innovation effects students.

19 I am concerned about evaluating my impact on students.

24 I would like to excite my students about their part in this approach.

31 I would like to use feedback from students to change the program.

Stage 5

5 I would like to help other faculty in their use of the innovation.

10 I would like to develop working relationships with both our faculty and outside faculty using the innovation.

18 I would like to familiarize other departments or persons with the progress of this new approach.

27 I would like to coordinate my effort with others to maximize the innovations effects.

29 I would like to know what other faculty are doing in this area.

Stage 6

2 I now know of some other approaches that might work better.

9 I am concerned about revising my use of the innovation.

20 I would like to revise the innovation's instructional approach.

22 I would like to modify our use of the innovation based on the experiences of our students.

32 I would like to determine how to supplement, enhance, or replace the innovation.

Source: Hall, G., George, A., and Rutherford, W. (1986). Measuring Stages of Concern About the Innovation: A Manual for Use of the SoC Questionnaire.

Figure 2.2

Work done by Bailey and Palsha (1992) propose modifying the SoCQ. Using math teachers from North Carolina involved in Algebra, training various models were evaluated and compared to the original study. In summarizing their research, they recommended including qualitative data "as a means of gathering detailed information" when studying the implementation of an innovation.

The second diagnostic dimension of the Concerns Based Adoption Model is the eight different Levels of Use (LoU). This component focuses on the behaviors that are or are 
not taking place in relation to the innovation. This also addresses what the individual is or is not doing in relation to the innovation. Three levels of nonuse and five levels of use have been identified. As in the SoCQ, Levels of Use show a progression beginning with nonuse and progressing to orientation, preparation, mechanical use, routine, refinement, integration and renewal. This tool is more complex and possibly more subtle than the SoCQ (Hall and Hord, 1984). The JeffCo Science program was monitored with the LoU instrument. It showed three to four years was necessary for the majority of teachers to move from nonuse to routine use of the innovation.

The third diagnostic tool, Innovation Configuration, addresses the innovation directly. It focuses on the description of the innovation itself and how it is being adapted (Hall and Hord, 1986). This method utilizes checklists, observations and interviews. Several research studies that utilized this method of data collection include configuration of team teaching and fidelity organization (Hall and Horde, 1984).

CBAM is used across the United States and in modified forms in the Netherlands and Flanders, the United Kingdom, other western European countries, and Australia. Bailey and Palsha (1992) identified fifty studies using CBAM through an Eric search. As an instrument to identify users concerns, CBAM provides data that identifies the concerns of those involved in change or the implementation of innovation. It is not an evaluative instrument but can be used in conjunction with staff development to address individual concerns and improve the use of an innovation.

\section{Summary}

The literature reviewed focused on four areas: change and school reform, staff development, information systems, and the Concerns Based Adoption Model, CBAM. First, the work of Fullan and Cuban noted that change is a process and second, the individual is important in creating long term change. Darling-Hammond related change is sometimes measured by indicators such as student performance or reported teaching styles. 
Sparks and Hirsh contend when staff development addresses the needs, concerns, and values of those implementing change or an innovation then sustained change is more likely. Research by Speck identified best practices related to staff development and reinforced the concept of the life long learner.

Third, a brief history of information systems was traced with work by Telem and Visscher. As school systems around the world grapple with data management, various solutions were adopted at different levels. Information system implementation occurred for a variety of reasons. In West Virginia, the need for current and reliable data in decision making propelled the use of WVEIS.

Finally, the theory and history of the Concerns Based Adoption Model was examined to illustrate the appropriateness of using the SoCQ to identify users' concerns on WVEIS and the impact on users' concerns as a result of attending the staff development provided by the WVEIS Data Conference. Brief explanations were given of the additional components of CBAM, Levels of Use and Innovation Configuration.

In West Virginia, the change investigated is the information system WVEIS. The staff development opportunity is the WVEIS Data Conference and the instrument used to monitor the innovation quantitatively is the SoCQ, one component of the Concerns Based Adoption Model. 


\section{Chapter 3}

\section{Methodology}

\section{Research Design}

Included in this study are multiple research methods. Using the Stages of Concern Questionnaire (SoCQ), quantitative data were collected. With a cross-sectional design, users' concerns were measured from a sample population. The data collected in June of 1998, the pre-conference survey, serve as baseline data of users' concerns related to the West Virginia Education Information System.

Collecting data in June and again in November provided longitudinal data used in gauging the impact of the WVEIS Data Conference on users' concerns based on several variables Administering the SoCQ before (pre-conference survey-baseline data) and after the WVEIS Data Conference (post conference survey) provided several data sets. Using the pre-conference surveys, variables of position, county size, and length of use were studied. The last variable, attendance at the WVEIS Data Conference, used pre and post surveys from individuals who attended and who did not attend the conference. The control group for the last variable came from those filling out the pre and post surveys who did not attend the conference. The dependent measure for each variable is the users' concerns as measured by the SoCQ.

Qualitative data gathered included nine individual interviews and artifacts such as agendas for the WVEIS Data Conference, field notes from selected 1998 conference sessions, and county and state memos/materials regarding WVEIS.

Nine participants were interviewed using an eleven-item instrument. Interview questions followed up on the change process and items from the SoCQ. The interviews and emergent themes provided a more comprehensive picture of users' concerns. The interview questions are found in Appendix E. 


\section{Participants}

The target population for this study included those county users of WVEIS who attended the WVEIS Data Conference and those individuals identified by their superintendents to fill out the survey sheet. Individuals who attended the conference had the opportunity to fill out the SoCQ. Of the 189 registered participants, 36 were state department or RESA. Approximately 150 attended the conference with 73 surveys completed. Five were discarded because the surveys were not complete or were filled out by RESA employees. Only surveys completed by county personnel (county level administrators, principals, secretaries, teachers, etc.) were used in this project. No surveys were included if they were filled out by RESA or West Virginia Department of Education employees.

During the same time frame, four surveys were sent to each county superintendent. Superintendents were asked to distribute these surveys to individuals who did not attend the WVEIS Data Conference. No other criteria were given. Of the 220 surveys sent to the counties, 67 were returned. Two were discarded because they were incomplete.

In order to address subquestion four, (Is there a significant difference in pre and posttest concerns of users who attended the 1998 WVEIS Data Conference and those who did not?) a post conference SoCQ was mailed directly to the 118 participants who completed the pre-conference Stages of Concern Questionnaire. The post conference survey was mailed the first of November 1998. A 50 percent return rate was exceeded when 80 surveys were completed, a return of 67.7 percent.

After identifying respondents' normed percentiles and graphing the results pre and post, nine participants were selected for interviews. The criteria for selecting those to be interviewed were based on the degree of change from pre to post conference survey on the normed percentile profiles. Three individuals with a great amount of change in the graph of normed percentiles were selected to be interviewed along with three individuals with a moderate change in the graph of normed percentiles. The remaining three interviewees were selected based on little or no change of the graphed mean percentiles. 
These interviews provided a greater depth of understanding of users' concerns and the innovation WVEIS.

\section{Data Collected}

The survey instrument used was the Stages of Concern Questionnaire found in Appendix C. The survey contains thirty five items and demographic information covering; county position, county enrollment, attendance at data conference, years of experience in education, use of other innovations, computer expertise, WVEIS expertise, staff development, length of time using WVEIS, the presence of an information system before WVEIS, and components of WVEIS used.

At the WVEIS Data Conference, selected sessions attended were described including number attending, presentation style, and technique. Documentation noted the various implementation strategies and progression of the use of WVEIS. This information was collected to provide the researcher with a better understanding of WVEIS and, therefore, will not be discussed.

Historical artifacts included memos, information sheets, and reports from counties, RESAs, and the West Virginia Department of Education. Again, this information helped provide background on WVEIS.

Nine interviews were conducted after administering and scoring the post conference SoCQ. Interviews were tape recorded and transcribed. A copy of the interview questions can be found in Appendix E with a summary of the responses in Appendix F.

\section{Stages of Concern Questionnaire}

Users' concerns about the innovation WVEIS are identified by using the refined version of the Stages of Concern Questionnaire. This instrument grew out of a need to measure concerns of administrators and teachers about using and facilitating an innovation. The survey was developed around the theory that individual concerns about an innovation move through stages that can be identified. Each stage reflects a level of intensity based upon the respondent's feelings and perceptions about the innovation. 
Developed in 1974 at the Research and Development Center for Teacher Education at the University of Texas at Austin, the survey instrument is a component of the Concerns Based Adoption Model.

The SoCQ has been used in Project CATS (Coordinated and Thematic Science), a National Science Foundation program for science in West Virginia; Rock Camp, a geology program with the West Virginia Bureau of Economic Geology; and will be used in Project MERIT, a math initiative of the West Virginia Department of Education.

\section{Statistical Treatment of Quantitative Data}

The treatment of data is described for each subquestion and includes the independent variable, dependent measure, and the statistical procedure.

Subquestion 1

Is there a significant difference between users' concerns based on job responsibilities?

The independent variable is the job responsibility; the dependent measure is the users' concern; and the statistical procedure is a one-way ANOVA on each of the seven stages. Categories with few respondents were aggregated into related positions or grouped together under Other.

Subquestion 2

Is there a significant difference between users' concerns based on county size as determined by student population?

The independent variable is county size; the dependent measure is the users' concern; and the statistical procedure is a one-way ANOVA on each of the seven stages for each county size represented.

\section{Subquestion 3}

Is there a significant difference in users' concerns based on the amount of time (years and time used during a regular workday)? 
There are two independent variables. One is the number of years WVEIS has been used; the second variable is the amount of time used each day. The dependent measure for both is the users' concern; and the statistical procedure is a one-way ANOVA on each of the seven stages for each variable.

Subquestion 4

Is there a significant difference in pre and post-test concerns of users who attended the 1998 WVEIS Data Conference and those who did not?

The independent variable is attendance at the conference; the dependent measure is the users' concern; and the statistical treatment is an unpaired t-test on pre and post conference responses from those attending and not attending the conference. Paired ttests were run on the stages that showed a significant difference in the unpaired t-test in the pre-conference survey.

\section{Internal Reliability of the Stages of Concern Questionnaire}

Hall, George, and Rutherford (1986) detailed the process of determining the internal reliability of the SoCQ as an instrument. In studies from 1972-1976, the SoCQ was used in cross sectional and longitudinal studies with eleven different innovations. Beginning in 1974, a two-year study of 830 teachers and professors provided data to calculate the coefficients of internal reliability found in Table 3.1. The alpha coefficients reflect the degree of reliability among items on a scale in terms of overlapping variance (Hall, George, and Rutherford, 1986). 
Table 3.1

\section{Coefficients of Internal Reliability for the Stages of Concern Questionnaire}

$\mathrm{N}=830$

\begin{tabular}{|c|c|c|c|c|c|c|c|}
\hline Stage & 0 & 1 & 2 & 3 & 4 & 5 & 6 \\
\hline Alphas & .64 & .78 & .83 & .75 & .76 & .82 & .71 \\
\hline
\end{tabular}

Responses to an item for an individual stage indicated a correlation higher to other items measuring the same stage than with responses to items measuring other stages. The range of these coefficients was from .61 at Stage 0 to .83 at stage 3 , which indicated a high internal reliability.

A second sampling from the same group occurred two weeks after the initial completion of the instrument. Of 171 sent surveys, 131 surveys were completed and mailed back in the retest of data. Correlations were computed and the coefficients ranged from .65 at Stage 0 to .86 at Stage 1. The correlations for the data are shown in Table 3.2 (Hall, George, and Rutherford, 1986). 
Table 3.2

\section{Coefficients of Internal Reliability for the Stages of Concern Questionnaire}

$$
\mathrm{N}=131
$$

\begin{tabular}{|c|c|c|c|c|c|c|c|}
\hline Stage & 0 & 1 & 2 & 3 & 4 & 5 & 6 \\
\hline Pearson-r & .65 & .86 & .82 & .81 & .76 & .84 & .71 \\
\hline
\end{tabular}

\section{Validity}

Hall, George, and Rutherford (1986) discussed the difficulty in establishing validity of the scores on the SoCQ as measures of the defined Stages of Concern. Because no other measures of concerns existed with which a comparison could be made, the test developers demonstrated that scores on the questionnaire related to each other and to other variables as concerns theory suggests. Intercorrelation matrices, judgments of concerns based on interview data, and confirmation of expected group differences and changes over time were components used to investigate the validity of questionnaire scores. The intercorrelation of the stages conducted by Hall and others is shown in Table 3.2 (Hall, George, and Rutherford, 1986). 
Table 3.3

\begin{tabular}{|c|c|c|c|c|c|c|c|}
\hline \multirow{8}{*}{ Stages } & \multicolumn{7}{|c|}{$\begin{array}{c}\text { Intercorrelation of 195-Item Stages of Concern Questionnaire } \\
\text { Scales }\end{array}$} \\
\hline & & 1 & 2 & 3 & 4 & 5 & 6 \\
\hline & 1 & 1.00 & .68 & .47 & .21 & .21 & .19 \\
\hline & 2 & & 1.00 & .78 & .43 & .37 & .43 \\
\hline & 3 & & & 1.00 & .60 & .51 & .59 \\
\hline & 4 & & & & 1.00 & .82 & .80 \\
\hline & 5 & & & & & 1.00 & .77 \\
\hline & 6 & & & & & & 1.00 \\
\hline
\end{tabular}

The highest correlations were found between the rating of participant concerns by investigators and the rank order of percentiles scores. These correlations are shown in Table 3.3 (Hall, George, and Rutherford, 1986).

In the 1974-1976 study, the participants concerns were estimated after individual interviews. The estimates of their peak stages of concern were compared to their actual peak stages measured by the SoCQ. The correlation of the peak stage estimates by investigators to actual percentile scores shows for all stages, except Stage 4, that validity was supported (Table 3.4). These validity studies provided increased confidence that the SoCQ measures the hypothesized Stages of Concern (Hall, George, and Rutherford, 1986). 
Table 3.4

\section{Correlation of Peak Stage Estimates and Rank Order of SoC Percentile Scores}

\begin{tabular}{|c|c|c|c|c|c|c|c|c|}
\hline & & & $\mathrm{I}=65$ & rritica & $=.25$ & & & \\
\hline \multirow{9}{*}{ 占 } & & & & $\begin{array}{l}\text { Pea } \\
\text { Stag }\end{array}$ & & & & \\
\hline & & 0 & 1 & 2 & 3 & 4 & 5 & 6 \\
\hline & 0 & .27 & .34 & -.11 & .02 & -.22 & -.22 & -.13 \\
\hline & 1 & .15 & .47 & .47 & -.09 & -.11 & -.50 & -.45 \\
\hline & 2 & .03 & .38 & .42 & -.21 & -.10 & -.24 & -.34 \\
\hline & 3 & -.25 & -.08 & .00 & .30 & -.04 & .02 & .09 \\
\hline & 4 & -.05 & -.22 & -.26 & -.01 & .13 & .08 & .33 \\
\hline & 5 & -.20 & -.48 & -.20 & -.03 & .31 & .54 & .15 \\
\hline & 6 & -.20 & -.20 & .16 & -.15 & .24 & .17 & .31 \\
\hline
\end{tabular}

The questionnaire is still used today by administrators, project evaluators, and professional development leaders. The unifying theme among individuals who have used SoCQ relates organizational change to the personal experiences and attitudes of the individuals involved.

\section{Reliability and Validity of Qualitative Research (Interview)}

The use of consistent practices in conducting the interviews and providing a set of procedures used to identify emergent themes strengthen the validity and reliability of the information acquired from the nine interviews (Wiersma, 1995). Immediately prior to the 
interview, the participant was given a copy of the interview questions along with the disclaimer. Each session was audio taped and transcribed. Analysis of the transcripts and emergent themes were provided to those interviewed to review and check for accuracy. A RESA director and a WVEIS coordinator from another region in the state also reviewed the analysis and emergent themes.

"Internal validity relies on the logical analysis of the results" (Wiersma, 1995). The information collected by interviews was organized by question with reference to some demographic data from the SoCQ survey. In analyzing the interviews, the following steps were followed. As the interviews were taped, notes were taken. Important thoughts, ideas, or terms were highlighted. Interviews were transcribed verbatim and reviewed with the tapes. The form used to record the interviews consisted of a table with the questions in the left column and the interviewees responses in subsequent columns to the right. Additional notes were taken while rereading the interviews. As similar comments, terms, or vignettes appeared in the transcription they were highlighted. Reflecting on each interview provided time to absorb the unique responses and ideas expressed. Next, the interviews were reread. Instead of rereading each interview completely, a different approach was taken. Looking at each question separately, the responses from all the interviews were read looking for additional vignettes or examples previously noted or for new themes. After examining in detail the nine interviews, one overarching concept concerning WVEIS and four themes seemed to emerge from the responses. The overarching concept and the four themes were identified, defined, and discussed. Citing examples or vignettes from the interviews provided convincing arguments for including them. To provide visual representations of the qualitative component, two schematics were developed. The first diagram represents the overarching concept of WVEIS and the second one displays the intertwining nature of the four themes. 


\section{Summary}

The research design for this study included quantitative data collected with a cross sectional design. Longitudinal data measured the impact of the WVEIS Data Conference on users' concerns with a pre and post conference survey.

Approximately 130 surveys were completed in the first round of data collection with 118 being used in the analysis. At the WVEIS Data conference, approximately 68 participants completed surveys. During the same period 220 surveys were sent to counties with approximately 62 being returned. After the second administration of the SoCQ in November, 82 were returned. Nine participants were selected from those participating in both surveys to be interviewed. The eleven-question interview allowed for more in-depth responses and a better understanding of users' concerns related to WVEIS.

The information collected include survey results, historical artifacts, and interview responses. ANOVA, unpaired t-tests, paired t-tests and mean percentile profiles were used to analyze the quantitative data. Commonalties and themes were identified in interview data.

The validity and reliability of the SoCQ is reported by Hall, George, and Rutherford (1986). Having the participants who were interviewed review the transcript analysis aids in ensuring the reliability and validity of the interview component. Using various forms of data collection, including quantitative and qualitative approaches, the data more clearly identifies users' concerns regarding WVEIS. 


\section{Chapter 4}

\section{Results}

\section{Introduction}

The purposes of this study were to determine the significant differences in users' concerns related to the West Virginia Education Information System (WVEIS) and, consequently, to explore the impact of the WVEIS Data Conference as a staff development opportunity on users' concerns. This research takes advantage of a unique opportunity to study the impact of the mandated implementation of technology-WVEIS.

The results are divided into two sections. The first section deals with the quantitative data collected by using the Stages of Concern Questionnaire (SoCQ) which was analyzed using the StatView statistics package. The second section reports results from interview questions from nine participants.

This chapter presents an analysis of the data collected guided by the following research questions:

1. Is there a significant difference between users' concerns based on job responsibility?

2. Is there a significant difference between users' concerns based on county size as determined by student population?

3. Is there a significant difference in users' concerns based on the amount of time (years and time used during a regular workday)?

4. Is there a significant difference in pre and post-test concerns of users who attended the 1998 WVEIS Data Conference and those who did not?

At the beginning of the statistical procedures the number (n) included in that question is identified. Included in this research are responses from 118 users in the pre-conference survey and 80 on the post conference survey. Variation in count occurs across

subquestions. For example, if a participant filled out the entire survey form and indicated his/her position, data from that survey is included in the appropriate subquestion. If the 
individual did not mark county size then the data from that survey sheet is not included in subquestion dealing with county size.

In Chapter 1, Limitations indicated an assumption that Stage 4 (Consequences) would receive low scores consistently throughout the survey. The questions for this stage relate the impact of WVEIS on students. Because WVEIS is not a curriculum innovation and direct student impact is minimal, this limitation was set. Stage 4 had the lowest mean scores of all stages in each subquestion. Although some of the p-values show a significant difference at Stage 4 (Consequences) they are not included in a detailed discussion.

The statistical procedures and variables are identified in each subquestion. Using the StatView software provided various means to analyze the subquestions. Each question has three tables and a graph that can be found in Appendix I. The first table for subquestions 1-3, in Appendix I, is an ANOVA and displays several values. The p-value "represents the probability that the statistic would have a value at least as extreme as the one observed" (StatView Reference, 1998). A p-value of less than 0.05 indicates a significant difference. In the mean table for each stage, also in Appendix I, each independent variable is identified with the count, mean, standard deviation, and standard error identified, with the mean score being used most. A graph of mean scores is a representation of the means table and is the figure included. In graphing the means, the greatest possible score is a 35. The last table is Fisher's Protected Least Significant Difference. In the Fisher's PLSD, each independent variable is paired with all other independent variables. The mean difference is displayed in the first column. If the mean difference is a negative number, then the second variable in the pair has a higher mean score than the first one. The column of critical difference identifies the value necessary for a significant difference. In the last column the p-value is given. If a significant difference exists between the pairing, an "S" appears outside the table next to the p-value column. A summary of that data is presented in this chapter for each subquestion.

Subquestion 4 uses unpaired and paired t-tests; those can also be found in Appendix I. A summary of that data is also included in this chapter. 
With each subquestion a graph of normed percentiles appears. To construct these graphs the mean values of each variable must be converted to normed percentiles. The chart in Appendix G shows the conversion table. These graphs bring together a view that spans the seven stages of each variable and provides a comparison among variables.

\section{Stages of Concern Questionnaire}

\section{Subquestion 1}

Is there a significant difference between users' concerns based on job responsibility?

The independent variable is the job responsibility; the dependent measure is the users' concern; and the statistical procedure is a one-way analysis of variance (ANOVA) on each of the seven stages. The number of respondents from each job responsibility is identified in the Mean Scores Table 4.1. Categories with few respondents were aggregated into related positions or grouped together under Other. The position, Other, comprises categories of one or two individuals; they include but are not limited to counselors, teachers, and attendance directors. The category Principals includes principals and assistant principals; also the category Superintendent includes assistant superintendents. Central Office includes other directors, supervisors, and those professionals not directly identified as assistant superintendents or superintendents. There were 118 surveys returned that are included in this subquestion. 


\section{Table 4.1}

\section{Mean Scores based on Position}

$$
\mathrm{n}=118
$$

\begin{tabular}{|c|c|c|c|c|c|c|c|c|}
\hline Position & Count & Stage 0 & Stage $1^{1}$ & Stage $2^{2}$ & Stage $3^{3}$ & Stage $4^{4}$ & Stage 5 & Stage $6^{6}$ \\
\hline Accountant & 11 & 7.182 & 9.091 & 7.727 & 6.182 & 3.818 & 12.000 & 7.455 \\
\hline Central Office & 27 & 10.926 & 13.222 & 13.519 & 11.926 & 7.556 & 16.556 & 11.222 \\
\hline Other & 6 & 11.333 & 12.000 & 15.500 & 8.00 & 7.833 & 19.00 & 10.833 \\
\hline Other Secretary & 16 & 9.688 & 10.250 & 9.125 & 7.625 & 2.188 & 8.00 & 5.188 \\
\hline Principals & 20 & 9.950 & 14.350 & 17.050 & 16.050 & 8.600 & 21.800 & 14.050 \\
\hline School Secretary & 5 & 5.600 & 5.400 & 4.00 & 7.400 & 7.200 & 7.200 & 5.60 \\
\hline Superintendents & 12 & 11.853 & 12.250 & 11.333 & 11.917 & 7.500 & 15.167 & 10.750 \\
\hline County Contact & 21 & 7.619 & 8.190 & 11.714 & 11.714 & 7.762 & 19.571 & 13.095 \\
\hline
\end{tabular}

1=A significant difference between means is found in the pairings Accountants/Principals, $\mathrm{p}=.0377$; Central Office / School Secretary, $\mathrm{p}=.0175$; Central Office/WVEIS County contact, $\mathrm{p}=.0107$; Principals/School Secretary, .0083; Principals/ WVEIS County Contacts, $\mathrm{p}=.0038$. See Table I.6.

2= A significant difference between means is found in the pairings Accountant, Central Office, $\mathrm{p}=$. 0299: Accountant/Other, $\mathrm{p}=.0398$; Accountant?Principals, $\mathrm{p}=.0010$; Central Office/School Secretary, $\mathrm{p}=.0091$; Other/School Secretary, $\mathrm{p}=.0112 ;$ Other Secretary/Principals, p=.0017; Principals/School Secretary, p=.0006; Principals/Superintendents p=,.0356; Principals/WVEIS Contact, $\mathrm{p}=.0222$; and School Secretary/ WVEIS County Contact, $\mathrm{p}=.0374$. See Table I.9.

3= A significant difference between means is found in the pairings Accountant/Central Office, $\mathrm{p}=.0102 ;$ Accountant//Principals, $\mathrm{p}=<.0001$; Accountant/Superintendents, $\mathrm{p}=.00274$; Accountant/WVEIS County Contact, $\mathrm{p}=.0172$; Central Office/Other Secretary, . $\mathrm{p}=.0286$; Central Office/Principals, $\mathrm{p}=.00249$; Other/Principals, $\mathrm{p}=.0058$; Other Secretary/Principals, $\mathrm{p}=<.0001$; Other Secretary/WEVEIS County Contact, $\mathrm{p}=.0475$; Prinicpals/School Secretary, $\mathrm{p}=.0058$; and Principals/WVEIS County Contacts, $\mathrm{p}=.260$. See Table I.12

4= A significant difference between means is found in the pairings Central Office/Other Secretary, p=.0160; Other Secretary/Principals, p=.0070; Other Secretary/Superintendents, $\mathrm{p}=.0480$; and Other Secretary/WVEIS County Contacts, $\mathrm{p}=.0174$. See Table I.15. 
$5=\mathrm{A}$ significant difference between means is found in the pairings Accountant/Principals, $\mathrm{p}=.0008$; Accountant/WVEIS County

Contact, $\mathrm{p}=.0081$; Central Office/Other Secretary. $\mathrm{P}=.0005$; Central Office/Principals, $\mathrm{p}=.02 .2$; Central Office/School Secretary, $\mathrm{p}=.0122$; Other/Other Secretary, $\mathrm{p}=.0029$; Other/School Secretary, $\mathrm{p}=.0111$; OtherSecretary/Principals, $\mathrm{p}=<.0001$; Other

Secretarty/Superintendents, $\mathrm{p}=.0144$; Other Secretary/WVEIS County Contact, $\mathrm{p}=<.0001$; Principals/School Secreatary, $\mathrm{p}=.0002$;

Principals/Superintendents, $\mathrm{p}=.0177$; School Secretary/Superintendents, $\mathrm{p}=.0498$; and School Secretary/WVEIS County Contacts, $\mathrm{p}=.0013$. See Table I.18.

6= A significant difference between means is found in the pairings Account/Principals, $\mathrm{p}=.0067$; Accountant/WVEIS County

Contact, $\mathrm{p}=.0189$; Central Office/Other Secretary, $\mathrm{p}=.0033$; Other Secretary/Principals, $\mathrm{p}=.0001$; Other

Secretary/Superintendents, $\mathrm{p}=.0239$; Other Secretary/WVEIS County Contacts, $\mathrm{p}=.0003$; Principals/School Secretary, $\mathrm{p}=.0090$;

and School Secretary/WVEIS County Contact, $\mathrm{p}=.0196$. See Table I.21

In Table 4.1, the category School Secretary has the lowest mean scores in Stages 0-2 and Stages 5-6 while Principals have the highest mean scores in Stages 1- 6. 


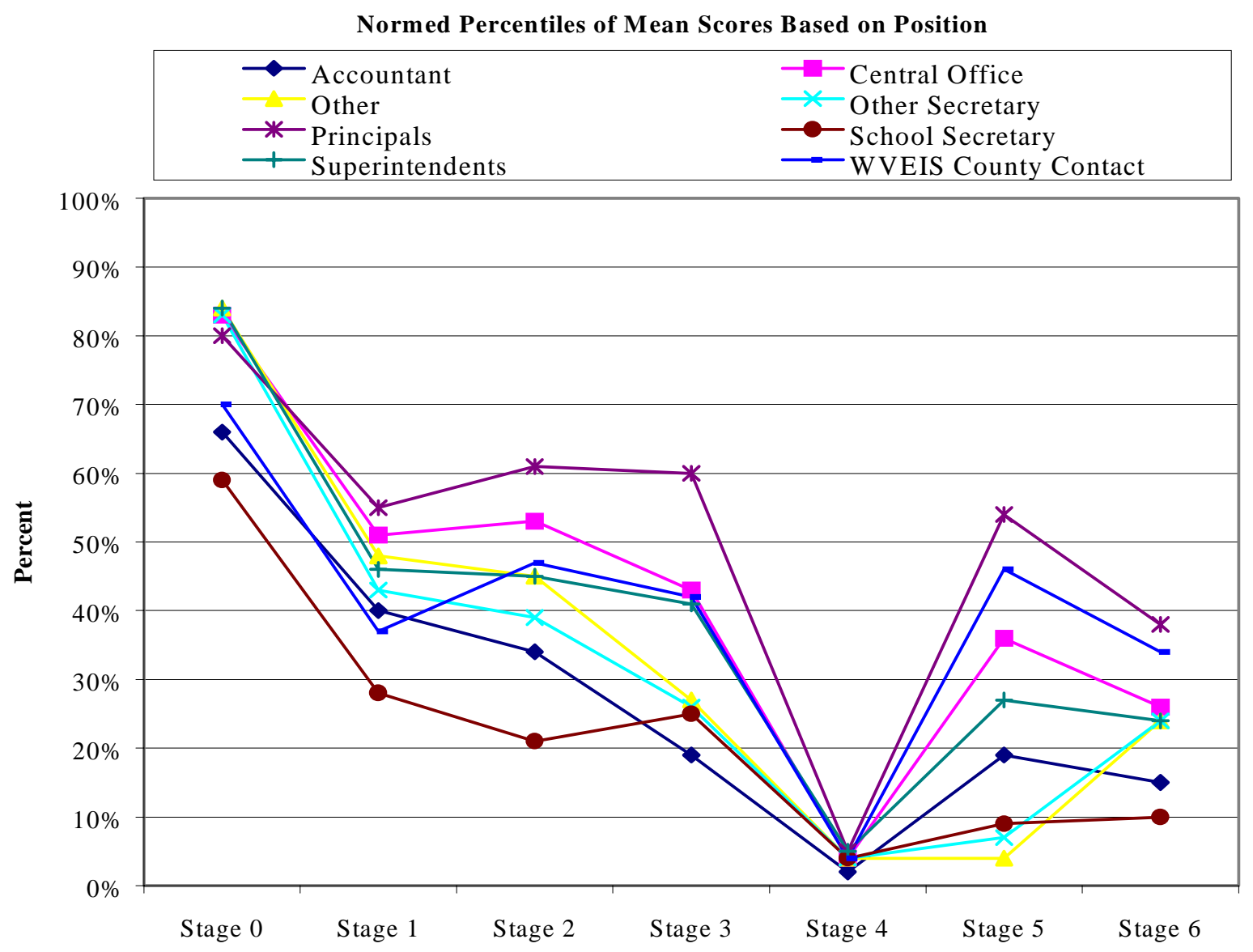

Stages of Concern

Figure 4.1

In a graphical representation of the stages the mean scores for each category are converted to normed percentile scores and displayed in Figure 4.8. This graph provides another way of examining the data. The graph in Figure 4.1 depicts the converted mean scores of each stage based on position. A normed percentile is established by using the SoCQ Quick Scoring Device (see Appendix G; Hall, George, \& Rutherford, 1979).

\section{Stage 0 (Awareness)}

A high normed percentile score in Stage 0 (Awareness) indicates the individual has low concerns, attention, or interest in the innovation. All respondents showed Stage 0 as their high normed score; this indicates they no longer have concerns about the innovation 
WVEIS as measured by the SoCQ. Tables and graphs for each stage can be found in Appendix I, Tables I.1-21 and Figures I.1-7.

\section{Stage 1 (Informational)}

Normed scores dropped in Stage 1. This stage is general in nature and indicates an interest in general characteristics of the innovation, effects, and requirements for use. The group, School Secretary, has very low scores in this area. This may suggest the group uses WVEIS on a daily basis as a component of their daily work as a tool.

\section{Stage 2 (Personal)}

In this stage, a mix of responses can be seen. Some groups normed percentiles rose from the previous stage while others dropped. Again the group, School Secretary, has very low scores while Principals have the highest normed percentiles. This stage reflects the concern the individual has about the demands of the innovation. Principals have high scores and numerous concerns about the demands of WVEIS. As seen in the graph, each position reacted differently.

\section{Stage 3 (Management)}

Attention at this stage reflects a focus on the processes and tasks of using WVEIS and relate to efficiency, managing, and time demands. Principals showed the highest normed percentiles in this stage. Other users seemed to cluster. Other, School Secretary, Accountant, and Other Secretary had low management concerns while Central Office, Superintendents, and WVEIS Contact had higher concerns but not as high as Principals. In addition, the large span from highest to lowest normed percentages can be seen in this stage.

\section{Stage 4 (Consequences)}

This stage focuses on the impact of the innovation on the student. WVEIS does not directly impact students on a curricular level. Because of WVEIS's limited impact on 
curriculum, Stage 4 (Consequences) was listed as a limitation of the study. Users' stages of concern affirmed the prediction of low mean scores in Stage 4 (Consequences)

Stage 5 (Collaboration)

Stage 5 (Collaboration) focuses on coordination and cooperation with others regarding use of the innovation and is considered an impact stage. School Secretary and Other Secretary have the lowest normed percentiles with Principals and WVEIS County Contacts scoring the highest. Although personal and management concerns were highest for Principals this stage was nearly as high. Principals surveyed demonstrated a desire to share the ways they are using WVEIS.

\section{Stage 6 (Refocusing)}

In the SoCQ, Stage 6 (Refocusing) represents the highest stage of implementation. Identified as refocusing, in this stage the individual has definite ideas about alternatives, alternate uses, or more universal benefits from the innovation. The casual user would not score high in this stage. Principals scored highest in Stage 6 while the group School Secretary had the lowest normed percentiles. The fact that WVEIS is a mandated program and no other options available may have had an impact on scores at this stage.

Table 4.2

\section{P-Values for Subquestion 1}

\begin{tabular}{|l|r|r|r|r|r|r|r|}
\hline & Stage 0 & Stage 1 & Stage 2 & Stage 3 & Stage 4 & Stage 5 & Stage 6 \\
\hline p value & .2651 & $.00249 *$ & $.0023^{*}$ & $.0004^{*}$ & .1367 & $<.0001^{*}$ & $.0009^{*}$ \\
\hline
\end{tabular}

*Indicates a significant difference

In examining p-values at each stage in Table 4.2, a non-significant difference among users' concerns is found at Stage 0 (Awareness) and Stage 4 (Consequences) based on job responsibilities. Significant differences are seen in Stages 1, 2, 3, 5, and 6. Therefore, the data suggest a significant difference in users' concerns based on position. 


\section{Subquestion 2}

Is there a significant difference between users' concerns based on county size as determined by student population?

The independent variable is the county size; the dependent measure is the users' concern; and the statistical procedure is a one-way ANOVA on each of the seven stages. The number of respondents from each county size is identified in Table 4.3

Table 4.3

\begin{tabular}{|c|c|c|c|c|c|c|c|c|}
\hline & Mea & Scores & ased on & $\begin{array}{l}\text { County } \\
=113\end{array}$ & ize (Enr & llment) & & \\
\hline Enrollment & Count & Stage 0 & Stage 1 & Stage 2 & Stage $3^{1}$ & Stage $4^{2}$ & Stage 5 & Stage 6 \\
\hline $0-2,000$ & 20 & 9.200 & 10.200 & 10.850 & 13.050 & 7.950 & 17.350 & 10.250 \\
\hline $2,001-4,000$ & 15 & 8.200 & 9.456 & 12.867 & 11.800 & 5.200 & 14.067 & 9.067 \\
\hline $4,001-6,000$ & 35 & 9.257 & 11.057 & 11.886 & 9.543 & 4.829 & 15.114 & 9.743 \\
\hline $6,001-10,000$ & 16 & 9.500 & 11.375 & 13.938 & 13.938 & 10.813 & 18.250 & 11.750 \\
\hline Over 10,000 & 27 & 11.037 & 13.148 & 11.963 & 10.185 & 6.444 & 15.963 & 12.111 \\
\hline
\end{tabular}

1= A significant difference between means is found in the pairing 4,000-6,000/6,001-10,000, p=. 0302. See Table I.33.

2= A significant difference between means is found in the pairings 2,001-4,000/6,001-10,000, $\mathrm{p}=.0240 ; 4,000-6,000 / 6,001-10,000$, $\mathrm{p}=.0044 ;$ and $6,001-10,000 /$ over $10,000, \mathrm{p}=.0480$.

The span of mean scores is much smaller in this subquestion than in subquestion 1. The greatest difference between high and low mean scores is in Stage 4, with 5.894. The least amount of difference between high and low means is 2.044 in Stage 6.

Lowest mean scores in Stages 0, 1, and 5 are found in County Size 2,001-4,000 (see Table 4.3). Stage 2 lowest mean score is registered by County Size 0-2,000, with the Stage 3 low in County Size 4,001-6,000. Highest mean scores for Stages 0-1 and 6 are in 
County Size over 10,000 with Stages 2-5 having the highest means registered in County Size 6,001-10,000.

Additional analyses for Subquestion 2 can be found in Appendix I Table I.22-42 and Figures I.9-15. The analyses include ANOVA tables, mean tables, and bar plots at each stage.

Converting users' mean scores to normed percentiles at each stage depicts minimal differences based on student enrollment. The lines, representing normed percentiles of county size based on enrollment, show limited differences. There appears to be less difference based on enrollment than on position when comparing the graph in Figure 4.1 with the graph in Figure 4.2.
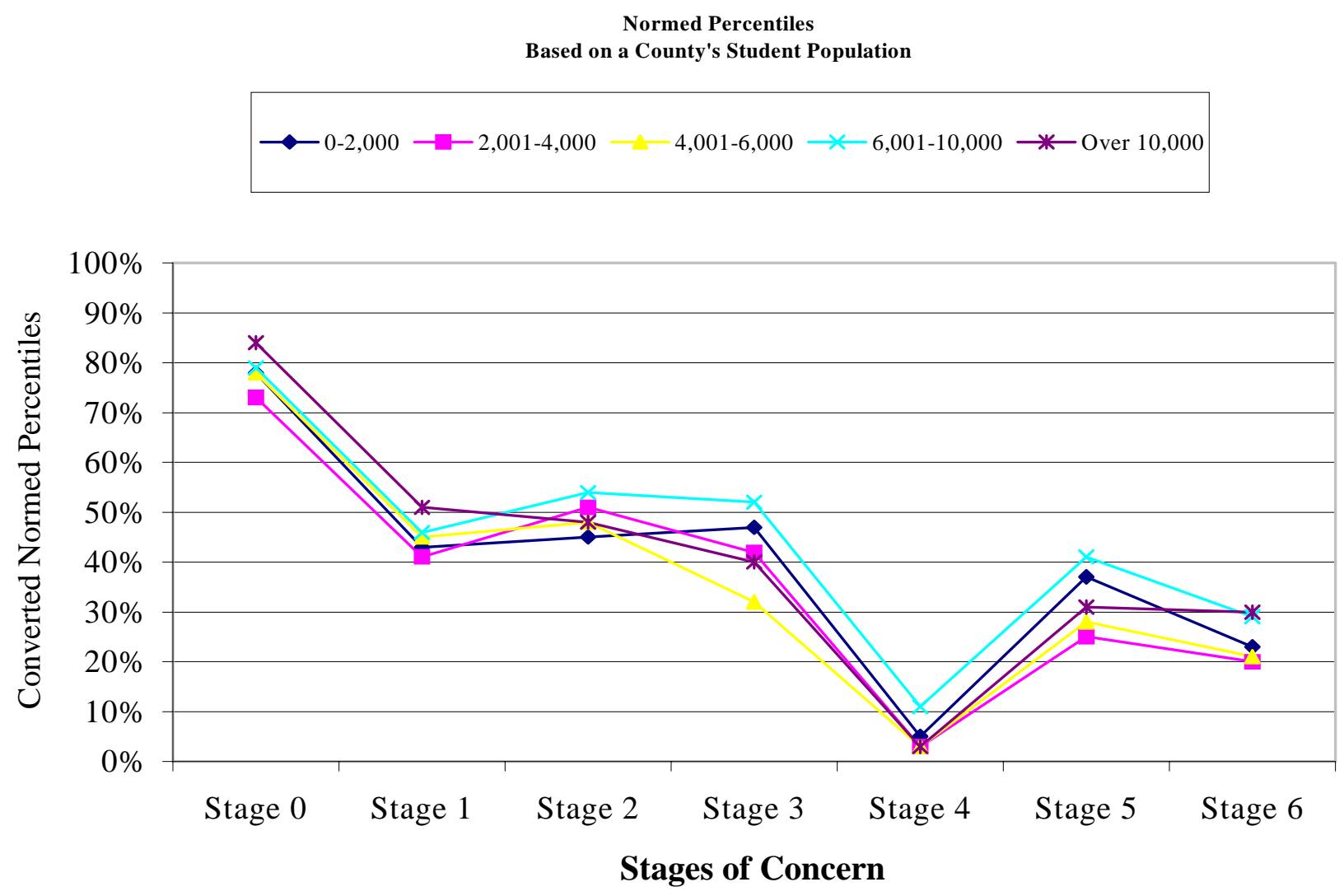

Figure 4.2 
In Figure 4.2, the profile across all enrollments is very similar. In Stage 0, the peak indicates little concern from all groups. Informational concerns in Stage 1, personal concerns in Stage 2, and management concerns in Stage 3 show little variation. The second peak, found in Stage 5, shows a wider variation among county size.

Table 4.4

P-Values for Subquestion 2

\begin{tabular}{|l|r|r|r|r|r|r|r|}
\hline & \multicolumn{1}{|c|}{ Stage 0 } & \multicolumn{1}{c|}{ Stage 1 } & Stage 2 & Stage 3 & Stage 4 & Stage 5 & Stage 6 \\
\hline $\mathrm{p}$ value & .6704 & .4846 & .8305 & .1331 & $.0488^{*}$ & .6229 & .5696 \\
\hline
\end{tabular}

*Indicates a significant difference

There is a non-significant difference among users based on student enrollment at all stages except Stage 4 (Consequences). Stage 4 has limited effect on WVEIS as stated in the limitations. The data suggest county size as determined by enrollment does not significantly effect users' concerns.

\section{Subquestion 3}

Is there a significant difference in users' concerns based on the amount of time (years and time used during a regular workday)?

There are two independent variables. One is the number of years WVEIS has been used; the second variable is the amount of time used each day. The dependent measure for both is the users' concern; and the statistical procedure is a one-way ANOVA on each of the seven stages for each variable.

The analysis for Subquestion 3 includes ANOVA tables, mean tables, and bar plots at each stage for the duration, in years, that individuals indicated and for the amount of time users are logged on to WVEIS daily. These tables and figures can be found in Appendix 
I Tables I.43-63 Figures I .17-23. A summary of that information is presented in Tables 4.5 and 4.6 .

Table 4.5

\begin{tabular}{|l|r|r|r|r|r|r|r|r|}
\hline \multicolumn{7}{|c|}{ Mean Scores Based on Amount of Time in Years } \\
\hline Length of Time & Count & Stage $0^{1}$ & Stage 1 & Stage 2 & Stage 3 & Stage 4 & Stage 5 & Stage 6 \\
\hline 1 year or less & 8 & 14.250 & 14.250 & 14.625 & 13.125 & 13.125 & 18.00 & 12.375 \\
\hline 1-2 years & 8 & 11.250 & 15.250 & 12.625 & 10.625 & 4.625 & 15.625 & 10.250 \\
\hline 2-3 years & 19 & 9.421 & 13.158 & 13.579 & 10.421 & 4.421 & 16.368 & 11.105 \\
\hline 3-4 years & 25 & 10.760 & 12.800 & 12.320 & 12.200 & 5.640 & 14.120 & 8.640 \\
\hline 4-5 years & 24 & 9.333 & 10.333 & 11.125 & 11.250 & 6.083 & 16.250 & 9.833 \\
\hline$>5$ years & 31 & 7.000 & 7.710 & 11.452 & 10.581 & 8.710 & 16.903 & 12.290 \\
\hline
\end{tabular}

1=Asignificant difference between means is found in the pairings 1 year or less/4-5 years, p=. 0480; 1 year or less/greater than 5 years, $\mathrm{p}=.0030$; and 3-4 years/greater than 5 years, $\mathrm{p}=.0223$. See Table I.45.

$2=$ A significant difference between means is found in the pairings 1 year or less/greater than 5 years, $\mathrm{p}=.0133 ; 1-2$ years/greater 5 years, $\mathrm{p}=.0045 ; 2-3$ years/greater than 5 years, $\mathrm{p}=.0052$; and 3-4 years/greater than 5 years, $\mathrm{p}=.0047$. See table I.48.

$3=$ A significant difference between means is found in the pairings 1 year or less $/ 1-2$ years, $\mathrm{p}=.0150 ; 1$ year or less, 2-3 years, $\mathrm{p}=$. 0033; 1 year or less/3-4 years, $\mathrm{p}=.0085 ; 1$ year or less/4-5 years, $\mathrm{p}=.0136$; and 2-3 years/greater than $5 \mathrm{years,} \mathrm{p}=.0346$.

In Table 4.5, lowest mean scores for Stages 0-1 are found in users with greater than five years of time. In Stage 2, users with four-five years of experience had the lowest mean. Stages 3-4 registered low means in those users with two-three years experience. Users with three-four years experience had the lowest means in Stages 5-6. High mean scores in Stages 0,2,3,4,5, and 6 can be seen in users with one year or less of use. Stage 1 showed users with one-two years with the highest mean. 
Converting the mean scores from Table 4.5 into normed percentiles, Figure 4.3 shows the concerns profile for this variable. The conversion chart is found in Appendix G.

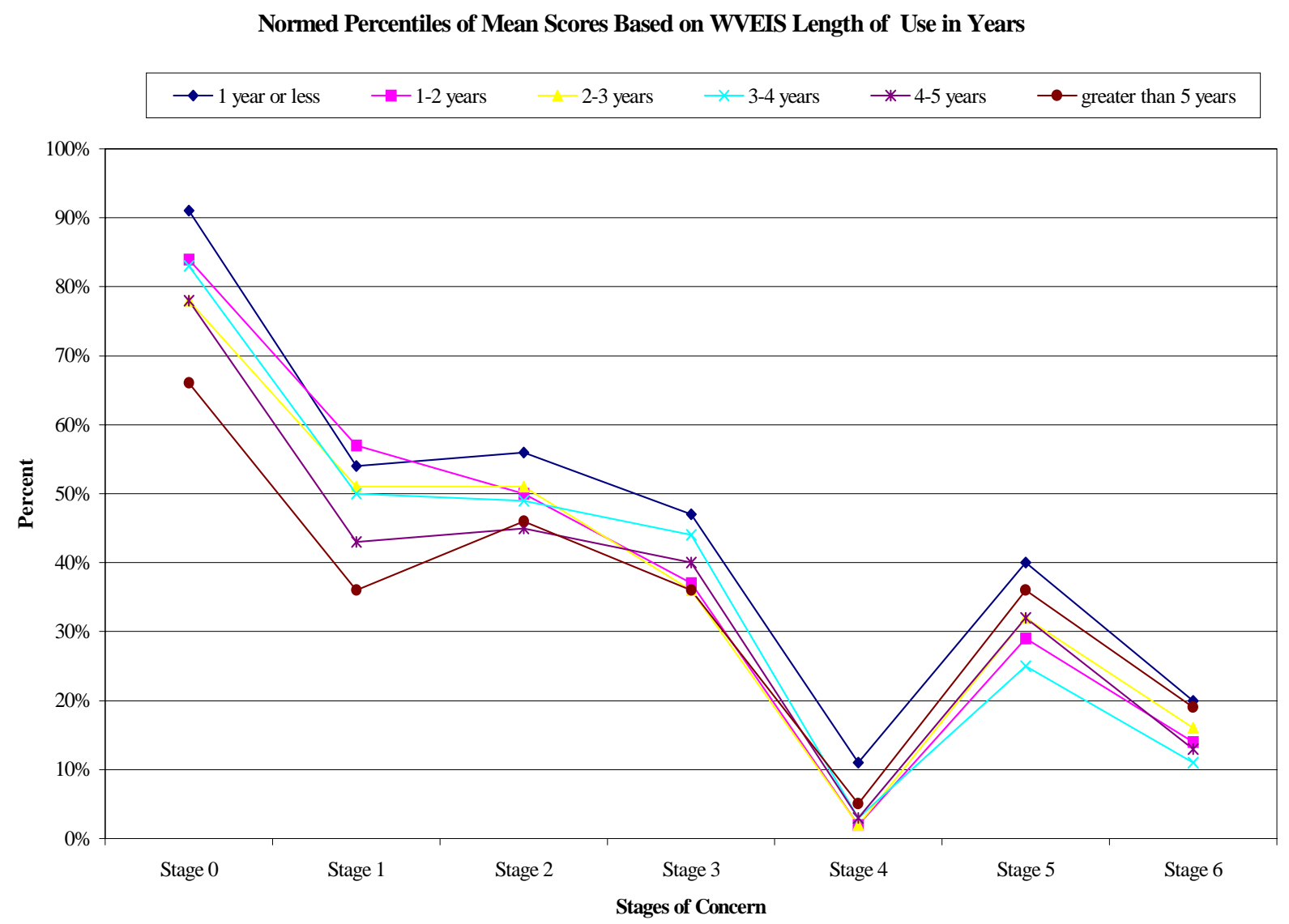

Figure 4.3

The general profile for the variable time in years, Figure 4.3 , is similar to the profile for county size (see Figure 4.2). A greater spread between high and low normed percentiles can be seen in Stage 0,1,2, and 3, but the overall shape is repeated. 
Table 4.6

\section{P-Values for Subquestion 3 (Years)}

\begin{tabular}{|c|c|c|c|c|c|c|c|}
\hline & Stage 0 & Stage 1 & Stage 2 & Stage 3 & Stage 4 & Stage 5 & Stage 6 \\
\hline $\mathrm{p}$ value & $.0406^{*}$ & $.0064^{*}$ & .8446 & .8835 & $.0271^{*}$ & .8600 & .4487 \\
\hline
\end{tabular}

*Indicates a significant difference

Examining mean scores at Stage 0, those with greater than five years experience have the lowest mean scores and normed percentiles (see Table 4.5 and Figure 4.3). Hall, George, \& Rutherford (1986) comment "users of an innovation with a high Stage 0 score indicates lack of concern about the innovation." Although a significant difference occurs in Stage 0 (see Table 4.6) the scores are high throughout the population. A significant difference is also seen in Stage 1. Those with greater than five years experience with WVEIS have significantly lower mean scores and normed percentiles than those with fewer years experience. Stage 4 scores show a significant difference in means but looking at the graph in Figure 4.3, the normed percentile variation from high to low is small and the overall normed percentiles are the lowest. This corroborates the limitation for Stage 4 found in Chapter 3.

There is a non-significant difference in Stages 2, 3, 5, and 6. Overall, the data suggest there is a non-significant effect on users' concerns based on length of years using WVEIS.

\section{WVEIS Use in Minutes}

The independent variable is the amount of time users log onto WVEIS during a day; the dependent measure is the users' concern; and the statistical procedure is a one way ANOVA on each of the seven stages. The analysis for this subquestion includes ANOVA tables, mean tables, and bar plots at each stage that can be found in Appendix I (See Tables I.64-84 and Figures I.24-30). The number of respondents is identified in Table 4.7. 
The following times are correlated to the term used as a descriptor in the table.

Infrequent represents less than five minutes, two-three days a week; minimal is less than 10 minutes each day; regular is up to 30 minutes each day; and steady represents use of over 30 minutes each day.

Table 4.7

\begin{tabular}{|c|c|c|c|c|c|c|c|c|}
\hline \multicolumn{9}{|c|}{ Mean Scores Based on Amount of Time in Minutes } \\
\hline Length of Time & Count & Stage 0 & Stage $1^{1}$ & Stage 2 & Stage 3 & Stage 4 & Stage 5 & Stage 6 \\
\hline Infrequent & 3 & 9.667 & 9.667 & 8.333 & 10.667 & 4.00 & 12.667 & 9.333 \\
\hline Minimal & 18 & 10.278 & 14.00 & 13.944 & 11.778 & 8.778 & 14.333 & 10.222 \\
\hline Regular & 23 & 9.826 & 11.217 & 12.783 & 12.000 & 6.783 & 17.739 & 11.913 \\
\hline Steady & 69 & 8.623 & 10.072 & 11.348 & 10.420 & 6.072 & 16.188 & 10.449 \\
\hline
\end{tabular}




\section{Normed Percentiles of Mean Scores Based on WVEIS Time of Use in Minutes/Day}

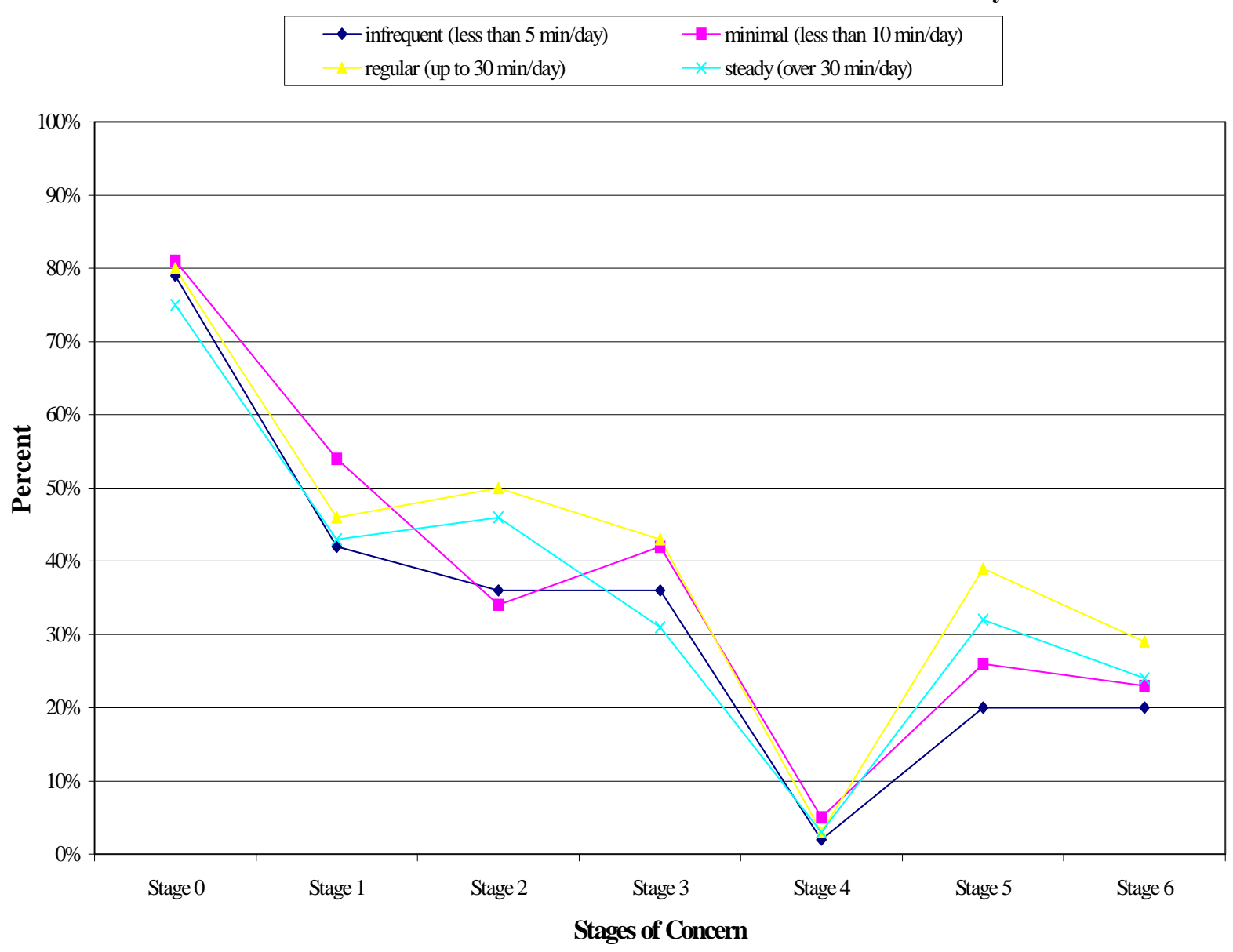

Figure 4.4

Table 4.8

P-Values for Subquestion 3 (Minutes/Day)

\begin{tabular}{|c|c|c|c|c|c|c|c|}
\hline & Stage 0 & Stage 1 & Stage 2 & Stage 3 & Stage 4 & Stage 5 & Stage 6 \\
\hline $\mathrm{p}$ value & .6884 & .1821 & .4976 & .7383 & .4765 & .5714 & .8071 \\
\hline
\end{tabular}

*Indicates a significant difference 
Over half of those surveyed use WVEIS over thirty minutes daily (see Table 4.7). Those that use WVEIS infrequently and minimally have lower personal concerns (Stage 2) and less collaboration (Stage 5) and refocusing (Stage 6) concerns. Examining Stage 2, in Figure 4.4, differences emerge. Users with regular and steady use show a slight increase while users with infrequent and minimal use continue to show a decline. Although mean scores (Table 4.7) were higher in stages 5 and 6, the normed percentiles are lower than Stages 0-4.

In Table 4.8, there is a non-significant difference among users' concerns based on WVEIS use in minutes per day. The data suggest time, in years of use or in minutes per day, does not appear to be a factor in users' concerns.

\section{Subquestion 4}

Is there a significant difference in pre and post-test concerns of users who attended the 1998 WVEIS Data Conference and those who did not?

The independent variable is attendance at the conference; the dependent measure is the users' concern; and the statistical treatments are unpaired t-tests on pre and post conference responses from those attending and those not attending the conference. Statistical comparisons were based on the 59 surveys returned by those who attended the conference and the 58 surveys returned by those not attending the conference.

Paired t-tests were run on the Stages 3, 5 and 6; because there were significant differences between the two groups at the pre treatment point for those three stages. There were 80 surveys returned in the second round, a return rate of $68 \%$, but only 72 (37 attended, 35 did not attend) could be used in these calculations. If respondents did not indicate attendance or non-attendance then the survey could not be used.

In Table 4.9, the mean scores of each stage are grouped by conference attendance and pre/post administration of the SoCQ. In the pre-conference survey, a significance at Stages 3, 5, and 6, showed those attending had higher mean scores than those not attending. There were no significant differences found on the post conference survey. 
The mean scores were converted to normed percentiles (Hord, Rutherford, HulingAustin, \& Hall, 1987, see Appendix G) and are displayed graphically in Figure 4.5. This graph shows little difference among the pre/post and attended/did not attend.

Table 4.9

\begin{tabular}{|c|c|c|c|c|c|}
\hline \multicolumn{6}{|c|}{ Mean Scores by Stage } \\
\hline & & \multicolumn{2}{|c|}{ Pre-conference Survey } & \multicolumn{2}{|c|}{ Post Conference Survey } \\
\hline & Stage & $\begin{array}{c}\text { Attended } \\
n=59\end{array}$ & $\begin{array}{c}\text { Did Not Attend } \\
n=58\end{array}$ & $\begin{array}{c}\text { Attended } \\
n=37\end{array}$ & $\begin{array}{c}\text { Did Not Attend } \\
n=35\end{array}$ \\
\hline Awareness & Stage 0 & 9.390 & 9.638 & 6.649 & 8.571 \\
\hline Informational & Stage 1 & 10.966 & 11.328 & 9.243 & 8.514 \\
\hline Personal & Stage 2 & 13.169 & 11.052 & 9.811 & 9.743 \\
\hline Management & Stage 3 & $13.051^{1}$ & 9.207 & 11.027 & 10.057 \\
\hline Consequences & Stage 4 & 7.915 & 5.552 & 5.081 & 5.114 \\
\hline Collaboration & Stage 5 & $17.898^{2}$ & 13.983 & 17.784 & 14.029 \\
\hline Refocusing & Stage 6 & $12.000^{3}$ & 9.103 & 10.162 & 10.143 \\
\hline
\end{tabular}




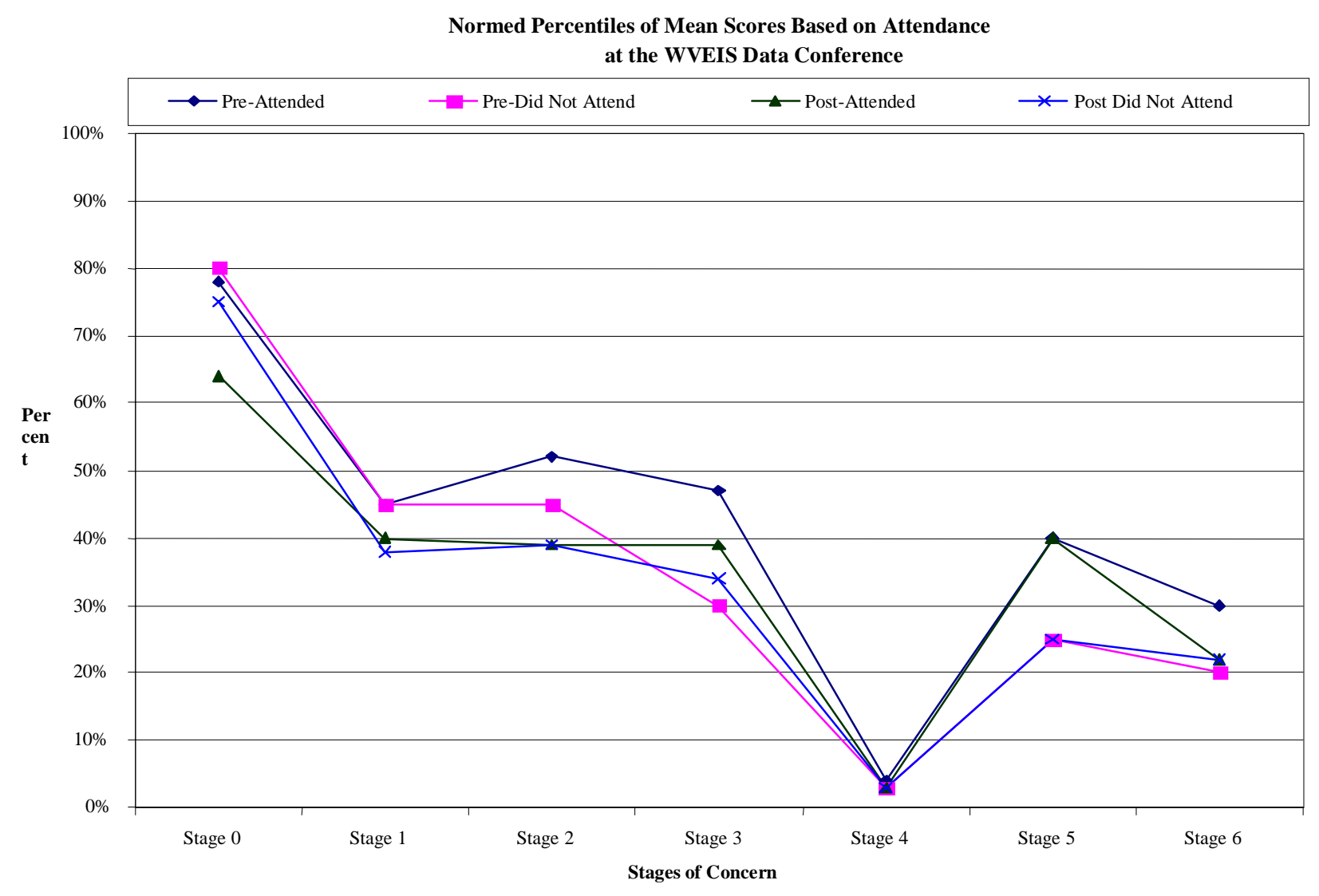

Figure 4.5

As stated before, paired t- tests were run on pre and post data for Stages 3, 5, and 6 for each group. No significant changes emerged.

Table 4.10

\begin{tabular}{|l|r|r|}
\hline \multicolumn{2}{|c|}{ Pre/Post Mean Differences } \\
\hline & Attended & Did Not Attend \\
\hline Stage 3 (Management) & 2.135 & .400 \\
\hline Stage 5 (Collaboration) & .432 & 1.029 \\
\hline Stage 6 (Refocusing) & .973 & -.114 \\
\hline
\end{tabular}

Note: All mean differences/changes were non-significant. 
Considering attendance at the WVEIS Data Conference the treatment, the pretreatment concerns for Stages 0,1,2, and 4 showed no significant differences. At the post treatment point, there were no significant differences between the groups for any of the stages.

Although there were significant differences found in pre-conference scores in Stages 3,5 , and 6 , no significant difference appeared when running paired t-tests comparing pre/post changes for each group.

Although there were significant differences in some stages between those attending and not attending on the pre-conference scores, the data suggest the WVEIS Data Conference did not directly impact the users' concerns. This is reinforced by the interview data. Individuals could identify one or two things they learned from the conference but it did not appear to be a major factor in their use of WVEIS.

\section{Interviews with WVEIS Users}

Another dimension used to identify users' concerns were interviews. To better understand and explain users' concerns, nine interviews were conducted in December of 1998. All interviews but one were conducted in person and tape-recorded. One participant, at his request, preferred to answer the questions via email in order to accommodate schedules and time constraints. A description of the process for analyzing the interview responses is found in Chapter 3. The questions used in the interviews are found in Appendix E with a synopsis of the responses for each question in Appendix F. An introduction and discussion of the emergent themes provides greater depth in identifying users' concerns as they relate to WVEIS.

\section{Overarching Concept}

As the interview questions were posed to participants, those interviewed pointed out a difference between the concept of an information system and the current information system in use, WVEIS. An analysis of the interviews suggests a difference in how users feel about the ideal information management system and the actual hardware and software used and referred to as WVEIS. The responses may have resulted due to the 
wording of question three. In the interviews, participants were asked to comment about the concept of a statewide system that became WVEIS. They described differences between the concept and the reality of WVEIS. One WVEIS contact and one superintendent both felt the "concept was excellent" but expressed a need to make WVEIS more user friendly. The junior high principal pointed out the role of the committees that looked at different software packages and made recommendations. The differences between the concept and what is in use were also pointed out in responses to question four that dealt with using WVEIS. Some responses compared WVEIS to previous packages used by counties. Comments were made about other features individuals wanted to see in an information system. The diagram, in Figure 4.6, illustrates the concept of an information system and the actual application of WVEIS. There is considerable overlap between what is being used and what is envisioned. Perhaps, it is the difference between the concept and the reality that can provide for the growth and refinement of WVEIS.

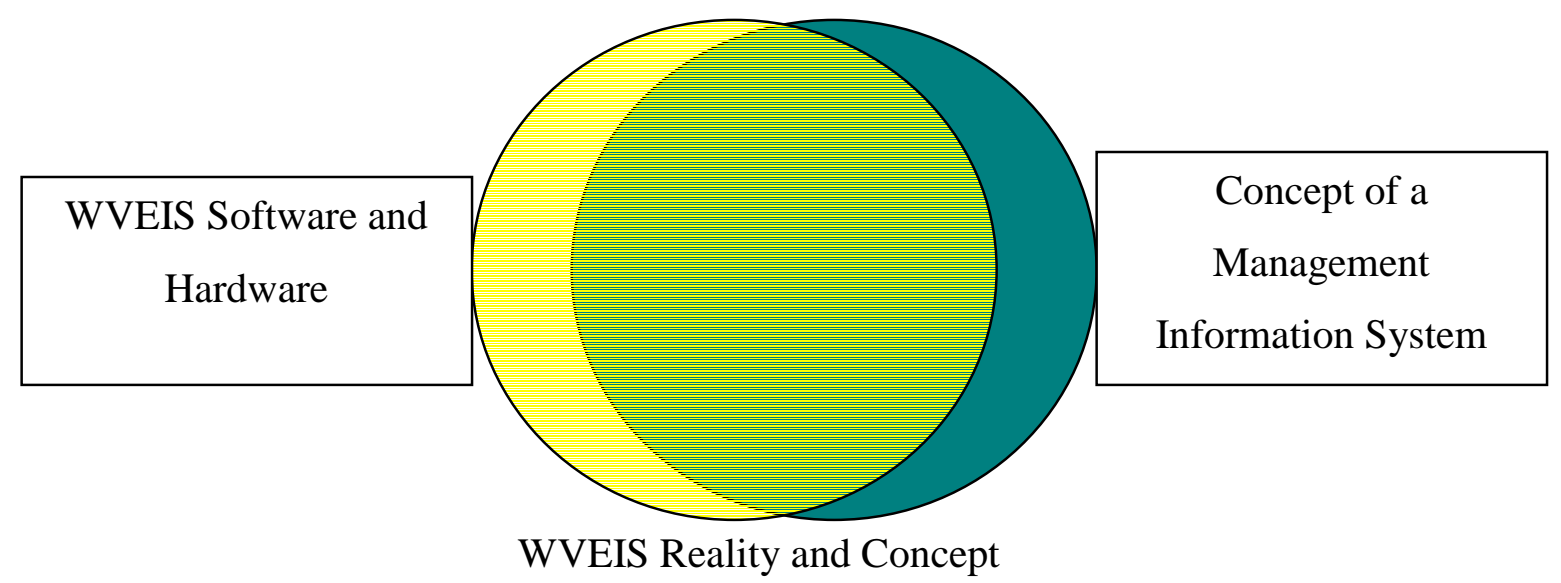

FIGURE 4.6 


\section{Emergent Themes}

After reviewing and analyzing the responses, four themes emerged; time, change, consistency, and communication. In each theme, both positive and negative aspects are identified. There are also examples given that show how the themes may relate to and/or affect the other themes. Compelling vignettes from the interviews are offered as evidence to the validity of each theme.

\section{Time}

In considering the theme of time, two definitions explain the concept. The first definition of time considered refers to a point or period when an event occurs, timing; the second definition relates to a measurable unit such as minutes and hours. Also the value of one's time (minutes and hours) surfaced and is discussed.

Each participant interviewed mentioned time. Comments included the timing of the implementation, the time saved in doing one task, and the time needed for staff development. Time emerged as an important theme.

The use of information systems was sporadic around the state. Related to the timing of WVEIS implementation, the senior high principal with prior computer programming experience noted, "I thought it was time for a - not necessarily a statewide- but some sort of system that was available to all the schools." He indicated school systems were requesting software solutions to do attendance reporting and cited that the need for an information system existed. The timing for the implementation of WVEIS coincided with the need and was looked on by the high school principal interviewed as coming at the right time.

An elementary principal discussed a task that took a considerable amount of time but is now done more quickly through WVEIS, thus conserving the commodity of time. He related, "When we pre-register kindergarten kids before the kindergarten screening takes place we input them as NK kids into the WVEIS system with no registration date and the system allows us to do that and from there we can type letters, we can print mailing labels 
for specifically those kids ... we're able to do all those labels and it saves tons and tons of time sitting at a typewriter to do that."

Another example of appropriate time management involved the retrieval of data. One of the two superintendents explained, "... the amount of time that it would take to get the information I requested manually, that time can be much better spent on other issues."

From the negative side, the elementary principal chose not to learn a WVEIS related task because the frequency would be insignificant, "Quite frankly I don't think it's worth my time learning it (importing files from Windows 95) because I wouldn't use it that frequently."

The computer coordinator described the frustration and how WVEIS caused more time to be used in working with personnel files. "Every position had a billet number attached to the position. You could track who was in and out of that position by that number. But with WVEIS every time someone leaves a position it gives it (the position) a new number. We've adapted...but it's much more time consuming to try to track especially when you get into grievances.

The timing of the WVEIS implementation, the amount of time in minutes and hours saved or lost, and the value of one's time comprised the theme time. The timing for WVEIS implementation brought some counties a solution and others a change in the information system being used. Time appeared to be important to the individuals interviewed. They are concerned with WVEIS saving time in some instances and taking more time in others. WVEIS may have also changed the way users budget their time. Those interviewed use WVEIS to help them manage their time better, to allow more time for other tasks, and want the staff development and training to be worth their time involved in attending.

In looking at connections between time and the other themes, several examples are presented in subsequent sections. First, OfficeVision, a component for communication via WVEIS, is cited by several individuals interviewed as a time saving tool. Consistency of tasks and reporting are commented on by those interviewed as saving time. The next 
theme, change, seemed to be most closely associated with time. Changing attendance registers to WVEIS saved the teachers time, but a change in billet numbers used more time.

\section{Change}

Change permeates the concept and the reality of WVEIS. The definition of change includes three meanings. The first meaning, to make different, is easy to see and surfaced clearly in the interviews. Information systems are in schools in West Virginia now. If there were systems ten years ago, they look different now than they did then. The second definition, to make a shift, denotes doing the same tasks but perhaps in a different manner. In WVEIS, doing tasks in a different manner is evident in scheduling, making morning announcements via OfficeVision, and electronic attendance registers. We still do each task but through WVEIS, it may not have the same appearance or same steps. The last definition, to transfer or transition, shows the merger between the concept and reality of WVEIS. In the following examples, the three definitions of change are more fully characterized by those interviewed.

As the implementation of the statewide information system progressed, the role WVEIS plays has changed. Each year something is altered with WVEIS, for example, additional memory is physically added to the AS/400, another report is required for electronic submission, or class codes changed with the introduction of new classes. Moving through the continuum of time from inception to the present, WVEIS itself has changed along with its role.

The elementary principal interviewed shared a change in teacher duties as he discussed attendance. "We did away with attendance registers. The attendance is all kept in the computer. The teachers, I think, have probably forgotten how much time they devoted to those attendance registers on a daily basis and then once every school month to calculate nonmember days and all those kinds of things. So they've been very spoiled by that. They don't have to do that anymore; they (attendance registers) really are extremely frustrating. ... It's been great." Not only did the teacher role and 
responsibilities change but time was saved in the process. He also added, "Very seldom am I in a paper file," another example of how his tools (electronic file vs. paper file) have transitioned to the electronic medium.

A high school principal discussed change as it related to his school management style. "I don't know that all schools in the state and all counties are using it, but when you use WVEIS that is a change in how you operate ... your daily management of your school (changes). You manage the school differently because of WVEIS. If the testing data gets out there in a way that you can retrieve it, it can become a way you can become an instructional leader. It impacts instruction to some degree with the way we're using it for the responsible students program. The way we're collecting the data and utilizing it helps us manage our program in a more effective way ... because we can manage it well; it has freed up instructional time for teachers ..." With his management style changing and the transformation of programs described, this principal took the data compiled and stored in WVEIS and used it in ways to assist teachers and students.

In the next example, a change in the way final grades for a marking period are input into WVEIS generated an examination of the grading term and reporting procedures for the junior high principal. Grade Quick software provided a new way to maintain the teacher grade book and to directly enter report card grades into the WVEIS system. The junior high principal said, “... what I would do would be to have all of our teachers using the Grade Quick Program. Go to a nine-week grading system and then use the grade Quick Reports at mid term to give everybody a fairly detailed mid-term report. I think you would have a better grading system." His vision of how grading should change is transformation in process linked to the evolution of WVEIS.

Not all changes necessitated by the move to WVEIS were welcomed or viewed in a positive light. Some counties had no information systems before WVEIS while other counties built custom made systems. A junior high principal commented about the switch from a county system to WVEIS, "The information was fairly similar, but it was how you could use the information and how you could get from one screen to another that I didn't 
like the current system (WVEIS) as well as what we had before. Part of that, however, to be fair and as I look back on it, part of the criticism came because I was familiar with ours, and it's just like anybody else who has to change... if you're not familiar with something, you don't want to change. So part of that negativity came from just not wanting to change."

Principals and schools operate differently. Changes in management and day to day tasks appear to occur as additional wiring and computers extend into individuals' offices and classrooms. WVEIS has brought changes to schools, school systems and to the WVDE. As WVEIS evolves, and continues to be modified as seen with the pilot Grade Quick, the visible differences and the shifts in management pave the way for the transition of WVEIS for future use.

The next facet of the theme change identified in the interviews refers to how and when the software or structure of WVEIS may change. The interviewees noted the differences in jobs and responsibilities as WVEIS implementation progressed. It appeared they anticipated other changes as WVEIS evolves. The junior high principal remarked, “... replace it with a system that is more user friendly and I can manipulate data with it better, fine. If it's not a system that also requires a lot of retraining, okay. You've got to look ahead. ... But to say no it should not be replaced would be shortsighted." Others expressed their concerns over staff development and the time that might be needed to adjust, but all indicated an expectation that WVEIS would continue to evolve and change.

Some of the components of change suggested in the interviews seemed user specific. One superintendent used WVEIS to aid in identifying students for free and reduced lunch and the high school principal made morning announcements via OfficeVision. Both tasks are necessary in a system or a school but the superintendent and principal changed the way they obtained data or distributed information by using WVEIS. 


\section{Consistency}

The third theme, consistency, can be defined as agreement of parts or features. The first examples relate the consistency of WVEIS programming and the tasks needing to be done; later examples elaborate on the collegiality that those interviewed identified, and the last example addresses the negative side of consistency.

Maintaining an attendance register through WVEIS is one example of consistency. Using WVEIS for this repetitive task during each marking period freed teacher time for other instructional purposes and provided the elementary principal and his teachers a common tool for reporting attendance.

In describing the nature of the software package used by WVEIS a county contact says, "WVEIS is a generic package ... so it meets demands of Spokane, Washington, as well as Boca Raton, Florida." This "generic package” idea is alluded to by a principal, "I thought it was time for ... some sort of system that was available to all schools that was consistent and generated reports in a format that the state would accept." The need to complete common tasks and report them uniformly is supported through WVEIS.

Both superintendents interviewed commented on the electronic submission of state reports. In 1998-99, submission of seventeen reports through WVEIS is required. The first submission, the master list of schools, due in August before school begins, is followed by the preliminary certified list of personnel and continues through June with the tenth month report. Throughout the year the task of reporting is carried out consistently through WVEIS electronically as information culled from each county's files is submitted in the same form, and using similar data sets.

Collegiality can be tied into consistency and communication. As the individuals interviewed spoke of work related tasks the common denominator dealt with knowing there were other individuals doing the same task, looking at similar screens, and that they were available to help you work through it. Two examples follow that explain the collegiality expressed in the interviews. 
Each principal described the common tasks needing done and explained the role of WVEIS. When asked how he used WVEIS, a senior high principal's remarks reflected others' thoughts when he said, “We obviously do all the scheduling, we do all the attendance, we do all the disciplinary referrals (on WVEIS)." The junior high principal elaborated on the staff development he received and ties it to collegiality with this description of a staff development session; "The best staff development we probably had was when we just got together with principals and our management information staff and sat down and worked through situations we had to go through...like scheduling. We just sat down and all of us went to a computer. We collectively decided what code numbers and force codes and those kind of things we were going to use. How do you related arts cluster, all those types of things." The principals present in that session not only completed several required tasks together but can turn to one another for assistance.

The treasurer highlighted the positive aspects of the financial components of WVEIS as she discussed her role as an auditor and then as a treasurer. "I thought it would be nice to have everyone in a uniform kind of program. It would be nice, it is nice now to be able to talk to colleagues and they have the same problems and software related questions as I would. When you're on your own software you didn't have anyone else to relate to."

Collegiality is not a component of WVEIS nor an expected outcome but those interviewed brought up the importance of having colleagues they could meet with and discuss the components of WVEIS that each shared. From reports to procedures, the consistency found in WVEIS across the state may have encouraged this form of collegiality and one on one mentoring.

As the interviews suggest, collegiality surfaced as individuals needed help to solve a problem and asked a counterpart in another school or county. The uniformity and consistency WVEIS exhibits through common procedures and reporting can be seen across the county and state. The responses suggested the collegiality mentioned in helping others do these similar tasks may be encouraged as WVEIS expands and users increase. 
Even with the consistency present in WVEIS, the responses by those interviewed suggested some users find new and different ways of using the WVEIS system. Some examples included different tasks or extending the capabilities and original purpose of WVEIS, such as doing announcements through OfficeVision. Because of the consistency of WVEIS, replicating these new and different uses is possible. Those interviewed suggested the need to share "these best practices."

The negative component of consistency surfaced when individuals talked about his/her county's information system before WVEIS. Without customized packages or unique applications, some flexibility seemed sacrificed for consistency's sake. One WVEIS county contact remarked, “... it is so generic in nature you 've lost a lot of individuality- things this county had ... are no longer." Another example of the problems associated with each county working independently is shared by the treasurer. She noted the problems caused by a lack of consistency when asked about auditing. She replied “...it was difficult because every county had different kind of records, and you weren't sure what to ask for, and you didn't know what to ask for, and what their system was capable of producing. It's definitely easier from an auditing standpoint having everyone on the same system." In looking at the balance between positive and negative benefits related to consistency, the balance appears to tip in favor of consistency.

The intertwining of the themes through consistency was seen in previous examples. WVEIS attendance registers save time for teachers and are automated tasks that produce similar data sets across the state. Mentoring others through tasks that are the same reflect the last theme, communication, and can be related to consistency through the examples of collegiality.

\section{Communication}

The last of the four themes suggested by the interview data is communication. Defined as a process to exchange information, communication as a theme involves both positive and negative scenarios. Collegiality is a positive form of communication and is 
related in consistency as is uniform statewide reporting. Losing the physical presence of WVEIS and poorly communicating information are negative notes in this theme.

One example of communication is OfficeVision, the email component in WVEIS. Eight of the nine individuals interviewed indicated using OfficeVision. In the preconference data collection nearly 90 percent indicated they used OfficeVision to communicate with others. Interviews suggested this email system encouraged communication within buildings, across counties, and across the state and saved time, paper, and effort.

Checking the WVEIS email is a change in habit for users but "helps cut down on the "telephone tag" commented one of the superintendents. The use of OfficeVision to help others use WVEIS is implied in the interviews as a component of one on one mentoring. Using the email portion of WVEIS appears to be an accepted practice by those interviewed and those surveyed.

In one example the senior high principal related, "we do our announcements by OfficeVision...every morning my secretary types the announcements on OfficeVision and sends them out (electronically). We actually only print three hard copies. Also, we communicate internally through OfficeVision pretty extensively now. I was gone for a couple of days last week and when I came back I had about twelve OfficeVision messages from my staff."

A superintendent told how he used WVEIS with his principals, "I use distribution lists to communicate to my principals and try to keep them informed. I ask questions. I ask them to reply, to respond. Also, I can communicate with people that I know across the state easily. Actually it's more easy to use (OfficeVision) than the Internet for me."

The sharing of information includes the various reports that are submitted via WVEIS to the WVDE. The second month report and certified list are samples of communications to the West Virginia Department of Education interviewees identified. The West Virginia Report Card is one avenue for reporting that information to the general public. 
The lack of communication or the inability to communicate effectively was identified in the interviews as a negative view of communication. When the system would go down or users were dropped frustration occurred. One superintendent remarked, "I'm currently having .... a lot of complaints from my people. We are having a lot of line problems. We're getting dropped (the connection between the AS/400 and the user is being interrupted) right in the middle of payroll, right in the middle of a vendor check granting requisitions, just for no reason it seems. ... it's very frustrating and it's hurting me in getting our people to use the system more out in the field....because they are trying to go in and use it and they get kicked off of it and can't get signed back on a...it's frustrating them."

The elementary principal described another side of communication or lack of adequate communication while describing a staff development session with these remarks, "I think sometime those people who know computers well and who make a living with computers tend to talk over the heads of those of us who are real novices at the whole thing ... They try very patiently to explain the whole thing, but I just don't get it." He goes on to refer to this as the "dummy factor." Not being able to understand a task or process contributed to poor communication.

The comments from those interviewed helped paint the picture of WVEIS and provide a better view of users' concerns. In Figure 4.6, the difference between the concept and reality of WVEIS was shown. The four themes of time, change, consistency, and communication emerged from the responses of those interviewed. In Figure 4.7, the diagram illustrates WVEIS as the focus with the four themes connected and flowing around WVEIS. 


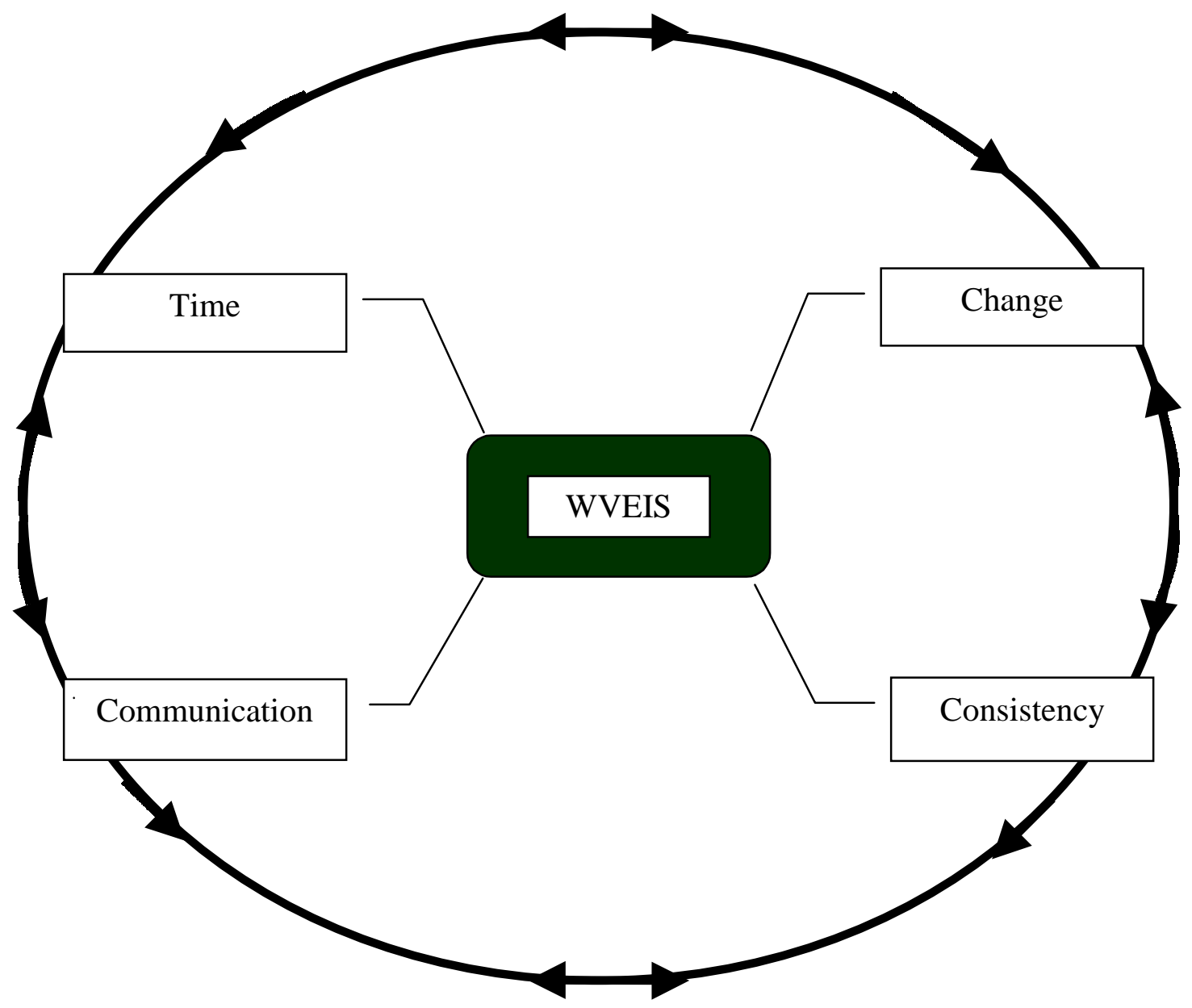

Emergent Themes

Figure 4.7

There also appears to be a connection between the emergent themes and the SoCQ. Time as a theme could be considered a management concern from Stage 3. Communication is necessary to deal with concerns in Stages 0-3, and in collaboration Stage 5. The discussion of collegiality under consistency also has ties to Stage 5. The theme change is the focus of the SoCQ. When a change occurs, what are the concerns of the participants and how can they be addressed. By analyzing the data from the SoCQ and examining the interviews for emergent themes a more focused picture of users' concerns could be developed. 


\section{Chapter Five \\ Summary, Conclusions, and \\ Recommendations}

This chapter contains a summary of the results as presented in Chapter 4, a discussion of the results, conclusions, and recommendations for further study.

\section{Summary of Results}

The purposes of this study were to determine if there are significant differences in users' concerns related to the innovation West Virginia Education Information System (WVEIS) and, consequently, to explore the impact of the WVEIS Data Conference as a staff development opportunity on users' concerns. The study was guided by the following subquestions:

1. Is there a significant difference between users' concerns based on job responsibility?

2. Is there a significant difference between users' concerns based on county size as determined by student population?

3. Is there a significant difference in users' concerns based on the amount of time (years and time used during a regular workday)?

4. Is there a significant difference in pre and post-test users' concerns based on those attending the 1998 WVEIS Data conference?

\section{Sub Question 1-Job Responsibilities}

Using an analysis of variance (ANOVA) to determine the significance of job responsibility on users' concerns a p-value needed for significance is 0.05 . In all but Stage 0 (Personal), and Stage 4 (Consequences) significant differences were noted. Comments from the interviews elaborated on individual concerns, such as scheduling for principals and submitting second month reports for superintendents. These important tasks and issues could relate to Stage 3 (Management) concerns on the Stages of Concern Questionnaire (SoCQ). In reviewing Figure 4.1, the graph of normed percentiles based 
on position, high levels of concerns are evident in Stage 0 (Awareness). In users of an innovation, this is considered positive. With over eighty percent of the group having used the system for two years or more there is no perceived need for awareness training. The span in intensity of concerns (difference between normed high and low percentiles) was greatest at Stage 3 (Management) and Stage 5 (Collaboration) with principals indicating a higher level of concerns over management and collaboration than other groups. The peak in Stage 5 may suggest principals are looking for ways to share their expertise with WVEIS. Relating the level of principals in Stage 5 with the request for sharing best practices from the interview component seems a good fit.

The data from the SoCQ suggest a significant difference in users'concerns based on job responsibilities. The interview data also corroborate this finding. Of the nine interviewed, two were superintendents, three principals, and the remaining four had different positions. Shared responses were very specific about positions. The superintendents referred to required state level reporting, principals commented on scheduling, and the treasurer noted the importance of WVEIS in auditing. Each group seemed almost isolated within WVEIS. The emergent themes from the interviews of time, change, consistency, and communication seem to be universally reported but were described in terms of the individual, thus supporting the difference based on job responsibilities.

\section{Subquestion 2-Enrollment}

Using an analysis of variance to determine the significance of county size on users' concerns, a p-value needed for significance is 0.05 . Examining county size by enrollment produced a significant difference only at Stage 4 (Consequences). The significance is minimal and involved counties with a population of 6,001-10,000 with all other county sizes except 0-2,000. The p-value for Stage 4 was 0.0488. This stage had the lowest mean scores and normed percentiles. It also demonstrated the least difference between high and low normed percentiles. Also identified in the limitations of the study, Stage 4 was expected to have very low means and normed percentiles. In the interview component, a principal in a county of less than 2,000 students indicated similar tasks and 
problems with WVEIS as a principal in a county of over 10,000 students. No significant difference is indicated overall of enrollment affecting users'concerns nor did responses, in interviews, seem affected by county size.

\section{Subquestion 3-Amount of Time (Years and Daily Use)}

Examining the number of years users participated with WVEIS and the amount of time they spend on WVEIS daily produced only limited examples of significant differences. An ANOVA was also run on the data from this subquestion.

A significant difference $(\mathrm{p}<0.05)$ is noted in Stage 0 (Awareness), Stage 1 (Personal), and Stage 4 (Consequences) based on length of use in years. In four of the stages there is no significant difference in users' concerns based on the length of time in years WVEIS has been used.

There was no significant difference in users' concerns about WVEIS based on minutes per day, in any stage. In interviews, time emerged as a theme but did not relate to time as measured in daily use or years. It appears the amount of time WVEIS is being used daily has become a component of their job. Those interviewed talked about the time needed to learn a system, the time needed for staff development, and how time demands changed as a result of WVEIS but not about concerns based on the length of time they had used the system on a daily or yearly basis. The data suggest that users' concerns based on time were not significant overall.

\section{Subquestion 4-WVEIS Data Conference}

In order to compare users' concerns between two distinct groups, those that attended and those that did not attend the WVEIS Data Conference, unpaired t-tests were run at each stage. If a significant difference is to be noted a p-value of less than 0.05 is needed. There were significant differences between the two groups at Stage 3 (Management), Stage 5 (Collaboration), and Stage 6 (Refocusing). Using paired t-tests (pre attended/post attended; pre did not attend/post did not attend) on the means of each group no significant differences were found. 
Although the mean scores for each stage migrated toward one another, a second unpaired t-test was run on the post conference data. No significant difference was noted between the two groups.

In the interviews, respondents spoke about their experience at the WVEIS Data Conference, not in major advances but in coming away with "one or two things that will help" or learning about future requirements or reports. The interviews did not highlight the conference as critical to using WVEIS effectively but "a nice conference to attend."

The data suggest that attendance at the WVEIS Data Conference has no significant effect on users' concerns. Work done by Vaughan (1997) showed how a workshop setting could address user concerns when sessions were designed to address specific needs.

\section{Conclusions Based on Results of this Study}

1. Is there a significant difference between users' concerns based on job responsibility?

The data indicate there is a significant difference between users'concerns based on job responsibility. WVEIS, as a tool used by educators, encompasses many tasks as an information system. The many components of the system are to a degree user specific. A treasurer deals with the FMS component, a principal with SMS, and most users send email via OfficeVision. This suggests that job responsibility should be considered in planning staff development and training for WVEIS. It should also be considered if any major changes are considered affecting WVEIS.

The depth of implementation of WVEIS is not easily inferred by the SoCQ but the data suggest that principals may be an important group to consider concerning WVEIS. It is in the principal subgroup that high concerns are seen in Stage 3 (Management) but it is also the same group that scores highest in collaboration and refocusing (Stage 5 and 6). With high scores in the last two areas, this group appears to be willing to work with others to find out what they are doing and to help those less experienced with WVEIS. This group could be targeted as trainers of trainers for sharing best practices related to 
WVEIS across the state. Fullan (1992) emphasizes the importance of the principal in the change process.

2. Is there a significant difference between users' concerns based on county size as determined by student population?

The data indicate there is not a significant difference between users' concerns based on county size nor is there much difference in the general profile of normed percentiles as determined by student population. It appears that WVEIS has leveled the playing field regardless of county size. Through telecommunication, reports from a rural county are transmitted in the same fashion as an urban county. It appears that with the same tasks, there are similar levels of concerns.

This lack of difference in concerns suggests that a county system as a boundary is bit more blurred than before WVEIS. The RESAs house the AS/400 for use by each of their respective counties and offer technical assistance for WVEIS. Perhaps the addition of WVEIS to the responsibilities of RESAs has strengthened their position and importance in the educational infrastructure of West Virginia.

3. Is there a significant difference in users' concerns based on the amount of time (years and time used during a regular workday)?

Based on the number of years WVEIS has been used a significant difference is noted in certain stages (three of seven) in users' concerns. Although some difference in mean scores exist across stages, the profile of normed mean percentiles is similar across all amounts of time in years and minutes. The data indicate there is no significant difference in users' concerns based on the amount of time (years and time used during the day) WVEIS is used.

The greater the acceptance of an innovation the lower the concerns generally are in the early stages and the higher they should be in the Stages 5 and 6. Those responding to the questionnaire were all users, therefore high scores in Stage 0 (Awareness) are considered an indication that users have a lack of concern about WVEIS in general. For 
those users with five years or more experience concerns are lower in Stage 1 (Informational) than those with one year or less. There are still high scores on the normed percentile profile for many in Stages 2 and 3, suggesting uncertainties about WVEIS and concern about management, time, and logistical aspects of WVEIS. Time as an emergent theme in the interviews helps corroborate these scores. This effect may in part be related to the mandated nature of WVEIS. Even if, as Stage 6 (Refocusing) suggests, a new way or improvement would be considered; the difficulty found in modifying WVEIS does not encourage a greater involvement from the stand point of the SoCQ.

The expectation in regard to the amount of time using WVEIS was that the longer it was used the greater the involvement would be. This was only partially true. Those with the most experience had few concerns in the early stages but did not have different normed percentile profiles as might be expected. WVEIS is being used, but it appears the implementation is still at a very basic level. The most intense concerns are still in the informational and personal stages. The data may suggest since WVEIS use was mandated, individuals are complying but not truly accepting the innovation. Again, Fullan (1992) points out you can't mandate what matters.

4. Is there a significant difference in pre and post-test users' concerns based on those attending the 1998 WVEIS Data Conference?

The data indicate there is not a significant difference in pre and post-test users' concerns based on attending the 1998 WVEIS Data Conference. There is little difference in normed percentile profiles between those attending or not attending, nor any movement from pre to post conference

Results of this study find little evidence to indicate that the WVEIS Data Conference effectively addresses users' concerns nor were there changes in profiles of normed percentiles for users who attended or did not attend the conference. Although the literature on change recommends staff development, this opportunity did not statistically affect users' concerns. Those who design the WVEIS Data Conference may want to 
review the findings of this study. In order to affect users' concerns the format and presentation style of sessions may need to be evaluated. A consideration of regional workshops or sessions specific to job responsibilities would also address subquestion 1. It may also be appropriate to consider expanding the number of sessions dealing with best practices and unique uses of WVEIS along with hands on opportunities for new tasks or new users. Another suggestion is to look very closely at using principals as trainers of trainers to share the best practices possibly at the following venues: WVEIS Data Conference, Principal Seminars, and the Principals Academy.

Users' concerns appear to be most impacted by job responsibilities. Counties and RESAs need to be cognizant of that fact as they attempt to further the implementation of WVEIS. If staff development opportunities are offered, they need to increase the users confidence and ability to use WVEIS and tap into those users who have high impact concerns in Stages 5 and 6 and can further the use and implementation of WVEIS.

\section{Recommendations for Further Study}

The following recommendations are given for further research related to the topic of this study.

1. Replicating this study in five years or whenever major changes to WVEIS are considered is recommended.

2. Building on the profiles identified in this study, a research project could target WVEIS use in principals and offer them specific staff development to address management (Stage 3) concerns and the opportunity to collaborate (Stage 5).

3. A survey to determine best practices and then a staff development opportunity to share them is recommended.

4. A study examining WVEIS implementation between counties that had information systems before WVEIS and counties that did not have an information system could compare progress and concerns, possibly using the Levels of Use from the Concerns Based Adoption Model. 
5. Another study could be done comparing results in West Virginia, where the use of an information system was mandated, to an area where implementation of an information system was voluntary.

6. Examining the relative importance of RESAs before and after WVEIS could also be a project for further study.

The research suggested in the recommendations may help identify how information systems have impacted educational organizations and individuals.

\section{Researcher's Reflections}

After spending many hours collecting data, conducting interviews, and analyzing results the time came to reflecting on those results and on the subject of this research, WVEIS. The researcher wishes to share some of those reflections.

There is no doubt that WVEIS meets the definition of an information system that Visscher (1996) provides. Many other school districts use the same basic software package. In this arena, West Virginia is providing schools and county systems a way to handle data. The system may not be state of the art for the next millennium but offers a way to manage data that other school systems and districts do not have. Now that WVEIS has become a part of the day to day routine in most schools, they are at a loss if the network goes down. Our next group of administrators will have WVEIS as the standard not the innovation or change. In nine years, as change goes, things are quite different.

Does the implementation of WVEIS relate to change or school reform? As with any other innovation how it is used is the essential factor. If the only difference is the fact that a class register is just kept electronically rather than paper/pencil then no reform occurred. If, on the other hand, WVEIS has freed up teacher time previously spent on that class register for reteaching or more hands on activities in science then there has been reform. Fullan (1991) points out that "you can't mandate what matters." The type of information system may not matter as much as the time spent with a student or what the nurse or principal is doing with the data or information culled from that system. 
Darling-Hammond (1997) also points out a need for local energy and ideas. It is at that interface that principals, nurses, treasurers, and other WVEIS users are making their presence felt. The process seems slow but those best practices and individual ideas are being shared informally in some cases and formally in others. The willingness to collaborate is there, especially among principals, but the venue is not clearly established.

The WVEIS Data Conference does not seem to affect users' concerns. Are there other things happening at the conference that cannot be measured by the SoCQ? How are those who do not attend the Data Conference find out about and learn to implement the changes and requirements in WVEIS? More questions than answers arise that relate to staff development issues. From the researcher's perspective, the staff development component holds promise for the continued implementation and evolution of WVEIS.

The SoCQ provided a rich source of data about users' concerns, but it did not uncover all types of change. The SoCQ indicated principals especially had high concerns with Stage 3 (Management) but the interview component highlighted the concern the principals had with time issues. The theme, time, relates directly to management and personal concerns. The interviews added to the data provided by the questionnaire. The results raised questions. Why are we not moving more into refocusing? Why are there such differences in intensity of responses especially principals? These questions can have two purposes. First, those in decision making positions can use them to guide the direction of WVEIS. A second purpose could pave the way for further research and continued study of WVEIS.

As reform efforts move through education in West Virginia from Local School Improvement Councils to Faculty Senates, the West Virginia Education Information Systems ranks as one that will stay. It has altered the way schools and administrators deal with data. As those in decision making positions employ the capabilities of WVEIS to help guide decisions that benefit students then true reform will emerge. 


\section{BIBLIOGRAPHY}

Bailey, D. and S. Palsha. (1992). "Qualities of the Stages of Concern Questionnaire and Implications for Educational Innovations." Journal of Educational Research 85, no. 4 (Mar-Apr): 226-32.

Barth, R. (1991). "Restructuring Schools: Some Questions for Teachers and Principals." Phi Delta Kappan 73, no. 2: 123-128.

Blanchard, K. (1995). "Six Levels of Concern in the Change Process." Emergency Librarian 23, no. 2 (Nov/Dec): 38.

Bradshaw, L. (1997). "Technology-Supported Change: A Staff Development Opportunity." NASSP Bulletin 81, no. 593 (December): 86-92.

Burdette, K. (1998), telephone conversation with the author, Parkersburg, WV. August.

Burke, P. (1994). “Teacher Leadership in Professional Development.” In Donovan R. Walling (Ed.). Teachers as Leaders: Perspectives on the Professional Development of Teachers. Bloomington, Indiana: Phi Delta Kappa Education Foundation.

Byrne, M. and others. (1989). "A Telecommunications Staff Development Project." Journal of Staff Development_10, no. 4 (Fall): 26-30.

Cuban, L. (1988). "Reforming Again, and Again, and Again." Educational Researcher 19, no. 10: 3-10.

Darling-Hammond. L. (1994). "Will $21^{\text {st }}$ Century Schools Really be Different?" Educational Digest 60, no. 1(Sept): 4-9.

Darling-Hammond, L. (1993). "Reframing the School Reform Agenda: Developing Capacity for School Transformation." Phi Delta Kappan 74, no. 10: 752-761.

Darling-Hammond, L. (1997). The Right to Learn, San Francisco: Jossey Bass Publishers.

Darling-Hammond, L.and M. McLaughlin. (1995). "Policies that Support Professional Development in an Era of Reform." Phi Delta Kappan 76, no. 8: 597-604.

Fullan, M. (1996). "Professional Culture and Educational Change." School Psychology Review 25, no. 4: 496-500.

Fullan, M. (1991). The New Meaning of Educational Change, New York: Teachers College Press. 
Fullan, M. and M. Miles. (1992). "Getting Reform Right: What Works and What Doesn't." Phi Delta Kappan. 73 no.10: 744-752.

Fullan, M. (1992). "Visions that Bind." Educational Leadership, 49, no. 5: 19-20.

Fuller, F. (1969). "Concerns of Teachers: A Developmental Conceptualization." American Educational Research Journal 6, no. 2: 207:226.

Fuller, F., O. Brown. (1975). "Becoming a Teacher." In K. Ryan (ed) : Seventy-fourth Yearbook of the National Society for the Study of Education, Chicago: University of Chicago Press.

Guskey, T. (1990). "5 Guidelines for School Innovation.” Education Digest 56, no. 2(Oct): 23-27.

Hall, G., S. Hord. (1987). Change in Schools, Facilitating the Process. Albany: State University of New York Press.

Hall, G., S. Loucks. (1978). "Teacher Concerns as a Basis for Facilitating and Personalizing Staff Development." Teachers College Records 80: 36:53.

Hall, G., W. Rutherford. (1976). "Concerns of Teachers about Implementing Team Teaching.” Educational Leadership 24, no. 3: 227-223.

Hall, G., A. George, and W. Rutherford. (1986). Measuring Stages of Concern About the Innovation: A Manual for Use of the SoC Questionnaire.( Austin: Southwest Educational Development Laboratory).

Hope, W. (1997). "Resolving Teachers' Concerns about Microcomputer Technology." Computers in the Schools 13, no.3-4:147-60.

Hord, S., W. Rutherford, L. Huling-Austin, G. Hall. (1987). Taking Charge of Change. (Alexandria: Association for the Supervision and Curriculum Development).

Kember, D. and R. Mezger, R. (1990). "The Instructional Designer as a Staff Developer: A Course Team Approach Consistent with a Concerns-Based Adoption Model." Distance Education 11, no.1:50-70.

Loucks-Horsely, S. (1994). "Significant Advancements in staff development of the Past Twenty-five Years." Journal of Staff Development 15, no.4: 7-8.

Maughan, G. (1998). class notes, West Virginia University, 1998.

McCarthy, B. (1982). "Improving Staff Development through CBAM and 4Mat." Educational Leadership 40, no. 1(Oct): 20-25. 
Mitchell, S. (1988). "Applications of the Concerns Based Adoption Model in Program Evaluation." (paper presented at the Annual Meeting of the American Educational Research Association, April).

Office of Technology Assessment. (1995). Teachers and Technology: Making the Connection. Washington, D.C, U. S. Congress,.

Osborne,B. (1993). "Understanding Change in a time of Change." (paper presented at the Second National Creating the Quality School Conference, Oklahoma City, OK., March).

Ragsdale, R. (1997). "Surprised by Technology: Unanticipated Outcomes of Technology Implementation." (paper presented at the Annual Meeting of the American Educational Research Association, Chicago, IL, March 24-28).

School Laws of West Virginia. (1995). Michie.Charlottesvillle.

Shotsberger, P. and A. Crawford. (1996) "An Analysis of the Validity and Reliability of the Concerns Based Adoption Model for Teacher Concerns in Education Reform." (paper presented at the Annual Meeting of the American Educational Research Association, New York, NY, April 8-12).

Smith, C. (1997). Theory and the Art of Communications Design. State of the University Press.

Sparks, D. (1994). "Reflections on Staff Development's Future." The Developer : 2-4.

Sparks, D. and S. Hirsh. (1997). A New Vision for Staff Development. Alexandria, Association for Supervision and Curriculum Development.

Speck, M. (1996). "Best Practice in Professional Development for sustained Educational Change.” ERS Spectrum 14, no. 2: 33-47.

Telem, M. (1996). "MIS Implementation in Schools: A Systems Socio-Technical Framework." The Journal for Research and Computers in Education 27, no. 2: 85-93.

Telem, M. (1998). "School Administration Computerization Impact on the Teacher's Role: A Case Study." Urban Education 33, no. 4: 534-554.

Tiede, L. (1992). “A study of selected Elementary School Principals' Use of Computers for Administrative Purposes.” (Ed.D. diss., Northern Illinois University).

Todd, N. (1993). "Faculty Concerns as Gateways to Teacher Competency with Computer Technologies. (paper presented at the convention of the Association for Educational Communications and Technology sponsored by the Research and Theory Division, New Orleans, Louisiana, January 13-17). 
United States Department of Education. (1996). "Report Sets Technology Literacy as Key Goal." Education Week 15, 25.

Vaughan, W. (1997). "The Effects of Concerns Based Professional Development on Teacher Concerns About Schoolnet Technology” (Ph.D. diss., Miami University).

Visscher, A. (1996). "Information Technology in Educational Research." International Journal of Educational Research 25, no. 4: 289-380.

Wedman, J. (1988). "Increasing the Use of Instructional Media in the Schools". Educational Technology 28, no.10 (Oct): 26-31.

Wiersma, W. (1995). Research methods in Education, An Introduction. Boston. Allyn and Bacon.

Willis, J. (1992). "Technology Diffusion in the "Soft Disciplines": Using Social Technology to Support Information Technology" Computers in the Schools 9 no.1: 81-105.

Wesley, M., Jr. and M. Franks.(1996). "Advanced Adoption of Computer Technology in the Classroom and Teachers' Participation in Voluntary Innovation Adoption" (paper presented at the Annual Meeting of the Mid-South Educational Research Association, Tuscaloosa, AL, November 6-8,). 
Appendices 


\section{Appendix A}

\section{School Law Quote Regarding WVEIS}

(f)Each regional educational service agency shall commence implementation of a uniform integrated regional computer information system as recommended by the state board of education on or before the first day of January, one thousand nine hundred ninety-one. Each county board of education shall use the computer information system for data collection and reporting to the state department of education beginning no later than the first day of July, one thousand nine hundred ninety-four. County boards of education shall bear the cost of and fully participate in the implementation of the system by: (1) Acquiring necessary, compatible equipment to participate in the regional information system; or (2) following receipt of a waiver from the state superintendent, operating a comparable management information system at a lower cost which provides at least all uniform integrated regional computer information system software modules and allows on-line, interactive access for schools and the county board of education office onto the statewide communications network. All data formats shall be the same for the uniform integrated regional information system and will reside at the regional computer. Any county granted a waiver shall receive periodic notification of any incompatibility or deficiency in its system. Continued inability of any county to meet the above criteria shall, upon notification to the county no later than the first day of April, one thousand nine hundred ninety-five, require the county to use the uniform integrated regional computer information system no later than the first day of July, one thousand nine hundred ninety-five. No county shall expand any system either through the purchase of additional software or hardware that does not advance the goals and implementation of the uniform integrated regional computer information system as recommended by the state board: Provided, That nothing contained herein shall prevent the state superintendent from granting a one-year extension to those counties projected to have budget deficits for the school year beginning on the first day of July, one thousand nine hundred ninety-four. (Schools Laws of West Virginia, 1995) 


\section{Appendix B}

HRE Approval

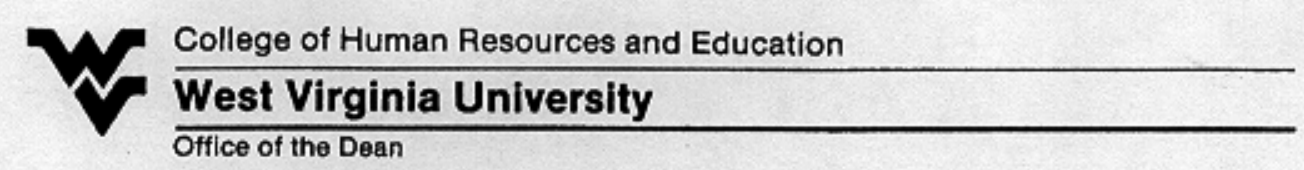

February 24, 1998

\section{MEMORANDUM}

TO: $\quad$ Toni DeVore

FROM: $\quad$ Emest R. Goeres

Associate Dean

RE: Human Resources \& Education H.S.\$98-025

Title: "Implementation of WVEIS and It's Impact on the Administrative Tasks of Schools"

Your Application for Exemption for your above-captioned research project has been reviewed under the Human Subjects Policies and has been approved.

This exemption will remain in effect on the condition that the research is carried out exactly as described in the application.

Best wishes for the success of your research.

\section{Attachment}

$\propto$ : Deans Office

Student Advising and Records

Phyllis Durden, Advisor

304 203-5700 a E02 Allen Hall o P.O. Box 6122 0 Morgentown, WV $25506-0122$ Equal Opportunity / Allirmative Action Inatitution 
HRE Approval

June 4, 1998

Dr. Ernest R. Goeres

Associate Dean

Dear Sir.

On February 24 1998, I received approval for an exemption under the Human Subjects Policies: Could this survey instrument be added to my exemption?

Sincerely,

\author{
Toni Lynne DoVore \\ Cohort II \\ Doctoral Student
}

1309 LISEATY STAEET • PARKERSBURG, WV • 26101

PHONE: 304.422.3776 - FAXt 304.420.95t3 


\title{
Appendix C
}

\author{
Stages of Concern Questionnaire
}

West Virginia Education Information System
WVEIS Concerns Questionnaire

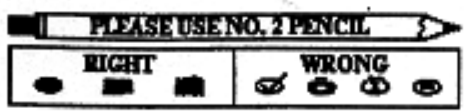

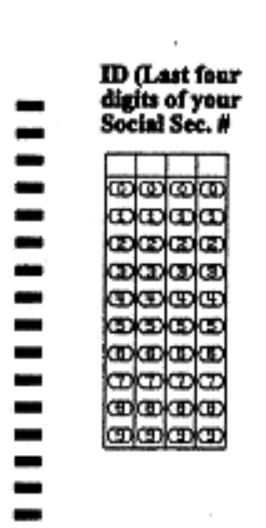

County

Position(o) you hold in your county (mark all that apply)

$\bigcirc$ Superintendent

C. Assistant Superintendent

$\bigcirc$ Attendance Officer

$\checkmark$ Curriculum Supervisor/Director

Principal/Assistant Prinoipal

$\square$ Guidance Counselor

Secretary in a sebool

Secretary other than in a school

Accountan//Financial office

Teacher

0 Food Service

$\checkmark$ Transportation

M Mainienance

County Contact for WVEIS

0 Other (describe)

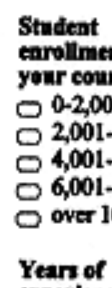

Student

Years of

earollinent in

your county

$0-2,000$

2,001-4,000

4,001-6,000

6,001-10,000

0 over 10,000

experiance

in education

1-3 yéars

- 4 49 years

10 - 15 years

16-20 yean

0 over 20 years
Did you attend the

Wviess Data

June, 1998?

$\square$ No

Yes

Are you currenthy

involved in implement ing other hanovitians or projects?

0 No

$\square$ Yes

1. How would you rate your level of computer expertise?

- Novice

- $\bigcirc$ Some experience

- Moderate experience

- $\square$ Experienced user

- $\square$ Experienced and proficient nger

4. How lang have you used any componen! of WVERs?

Leas than 1 year

$\square$ 1-2 years

2-3 years

3-4 years

045 years

$\square$ More than 5 years
2. How would you rate your level of expertioe whth WVisis?

$\square$ Novice

Some experience

$\checkmark$ Moderate experience

$\square$ Experienced user

$\bigcirc$ Experienced and proficient user
3. Which lien beit describes the stafi development you have recetved to implement WVHS?

No staff development on WVEIS roceived

$\checkmark$ Sessions conducted whillo logged onto WVEIS

Wholo-group instruction with no computer component

Mix of wholo-group and computer-based instruction

C. Self-twught

$\checkmark$ One-on-ane with a collengue

7. Which components of WVRIS do you currently nse? (Mark all that apply)

- $\square$ SMS - tadent mangegement system $\square$ BMS - bumm resources management system

- $\bigcirc$ FMS - financial management system $\bigcirc$ EMS - employec manigement aystem

6. Which ltem beat deacribes the dats management information sytem in plince in your county before WVRIS? of time your ane typically loesed and using WVETS?

$\square$ I do not use WVEIS

$\checkmark$ Rare - less thin 5 mimutes, 2-3 days a week

O Minimal - less than 10 minustes each dry

Regular - up to 30 minutes each day

$\square$ Frequent - over 30 minutes each day
I don't know what we did before WVEIS

There was no system before WVEIS

Minimal system before WVErs

Well-fumctioning system before WVEIS

\section{INSTRUCTIONS}

The questionnaire items on the other side of this form are used to determine what people who wre using or thinking about using various programs are concerned about at various times daring the imnovation adoption process. The items were devaloped from typical responses of school and college teachers who ninged from no knowiledge at all about various programs to many years experience in using them. Therefore, a gaod part of the hems on this qwestionuaire may appear to be of little relevance or irrelevant to you af thits time. For the completely irrelevant items, please mark " ${ }^{\prime \prime}$ on the seale. Other items will represent those concerns you do have, in varying degrees of intensity, and should be merked higher on the scale.

Please respond to the items in terms of your present concerns, or how you feel about your involvement or potential involvement with the Weat Virginia Educetion Information Syatem (WVEIS). We do not hold to any obe definition of this program, so please think of it in terms of your own perceptions of what it involves. Remember to respond to each item in terns of your present concerss about your involvement or potential involvement with the abovo-named innovation. Thank your for taking the time to complete this task.

Copyright 1974. Procedures for Adopting Educational lnnovations/ CBAM Project, RED Center for Teacher Education, University of Texas at Austin

(Please continue on the other side) 
Remember: "the-innovation" - "West Virginia Education Information System (WVEIS)"

Not true Somewhat Very true
Irrelexant of me now true of me now of me now

1. I am concerned about studen's' attitudes toward this innovation.

2. I now know of some approacbes that might work better.

3. I don't even know what the innovation is.

4. I am concemed about not having enough time to organize myself each dry.

5. I would like to help other faculty in their use of the innovation.

6. I have a very limited knowiledge about the innovation.

7. I would like to know the effect of reorganization on my professional status:

8. I am conoemed about conflict between my interests and thy responsibilities.

9. I am concerned about revising my use of the innovation.

10. I would like to deyelop working relationships with both our faculty and outside faculty using this innovation.

11. I am concerned about how the innovation affects students.

12. I am not concemed about this imnovation.

13. I would like to know who will mako the decisions in the new system.

14. I would like to diseuss the possibility of using the innovation.

15. I would like to know what resources are available if we decide to adopt this innovation.

16. I am concerned about my inability to manage all the innovation requires.

17. I would like to know how my teaching or administration is supposed to change.

18. I would like to familiarize other departments or persons with the progress of this new approach.

19. I am concerned about evaluating my impact on students.

20. I would like to revise the innovation's instructional approach.

21. I am completely oocupied with other things.

22. I would like to modify our use of the inmovation based on the experiences of our students.

23. Although I don't know about this innovation, I am concerned about things in the

24. I would like to excite my students about their part in this approach.

25. I am concerped about time spent working with nonacademic problems related to this innovation. 26. I would like to know what the use of the innovation will require in the immediate
future.

27. I would like to coordinate my effort with others to maximize the innovation's effects.

28. I would like to have more information on time and enengy commitments required by this innovation.

29. I would like to know what other faculty are doing in this area.

30. At this time, I am not interested in learning about this innovation.

31. I would like to determine how to supplement, enhance, or replace the innovation.

32. I would like to use feedback from students to change the program.

33. I would like to know how my role will change when I am using the innovation.

34. Coordination of tasks and people is taking too much of my time,

35. I would like to know how this innovation is better than what we have now.

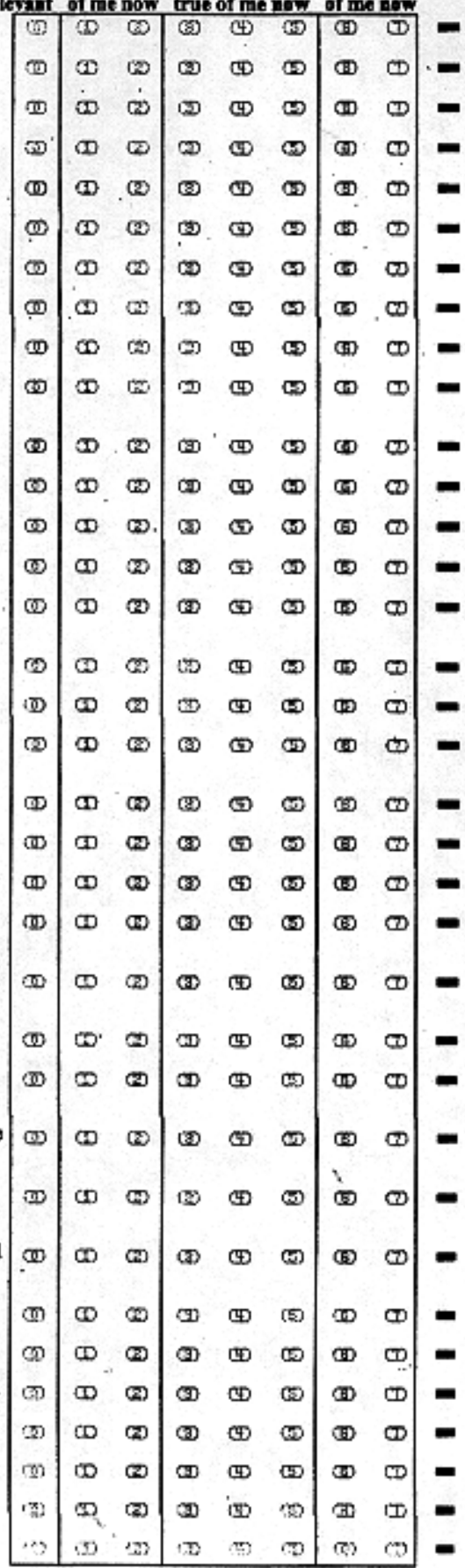




\section{Appendix D}

\section{Essentials of Best Practice in Professional Development for Sustained Change}

1. Increasing student learning is the goal.

2. The school is the unit of change.

3. Professional development is a multiple, diverse, and ongoing process, not a one-shot approach.

4. All educators should be involved throughout their careers-lifelong learners.

5. The principal is the key.

6. Improvement goals should involve stakeholders in the school.

7. Efforts must recognize and address the values, norms, and beliefs that shape school practice and culture.

8. Policies and practices must be connected to change and constructed by practitioners in contest.

9. Teachers develop ownership and commitment through input to change.

10. The primary goal is school improvement however; professional development must support both school and individual growth.

11. School districts must provide resources.

12. Planning and implementation should utilize adult learning theory.

13. Coaching and systematic support are required for the transfer of learning from training into daily practice.

14. Schools should provide recognition and rewards for efforts to grow professionally.

15. Stakeholders must share decisions about time, schedules, curriculum, personnel, space, and materials.

16. Professional development should support instructional and program improvement linked to instructional supervision, teacher evaluation, and curriculum implementation.

17. Teachers must have authentic opportunities to learn from colleagues "inside" the school.

18. Opportunities, time, and support mechanisms should be provided inside school to discuss, try out, reflect on, and hone new practices.

19. Broader support mechanisms outside the school are needed.

20. Cross-role participation stimulates shared understandings and new approaches.

Source: Speck, Marsha (1996) Best Practice in Professional Development for Sustained Educational Change, Spectrum: Spring. 


\section{Appendix E \\ Interview Questions}

1. In order to verify your position for the study, my records indicate you are a

2. How long have you worked in this position?

3. Describe your reaction when you first learned about the concept of a statewide information system that eventually became WVEIS.

4. Describe your reaction when you first learned you would be using WVEIS in your position.

5. How did you learn to use the system?

5.1. Did you participate in staff development or the WVEIS Data Conference?

5.2. If you need to do something in WVEIS and can't figure it out what do you do?

6. How do you use WVEIS in your position?

6.1. Do you just input data or do you retrieve information for various purposes? Elaborate.

7. How does WVEIS impact what you do as a ?

8. Are you involved in helping others use WVEIS? If yes, please elaborate.

9. There have been many change initiatives in WV. A few of them are site based management (LSICs, Faculty Senates), Projects CATS, School to Work, the policy changes that resulted from SB 300, etc. How does your experience with these change initiatives compare with your experiences with WVEIS?

10. How would you respond to the statement, "We need to replace WVEIS with a new information system."

11. Do you have additional comments or concerns you would like to express? 


\section{Appendix F}

\section{Analysis of Interview Data}

1. In order to verify your position for the study, my records indicate you are a

Participating in the interviews were two superintendents, three principals (one elementary/WVEIS county contact, one junior high, and one senior high), a director of management information systems/WVEIS county contact, a treasurer, a coordinator of computer operations (other in the demographic data of the Stages of Concern Questionnaire), and an accountant/secretary.

2. How long have you worked in this position?

The range in response was as little as four months to greater than twenty-nine years. Four individuals changed jobs in the last six months, one interviewee was a new employee to education, and the remaining four had worked in their respective counties from six to nearly thirty years.

3. Describe your reaction when you first learned about the concept of a statewide information system that eventually became WVEIS.

All responses included positive remarks about the concept from "an intriguing concept, an excellent idea," or "a nice goal" to "I thought it was really time (for WVEIS)."

4. Describe your reaction when you first learned you would be using WVEIS in your position.

Only one respondent indicated apprehension, others commented on the "positive effects of technology to reduce the time spent on administrative tasks." Other responses ranged from "I like to learn new things" to "anything new is exciting." Several participants' comments contained references to time and or timing. One 
individual responded, 'it came at a good time for me...we went on the system right when I took my job." Another said, "I'm always willing to look at how can I do something electronically to save myself more time." Some respondents expressed concerns about giving up the information system previously in use by their county.

5. How did you learn to use the system?

One individual related that the use of WVEIS was first delegated to another professional but indicated he had later learned to use the system through trial and error, RESA conducted workshops, and help from co-workers. Each respondent commented on the importance of hands-on, "just sitting at the computer and working through a task" such as scheduling. Time was again mentioned. Finding the time to attend staff development or training sessions was difficult for the principals, while others commented on the amount of time that it took to learn a new system.

Collegiality played an important facet with regard to learning how to use WVEIS. Each participant commented about calling another principal, secretary, colleague, or RESA person to help talk him or her through an activity or to clear up a question.

\subsection{Did you participate in staff development or the WVEIS Data Conference?}

Responses here mirrored question five. Each participant attended or was aware of staff development offered at the county level, from RESA, or at the WVEIS Data Conference hosted by the WVDE. Only one participant did not attend any WVEIS Data Conferences. Two respondents commented that sessions at the Data Conference were "over my head." Several indicated they learned about "improvements or learned what's coming someday."

The concept of collegiality surfaced again especially in informal settings. The need to share best practices, "to communicate the good things happening" and not to "reinvent the wheel" were cited. Another comment made dealt with being 
able to "vent frustrations" and finding out you were not the only one with a particular problem.

5.2. If you need to do something in WVEIS and can't figure it out what do you do? Reflecting the answers in 5 and 5.1 responses emphasized calling a colleague for assistance, sending an email, or working with someone close at hand or from across the state.

6. How do you use WVEIS in your position?

Only one individual interviewed did not report using Office Vision. Many of the respondents use WVEIS components specifically. The accountant/secretary and treasurer predominantly use FMS; principals use OfficeVision and SMS, and the superintendents interviewed are most familiar with the components they used in previous positions. Vignettes illustrate the change from employing teacher registers to using WVEIS for attendance and responsible student programs. Two of the principals are piloting the Grade Quick program and one delivers morning announcements as email messages to each teacher.

One recurring topic that emerged in this question relates to 6.1. Principals and superintendents cite using data for scheduling, test data analysis, grade reporting and state reporting. One individual commented, "the more information put (into the system) the more valuable the tool becomes."

6.1. Do you just input data or do you retrieve information for various purposes? Elaborate.

The input or retrieval of information seems to relate to position. The accountant/secretary, the coordinator of computer operations and principals input and retrieve data; participants felt both input and retrieval are aspects of their positions. For the director of MIS and the superintendents input is not a component but retrieval and analysis of the data is critical to doing their jobs efficiently and competently. 
Vignettes offered by interviewees describe how grade reports, budget reports, and state-required reports cull data from WVEIS and are submitted to the WVDE electronically.

7. How does WVEIS impact what you do as a $?$

For the service personnel the most common response is, "it's my job." What they do day in and day out involves WVEIS continuously. Principals and superintendents responded that WVEIS gives them time to do other tasks and provides more information and data to use as needed. Two principals note that WVEIS changes the way they manage their schools. It is a "paradigm shift in management."

The uniformity or consistency across the state that WVEIS provides surfaced here. One superintendent notes "when everyone does their job accurately then reporting (second month report) is painless and routine."

8. Are you involved in helping others use WVEIS? If yes, please elaborate.

Only the accountant/secretary, new to education, is not involved in helping others use WVEIS. One principal commented "no one asked me (for help)," but he is actively involved in helping his teachers pilot the Grade Quick program. Helping others ranges from working with a colleague in your building to helping others in similar positions in the same county or across the state. One instance epitomizes the electronic workplace. The expertise held by the coordinator for computer operations in one county allows her to help another county to move more efficiently and quickly onto WVEIS. This was facilitated by hiring substitutes from her county and training them after hours on the EMS component of WVEIS. By connecting them via the WVEIS network with the county one hundred miles south, this group works for the county she's assisting under her supervision while converting employee records to WVEIS data entries. Her motivation is "let me see if I can accomplish this!" Using 
the technology, her knowledge, and the willingness of both county superintendents to change the view of the traditional workplace, telecommuting is also a function of WVEIS.

9. There have been many change initiatives in WV. A few of them are site based management (LSICs, Faculty Senates), Projects CATS, School to Work, the policy changes that resulted from SB 300, etc. How does your experience with these change initiatives compare with your experiences with WVEIS?

Most service personnel interviewed have little contact with other change initiatives and few comments concerning them. Principals and superintendents responded differently. Echoing through their interviews consistently were comments such as "legislated changes, top down, and unfunded." Additional thoughts included "some of those changes are on paper only" and we had to institute these changes "without proper technical assistance to make the implementation."

Another thread seen in this question deals with how the change influences or affects the individual interviewed. Some felt they were passive participants in WVEIS (it was done to them). Other changes included their entire staffs and seemed to involve more interaction on their part.

Three of those interviewed took their positions at the time of or after the implementation of WVEIS and have no comparison or loyalty to another system. They do not see WVEIS as a change, but the standard.

10. How would you respond to the statement, "We need to replace WVEIS with a new information system.’?

Initial responses to this question include; "I would hate to start from the beginning, You can't replace it, You'll have a revolution on your hands, Good Luck (with the tone indicating sarcasm)." Probing further, most respond that a more "user friendly" 
program and a windows platform are needed improvements. Several comments were made about the need for extensive planning and assistance for implementation. One principal first commented, "I'm not sure you can replace it." Thinking it over he adds, "The concept is necessary.... I think you need to implement this one (WVEIS) fully and get everyone up to a certain level." He later reflects that as technology changes WVEIS will, too. His thoughts echo others.

One basic concern expressed by each individual involved the transfer of data from WVEIS to a new information system. Comments came from two sides. Some mentioned how much time it would take if all the data would have to be re-entered manually, others used the term "dump files" to indicate the need to electronically transfer the data.

Time and timing are mentioned in part relating to planning and when a new system would be implemented and to the amount of time needed to learn a new system. The dichotomy between the concept of an information system and the actual hardware and software that are WVEIS surfaces again as respondents worked to answer this question.

11. Do you have additional comments or concerns you would like to express?

Interviewees reiterated their strongest concerns including how slow the system is and how it appears to be overloaded. Others comment that it "works pretty good, the concept is correct," and one superintendent captures the change in attitudes of WVEIS users when he says, "In 1993 I hated WVEIS, in 1996 I accepted WVEIS, and in 1998 I actually like WVEIS." 


\section{Appendix G}

SoCQ Normed Percentiles

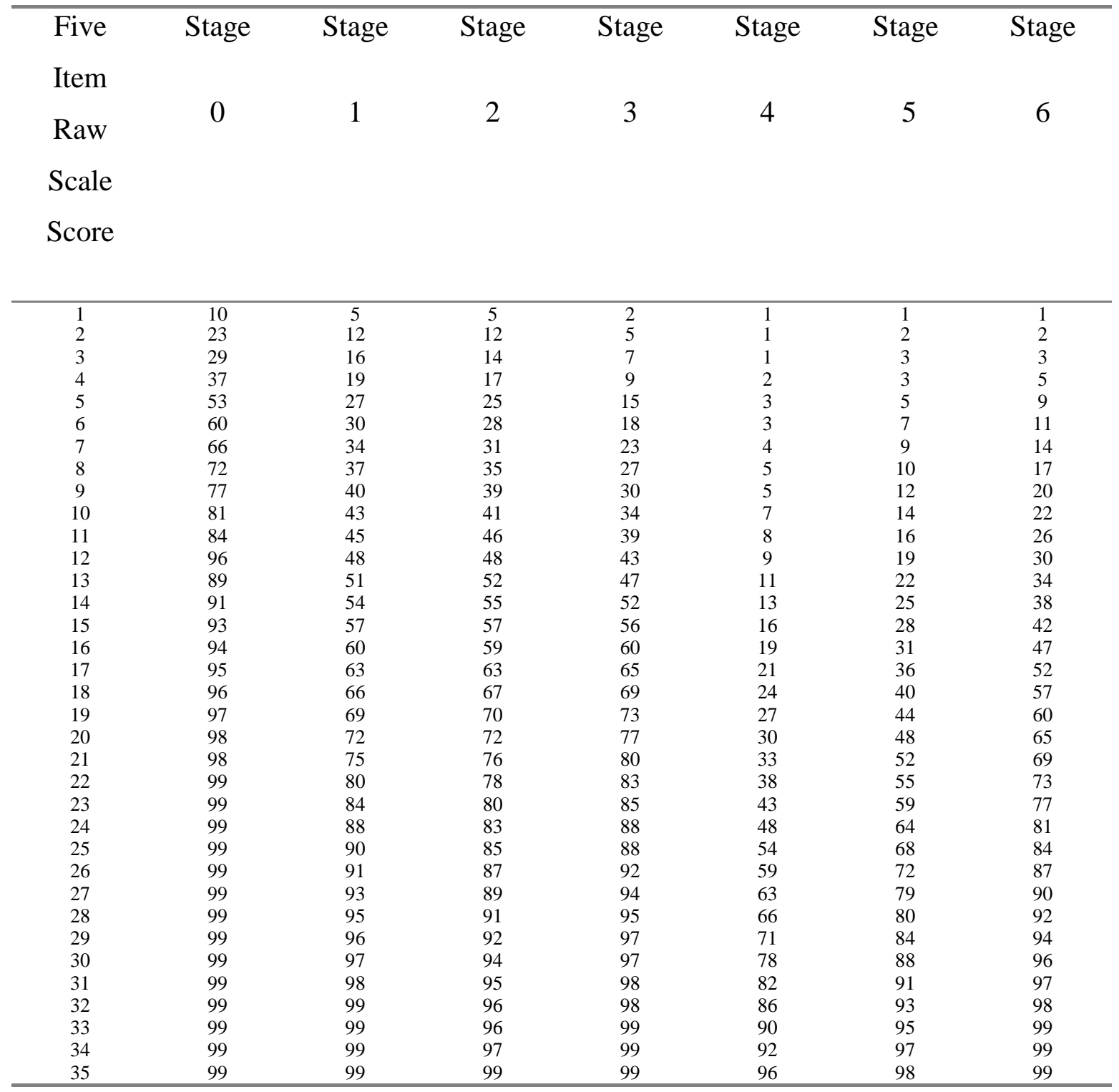

Source: Hord, S. Rutherford, W.; Huling-Austin, L.; and Hall, G.., (1987). Taking Charge of Change (p.50) 


\section{Appendix H}

Cover Letters

June 19, 1998

\section{Dear Superintendent;}

As a doctoral student at West Virginia University in the Cohort II program, I am beginning research on my dissertation topic. The focus of my research is on the West Virginia Information System (WVEIS). I know you are busy but I would appreciate it if you would take time to distribute the four attached surveys to county employees who did not attend the WVEIS Data Conference. I will be comparing data from those attending the conference with a similar group that did not attend the conference. Any encouragement you could offer to get the surveys completed and returned would be appreciated. Enclosed is a postage paid envelope that can be used to return the surveys to me.

With your help the response to the survey will be high and the results will be of interest to the educational community.

Sincerely,

Toni Lynne DeVore

Cohort II 
June 22, 1998

Dear Participant;

As a doctoral student at West Virginia University in the Cohort II program, I am beginning research on my dissertation topic. The focus of my research is on the West Virginia Information System (WVEIS). I will be comparing data from the Stages of Concern Questionnaire filled out by those attending the WVEIS Data Conference with a similar group that did not attend the conference.

The goal of this research is to identify movement along the Stages of Concern continuum as a result of participation in the Data Conference. This is the pre-conference questionnaire with a post conference questionnaire to be mailed in the fall of 1998.

Before you begin please note:

Your participation is entirely voluntary.

You do not have to respond to every item or question.

Your responses will remain anonymous and confidentiality will be maintained.

Please fill out the following demographic data in order to send a follow up survey.

Name

Mailing address

City State Zip

WVEIS address Email address

Last four digits of your social security number

Please return your completed survey and this demographic sheet to the box marked WVEIS Survey at the registration desk. Thank you for participating.

Sincerely,

Toni Lynne DeVore 
June 19, 1998

Dear Participant;

As a doctoral student at West Virginia University in the Cohort II program, I am beginning research on my dissertation topic. The focus of my research is on the West Virginia Information System (WVEIS). I will be comparing data from the Stages of Concern Questionnaire filled out by those attending the WVEIS Data Conference with a similar group that did not attend the conference.

The goal of this research is to identify movement along the Stages of Concern continuum as a result of participation in the Data Conference. This is the pre-conference questionnaire with a post conference questionnaire to be mailed in the fall of 1998.

Before you begin please note:

Your participation is entirely voluntary.

You do not have to respond to every item or question.

Your responses will remain anonymous and confidentiality will be maintained.

Please fill out the following demographic data in order to send a follow up survey.

Name

Mailing address

City State Zip

WVEIS address Email address

Last four digits of your social security number

Please return your completed survey and this demographic sheet to your superintendent. Thank you for participating.

Sincerely,

Toni Lynne DeVore 


\title{
Appendix I
}

Additional Tables and Figures

\section{Subquestion 1}

\author{
Stage 0 (Awareness)
}

Table I.1

$$
\mathrm{N}=118
$$

\section{ANOVA Table for STAGE 0}

\begin{tabular}{|c|c|c|c|c|c|c|c|}
\hline & $\mathrm{DF}$ & Sum of Squares & Mean Square & F-Value & P-Value & Lambda & Power \\
\hline & 7 & 341.188 & 48.741 & 1.302 & .2561 & 9.113 & .529 \\
\hline & 110 & 4118.278 & 37.439 & & & & \\
\hline
\end{tabular}

\section{Table I.2}

\section{Means Table for STAGE0 \\ Effect: Position}

\begin{tabular}{l|r|r|r|r|}
\multicolumn{1}{c}{} & \multicolumn{1}{c}{ Count } & \multicolumn{1}{c}{ Mean } & \multicolumn{1}{c}{ Std. Dev. } & \multicolumn{1}{c}{ Std. Err. } \\
\cline { 2 - 5 } Accountant & 11 & 7.182 & 6.524 & 1.967 \\
\cline { 2 - 5 } Central Office & 27 & 10.926 & 5.181 & .997 \\
\cline { 2 - 5 } Other & 6 & 11.333 & 7.062 & 2.883 \\
\cline { 2 - 5 } Other Secretary & 16 & 9.688 & 7.436 & 1.859 \\
\hline Principals & 20 & 9.950 & 5.042 & 1.127 \\
\cline { 2 - 5 } School Secretary & 5 & 5.600 & 3.130 & 1.400 \\
\cline { 2 - 6 } Superintendents & 12 & 11.583 & 8.575 & 2.476 \\
\cline { 2 - 5 } WVEIS County Contact & 21 & 7.619 & 5.408 & 1.180 \\
\cline { 2 - 6 } & \multicolumn{3}{|c}{}
\end{tabular}


Interaction Bar Plot for STAGE0

Effect: Position

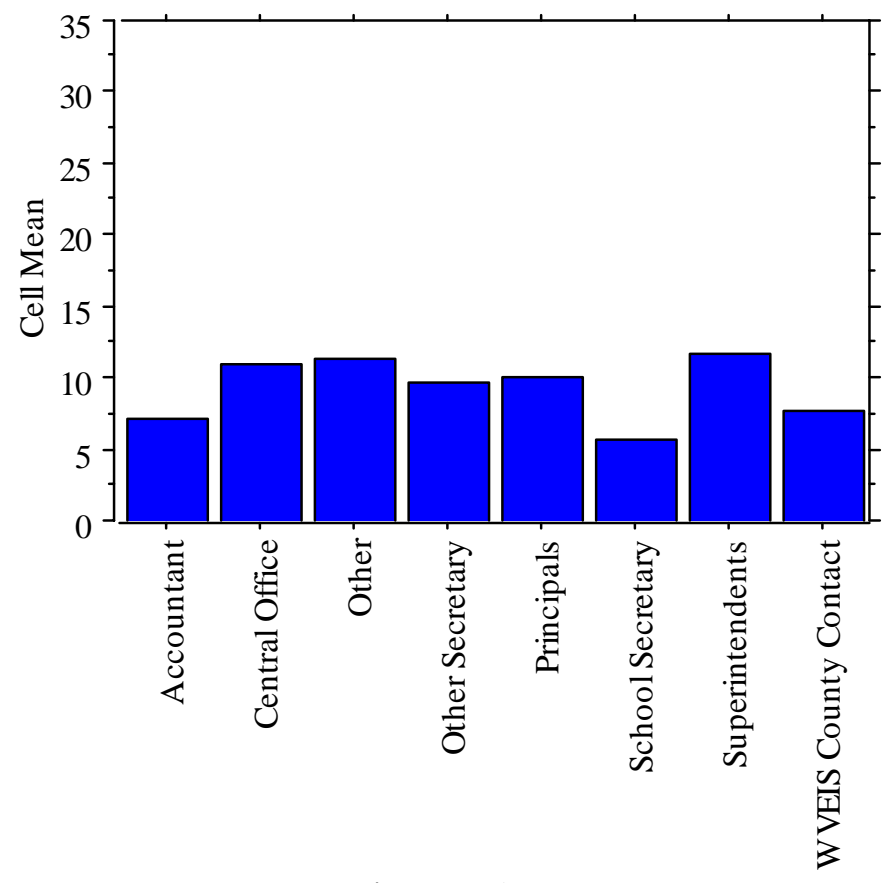

Figure I.1 


\section{Table I.3}

\section{Fisher's PLSD for \\ STAGE0 \\ Effect: Position \\ Significance Level: $5 \%$}

Accountant, Central Office

Accountant, Other

Accountant, Other Secretary

Accountant, Principals

Accountant, School Secretary

Accountant, Superintendents

Accountant, WVEIS County Contact

Central Office, Other

Central Office, Other Secretary

Central Office, Principals

Central Office, School Secretary

Central Office, Superintendents

Central Office, WVEIS County Contact

Other, Other Secretary

Other, Principals

Other, School Secretary

Other, Superintendents

Other, WVEIS County Contact

Other Secretary, Principals

Other Secretary, School Secretary

Other Secretary, Superintendents

Other Secretary, WVEIS County Contact

Principals, School Secretary

Principals, Superintendents

Principals, WVEIS County Contact

School Secretary, Superintendents

School Secretary, WVEIS County Contact

Superintendents, WVEIS County Contact
Mean Diff. Crit. Diff P-Value

\begin{tabular}{|r|r|r|}
\hline-3.744 & 4.337 & .0900 \\
\hline-4.152 & 6.154 & .1840 \\
\hline-2.506 & 4.749 & .2981 \\
\hline-2.768 & 4.552 & .2307 \\
\hline 1.582 & 6.540 & .6327 \\
\hline-4.402 & 5.062 & .0876 \\
\hline-.437 & 4.513 & .8481 \\
\hline-.407 & 5.473 & .8830 \\
\hline 1.238 & 3.826 & .5225 \\
\hline .976 & 3.577 & .5899 \\
\hline 5.326 & 5.904 & .0766 \\
\hline-.657 & 4.207 & .7574 \\
\hline 3.307 & 3.528 & .0659 \\
\hline 1.646 & 5.805 & .5753 \\
\hline 1.383 & 5.644 & .6281 \\
\hline 5.733 & 7.343 & .1246 \\
\hline-.250 & 6.063 & .9350 \\
\hline 3.714 & 5.613 & .1925 \\
\hline-.262 & 4.067 & .8985 \\
\hline 4.088 & 6.213 & .1950 \\
\hline-1.896 & 4.631 & .4189 \\
\hline 2.068 & 4.024 & .3106 \\
\hline 4.350 & 6.063 & .1579 \\
\hline-1.633 & 4.428 & .4663 \\
\hline 2.331 & 3.789 & .2253 \\
\hline-5.983 & 6.454 & .0689 \\
\hline-2.019 & 6.034 & .5086 \\
\hline 3.964 & 4.388 & .0761 \\
\hline & & \\
\hline
\end{tabular}


Stage 1 (Information)

Table I.4

ANOVA Table for STAGE 1

DF Sum of Squares Mean Square F-Value P-Value Lambda Power

\begin{tabular}{l|r|r|r|r|r|r|r|}
\cline { 2 - 8 } $\begin{array}{l}\text { Position } \\
\text { Residual }\end{array}$ & 7 & 747.542 & 106.792 & 2.407 & .0249 & 16.851 & .848 \\
\cline { 2 - 8 } & 110 & 4879.814 & 44.362 & & & & \\
\hline
\end{tabular}

Table I.5

Means Table for STAGE 1

Effect: Position

Accountant

Central Office

Other

Other Secretary

Principals

School Secretary

Superintendents

WVEIS County Contact

\begin{tabular}{|r|r|r|r|}
\multicolumn{1}{r}{ Count } & \multicolumn{1}{c}{ Mean } & Std. Dev. & Std. Err. \\
\hline 11 & 9.091 & 7.648 & 2.306 \\
\hline 27 & 13.222 & 6.369 & 1.226 \\
\hline 6 & 12.000 & 10.060 & 4.107 \\
\hline 16 & 10.250 & 7.514 & 1.879 \\
\hline 20 & 14.350 & 6.507 & 1.455 \\
\hline 5 & 5.400 & 4.037 & 1.806 \\
\hline 12 & 12.250 & 4.454 & 1.286 \\
\hline 21 & 8.190 & 6.322 & 1.379 \\
\hline
\end{tabular}

Interaction Bar Plot for STAGE 1

Effect: Position

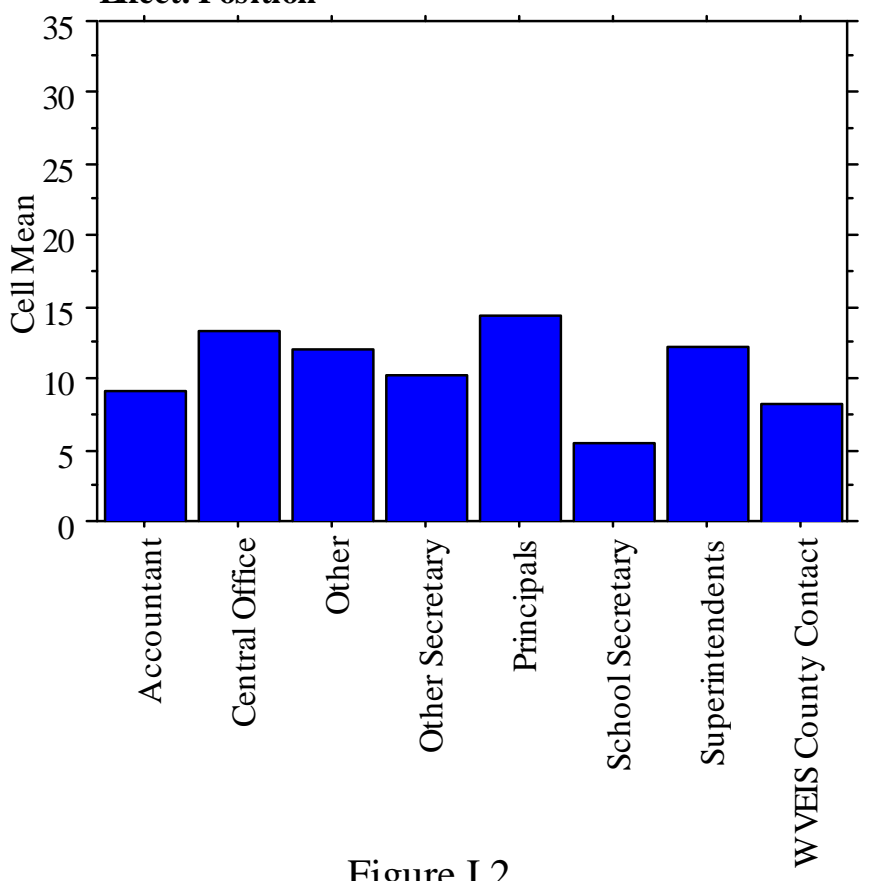

Figure I.2 


\section{Table I.6}

\section{Fisher's PLSD for STAGE 1}

\section{Effect: Position}

Significance Level: $5 \%$

Accountant, Central Office

Accountant, Other

Accountant, Other Secretary

Accountant, Principals

Accountant, School Secretary

Accountant, Superintendents

Accountant, WVEIS County Contact

Central Office, Other

Central Office, Other Secretary

Central Office, Principals

Central Office, School Secretary

Central Office, Superintendents

Central Office, WVEIS County Contact

Other, Other Secretary

Other, Principals

Other, School Secretary

Other, Superintendents

Other, WVEIS County Contact

Other Secretary, Principals

Other Secretary, School Secretary

Other Secretary, Superintendents

Other Secretary, WVEIS County Contact

Principals, School Secretary

Principals, Superintendents

Principals, WVEIS County Contact

School Secretary, Superintendents

School Secretary, WVEIS County Contact Superintendents, WVEIS County Contact
Mean Diff. Crit. Diff P-Value

\begin{tabular}{|c|c|c|}
\hline-4.131 & 4.721 & .0857 \\
\hline-2.909 & 6.699 & .3913 \\
\hline-1.159 & 5.170 & .6577 \\
\hline-5.259 & 4.955 & .0377 \\
\hline 3.691 & 7.119 & .3065 \\
\hline-3.159 & 5.510 & .2583 \\
\hline .900 & 4.913 & .7171 \\
\hline 1.222 & 5.957 & .6851 \\
\hline 2.972 & 4.164 & .1601 \\
\hline-1.128 & 3.894 & .5672 \\
\hline 7.822 & 6.426 & .0175 \\
\hline .972 & 4.579 & .6748 \\
\hline 5.032 & 3.840 & .0107 \\
\hline 1.750 & 6.319 & .5842 \\
\hline-2.350 & 6.144 & .4501 \\
\hline 6.600 & 7.993 & .1046 \\
\hline-.250 & 6.600 & .9403 \\
\hline 3.810 & 6.110 & .2192 \\
\hline-4.100 & 4.427 & .0692 \\
\hline 4.850 & 6.763 & .1581 \\
\hline-2.000 & 5.041 & .4334 \\
\hline 2.060 & 4.380 & .3535 \\
\hline 8.950 & 6.600 & .0083 \\
\hline 2.100 & 4.820 & .3898 \\
\hline 6.160 & 4.124 & .0038 \\
\hline-6.850 & 7.026 & .0559 \\
\hline-2.790 & 6.568 & .4016 \\
\hline 4.060 & 4.777 & .0950 \\
\hline
\end{tabular}


Stage 2 (Personal)

ANOVA Table for STAGE 2

Table I.7

\begin{tabular}{|c|c|c|c|c|c|c|c|}
\hline \multirow{2}{*}{ Position } & DF & Sum of Squares & Mean Square & F-Value & P-Value & Lambda & Power \\
\hline & 7 & 1303.756 & 186.251 & 3.439 & .0023 & 24.070 & .963 \\
\hline & 110 & 5958.075 & 54.164 & & & & \\
\hline
\end{tabular}

Table I.8

Means Table for STAGE 2

Effect: Position

Accountant

Central Office

Other

Other Secretary

Principals

School Secretary

Superintendents

WVEIS County Contact

\begin{tabular}{|r|r|r|r|}
\multicolumn{1}{r|}{ Count } & \multicolumn{1}{c}{ Mean } & Std. Dev. & Std. Err. \\
\hline 11 & 7.727 & 5.934 & 1.789 \\
\hline 27 & 13.519 & 7.738 & 1.489 \\
\hline 6 & 15.500 & 6.775 & 2.766 \\
\hline 16 & 9.125 & 8.156 & 2.039 \\
\hline 20 & 17.050 & 8.538 & 1.909 \\
\hline 5 & 4.000 & 3.391 & 1.517 \\
\hline 12 & 11.333 & 4.519 & 1.305 \\
\hline 21 & 11.714 & 7.636 & 1.666 \\
\hline
\end{tabular}

Interaction Bar Plot for STAGE 1

Effect: Position

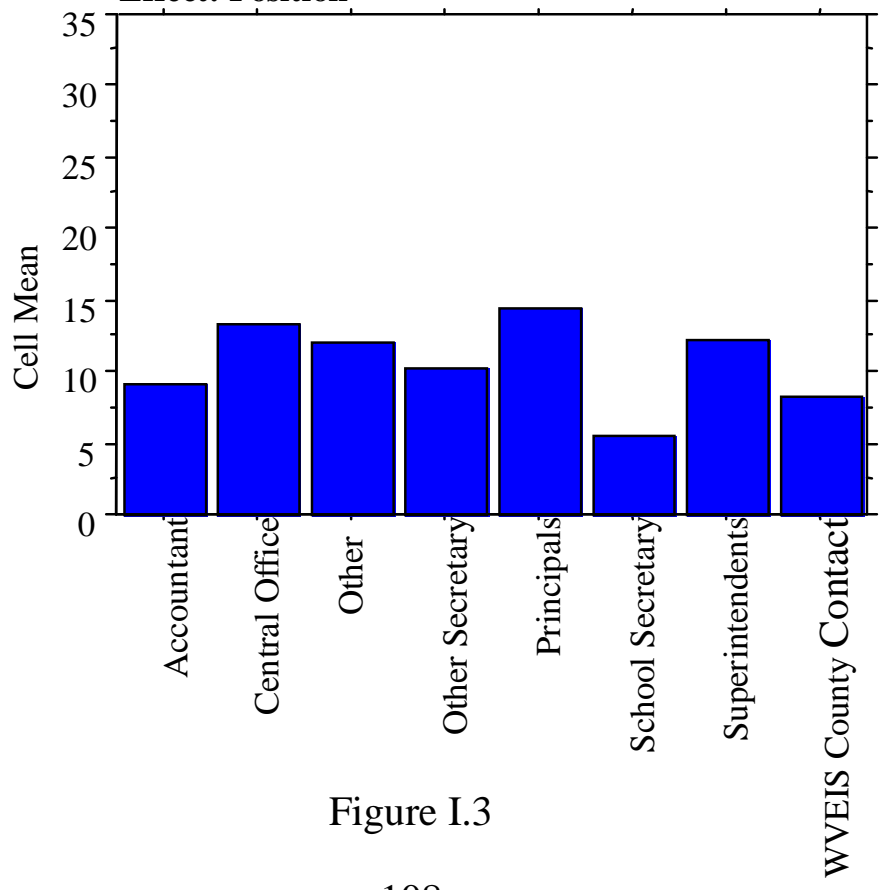

108 


\section{Table I.9}

\section{Fisher's PLSD for STAGE 2}

\section{Effect: Position}

Significance Level: $5 \%$

Accountant, Central Office

Accountant, Other

Accountant, Other Secretary

Accountant, Principals

Accountant, School Secretary

Accountant, Superintendents

Accountant, WVEIS County Contact

Central Office, Other

Central Office, Other Secretary

Central Office, Principals

Central Office, School Secretary

Central Office, Superintendents

Central Office, WVEIS County Contact

Other, Other Secretary

Other, Principals

Other, School Secretary

Other, Superintendents

Other, WVEIS County Contact

Other Secretary, Principals

Other Secretary, School Secretary

Other Secretary, Superintendents

Other Secretary, WVEIS County Contact

Principals, School Secretary

Principals, Superintendents

Principals, WVEIS County Contact

School Secretary, Superintendents

School Secretary, WVEIS County Contact

Superintendents, WVEIS County Contact

\begin{tabular}{|c|c|c|}
\hline Mean Diff. & Crit. Diff & P-Value \\
\hline-5.791 & 5.217 & .0299 \\
\hline-7.773 & 7.402 & .0398 \\
\hline-1.398 & 5.713 & .6287 \\
\hline-9.323 & 5.475 & .0010 \\
\hline 3.727 & 7.867 & .3498 \\
\hline-3.606 & 6.088 & .2430 \\
\hline-3.987 & 5.428 & .1484 \\
\hline-1.981 & 6.583 & .5520 \\
\hline 4.394 & 4.602 & .0611 \\
\hline-3.531 & 4.303 & .1067 \\
\hline 9.519 & 7.101 & .0091 \\
\hline 2.185 & 5.060 & .3940 \\
\hline 1.804 & 4.244 & .4013 \\
\hline 6.375 & 6.982 & .0731 \\
\hline-1.550 & 6.789 & .6518 \\
\hline 11.500 & 8.832 & .0112 \\
\hline 4.167 & 7.293 & .2600 \\
\hline 3.786 & 6.752 & .2689 \\
\hline-7.925 & 4.892 & .0017 \\
\hline 5.125 & 7.473 & .1769 \\
\hline-2.208 & 5.570 & .4337 \\
\hline-2.589 & 4.840 & .2914 \\
\hline 13.050 & 7.293 & .0006 \\
\hline 5.717 & 5.326 & .0356 \\
\hline 5.336 & 4.557 & .0222 \\
\hline-7.333 & 7.764 & .0639 \\
\hline-7.714 & 7.258 & .0374 \\
\hline-.381 & 5.278 & .8865 \\
\hline
\end{tabular}


Stage 3 (Management)

ANOVA Table for STAGE3

Table I.10

\begin{tabular}{|c|c|c|c|c|c|c|c|}
\hline & $\mathrm{DF}$ & Sum of Squares & Mean Square & F-Value & P-Value & Lambda & Power \\
\hline Position & 7 & 1109.723 & 158.532 & 4.195 & .0004 & 29.368 & .989 \\
\hline Residual & 110 & 4156.591 & 37.787 & & & & \\
\hline
\end{tabular}

Table I.11

\section{Means Table for STAGE 3}

Effect: Position

Accountant

Central Office

Other

Other Secretary

Principals

School Secretary

Superintendents

WVEIS County Contact

\begin{tabular}{|r|r|r|r|}
\multicolumn{1}{r}{ Count } & \multicolumn{1}{c}{ Mean } & Std. Dev. & Std. Err. \\
\hline 11 & 6.182 & 5.307 & 1.600 \\
\hline 27 & 11.926 & 5.342 & 1.028 \\
\hline 6 & 8.000 & 8.173 & 3.337 \\
\hline 16 & 7.625 & 5.227 & 1.307 \\
\hline 20 & 16.050 & 7.423 & 1.660 \\
\hline 5 & 7.400 & 2.510 & 1.122 \\
\hline 12 & 11.917 & 6.345 & 1.832 \\
\hline 21 & 11.714 & 6.612 & 1.443 \\
\hline
\end{tabular}

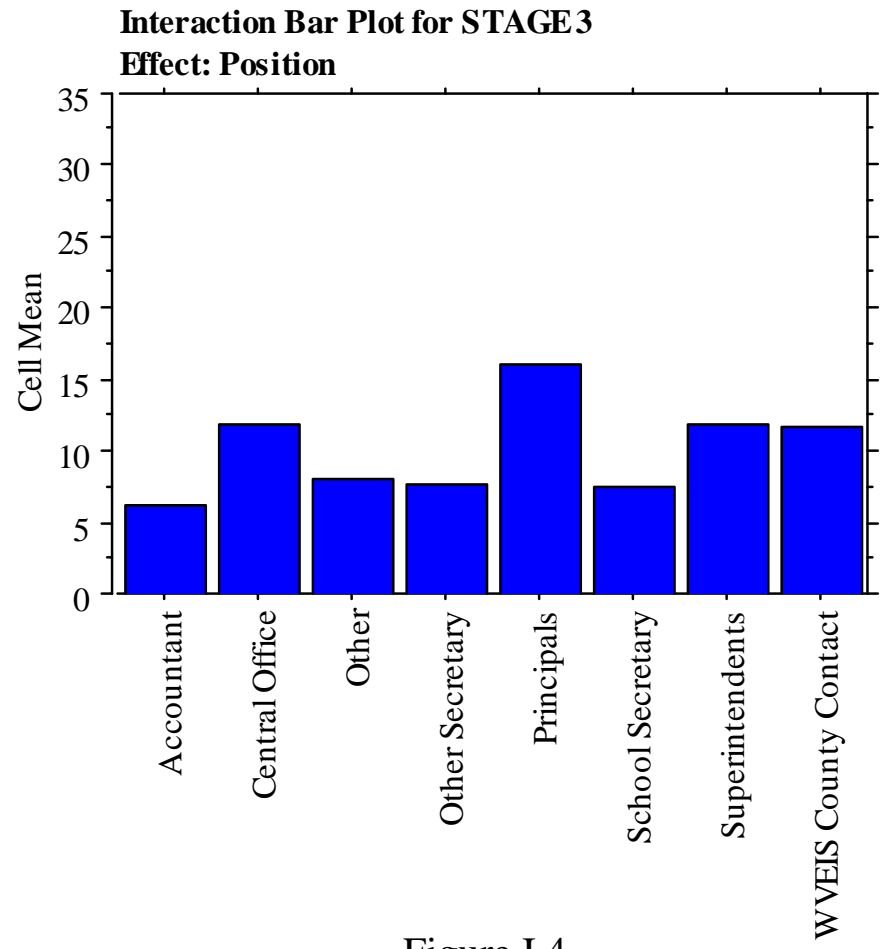

Figure I.4 
Table I.12

Fisher's PLSD for STAGE3

Effect: Position

Significance Level: $5 \%$

Accountant, Central Office

Accountant, Other

Accountant, Other Secretary

Accountant, Principals

Accountant, School Secretary

Accountant, Superintendents

Accountant, WVEIS County Contact

Central Office, Other

Central Office, Other Secretary

Central Office, Principals

Central Office, School Secretary

Central Office, Superintendents

Central Office, WVEIS County Contact

Other, Other Secretary

Other, Principals

Other, School Secretary

Other, Superintendents

Other, WVEIS County Contact

Other Secretary, Principals

Other Secretary, School Secretary

Other Secretary, Superintendents

Other Secretary, WVEIS County Contact

Principals, School Secretary

Principals, Superintendents

Principals, WVEIS County Contact

School Secretary, Superintendents

School Secretary, WVEIS County Contact

Superintendents, WVEIS County Contact

\begin{tabular}{|r|r|r|}
\multicolumn{1}{r|}{ Mean Diff. } & \multicolumn{1}{r}{ Crit. Diff } & \multicolumn{1}{r}{ P-Value } \\
\hline-5.744 & 4.358 & .0102 \\
\hline-1.818 & 6.183 & .5612 \\
\hline-1.443 & 4.771 & .5501 \\
\hline-9.868 & 4.573 & $<.0001$ \\
\hline-1.218 & 6.571 & .7140 \\
\hline-5.735 & 5.085 & .0274 \\
\hline-5.532 & 4.534 & .0172 \\
\hline 3.926 & 5.498 & .1599 \\
\hline 4.301 & 3.843 & .0286 \\
\hline-4.124 & 3.594 & .0249 \\
\hline 4.526 & 5.931 & .1333 \\
\hline .009 & 4.227 & .9965 \\
\hline .212 & 3.544 & .9060 \\
\hline .375 & 5.832 & .8988 \\
\hline-8.050 & 5.670 & .0058 \\
\hline .600 & 7.377 & .8722 \\
\hline-3.917 & 6.091 & .2052 \\
\hline-3.714 & 5.639 & .1945 \\
\hline-8.425 & 4.086 & $<.0001$ \\
\hline .225 & 6.242 & .9432 \\
\hline-4.292 & 4.652 & .0702 \\
\hline-4.089 & 4.043 & .0475 \\
\hline 8.650 & 6.091 & .0058 \\
\hline 4.133 & 4.448 & .0683 \\
\hline 4.336 & 3.806 & .0260 \\
\hline-4.517 & 6.484 & .1703 \\
\hline-4.314 & 6.062 & .1612 \\
\hline .202 & 4.408 & .9277 \\
\hline & & \\
\hline & \\
\hline &
\end{tabular}


Stage 4 (Consequences)

Table I.13

ANOVA Table for STAGE4

\begin{tabular}{|c|c|c|c|c|c|c|c|}
\hline & $\mathrm{DF}$ & Sum of Squares & Mean Square & F-Value & P-Value & Lambda & Power \\
\hline & 7 & 549.415 & 78.488 & 1.622 & .1367 & 11.352 & .644 \\
\hline & 110 & 5323.983 & 48.400 & & & & \\
\hline
\end{tabular}

Table I.14

Means Table for STAGE 4

Effect: Position

Accountant

Central Office

Other

Other Secretary

Principals

School Secretary

Superintendents

WVEIS County Contact

\begin{tabular}{|r|r|r|r|}
\multicolumn{1}{r|}{ Count } & \multicolumn{1}{c}{ Mean } & Std. Dev. & Std. Err. \\
\hline 11 & 3.818 & 10.147 & 3.059 \\
\hline 27 & 7.556 & 6.405 & 1.233 \\
\hline 6 & 7.833 & 7.653 & 3.124 \\
\hline 16 & 2.188 & 2.287 & .572 \\
\hline 20 & 8.600 & 7.577 & 1.694 \\
\hline 5 & 7.200 & 7.259 & 3.247 \\
\hline 12 & 7.500 & 4.523 & 1.306 \\
\hline 21 & 7.762 & 8.154 & 1.779 \\
\hline
\end{tabular}

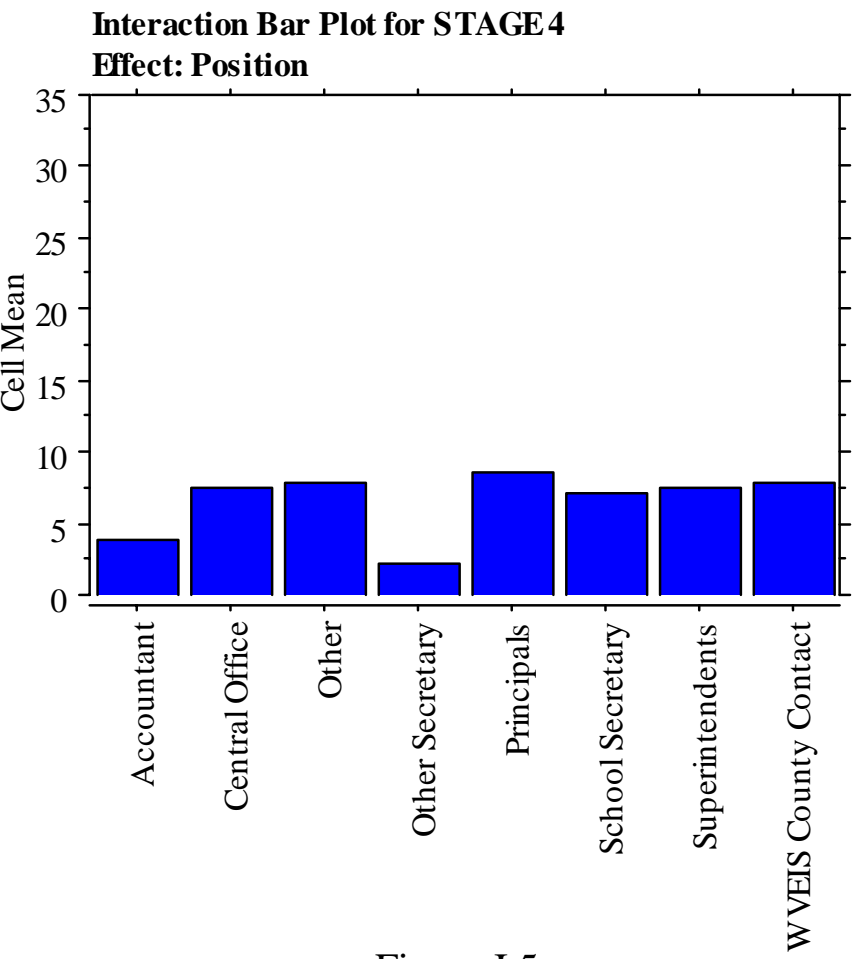

Figure I.5 


\section{Table I.15}

Fisher's PLSD for STAGE4

Effect: Position

Significance Level: $5 \%$

Accountant, Central Office

Accountant, Other

Accountant, Other Secretary

Accountant, Principals

Accountant, School Secretary

Accountant, Superintendents

Accountant, WVEIS County Contact

Central Office, Other

Central Office, Other Secretary

Central Office, Principals

Central Office, School Secretary

Central Office, Superintendents

Central Office, WVEIS County Contact

Other, Other Secretary

Other, Principals

Other, School Secretary

Other, Superintendents

Other, WVEIS County Contact

Other Secretary, Principals

Other Secretary, School Secretary

Other Secretary, Superintendents

Other Secretary, W VEIS County Contact

Principals, School Secretary

Principals, Superintendents

Principals, WVEIS County Contact

School Secretary, Superintendents

School Secretary, WVEIS County Contact

Superintendents, WVEIS County Contact

\begin{tabular}{|r|r|r|}
\hline \multicolumn{1}{r|}{ Mean Diff. } & \multicolumn{1}{r}{ Crit. Diff } & \multicolumn{1}{l}{ P-Value } \\
\hline-3.737 & 4.932 & .1360 \\
\hline-4.015 & 6.997 & .2579 \\
\hline 1.631 & 5.400 & .5508 \\
\hline-4.782 & 5.175 & .0698 \\
\hline-3.382 & 7.436 & .3694 \\
\hline-3.682 & 5.755 & .2075 \\
\hline-3.944 & 5.131 & .1306 \\
\hline-.278 & 6.223 & .9297 \\
\hline 5.368 & 4.350 & .0160 \\
\hline-1.044 & 4.067 & .6119 \\
\hline .356 & 6.712 & .9166 \\
\hline .056 & 4.783 & .9817 \\
\hline-.206 & 4.011 & .9190 \\
\hline 5.646 & 6.600 & .0929 \\
\hline-.767 & 6.418 & .8133 \\
\hline .633 & 8.349 & .8808 \\
\hline .333 & 6.894 & .9238 \\
\hline .071 & 6.382 & .9823 \\
\hline-6.412 & 4.624 & .0070 \\
\hline-5.013 & 7.064 & .1625 \\
\hline-5.313 & 5.265 & .0480 \\
\hline-5.574 & 4.575 & .0174 \\
\hline 1.400 & 6.894 & .6881 \\
\hline 1.100 & 5.034 & .6659 \\
\hline .838 & 4.308 & .7006 \\
\hline-.300 & 7.339 & .9356 \\
\hline-.562 & 6.861 & .8714 \\
\hline-.262 & 4.989 & .9173 \\
\hline & & \\
\hline
\end{tabular}

\section{Stage 5 (Collaboration)}

Table I.16

ANOVA Table for STAGE 5

\begin{tabular}{|c|c|c|c|c|c|c|c|}
\hline & $\mathrm{DF}$ & Sum of Squares & Mean Square & F-Value & P-Value & Lambda & Power \\
\hline Position & 7 & 2598.490 & 371.213 & 6.521 & $<.0001$ & 45.650 & 1.000 \\
\hline Residual & 110 & 6261.476 & 56.923 & & & & \\
\hline
\end{tabular}




\section{Table I.17}

Means Table for STAGE 5

Effect: Position

Accountant

Central Office

Other

Other Secretary

Principals

School Secretary

Superintendents

WVEIS County Contact

\begin{tabular}{|r|r|r|r|} 
Count & \multicolumn{1}{c}{ Mean } & Std. Dev. & Std. Err. \\
\hline 11 & 12.000 & 10.412 & 3.139 \\
\hline 27 & 16.556 & 6.980 & 1.343 \\
\hline 6 & 19.000 & 6.986 & 2.852 \\
\hline 16 & 8.000 & 5.379 & 1.345 \\
\hline 20 & 21.800 & 7.885 & 1.763 \\
\hline 5 & 7.200 & 3.701 & 1.655 \\
\hline 12 & 15.167 & 7.732 & 2.232 \\
\hline 21 & 19.571 & 8.183 & 1.786 \\
\hline
\end{tabular}

Interaction Bar Plot for STAGE 5

Effect: Position

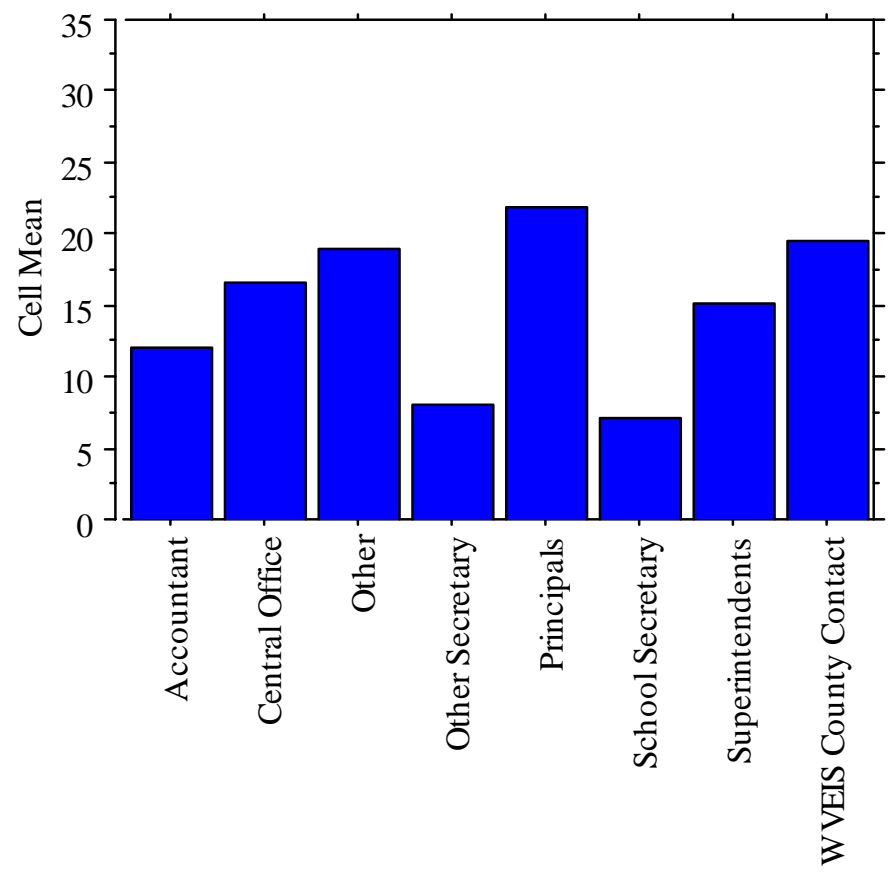

Figure I.6 


\section{Table I.18}

Fisher's PLSD for STAGE 5

\section{Effect: Position}

Significance Level: $5 \%$

Accountant, Central Office

Accountant, Other

Accountant, Other Secretary

Accountant, Principals

Accountant, School Secretary

Accountant, Superintendents

Accountant, WVEIS County Contact

Central Office, Other

Central Office, Other Secretary

Central Office, Principals

Central Office, School Secretary

Central Office, Superintendents

Central Office, WVEIS County Contact

Other, Other Secretary

Other, Principals

Other, School Secretary

Other, Superintendents

Other, WVEIS County Contact

Other Secretary, Principals

Other Secretary, School Secretary

Other Secretary, Superintendents

Other Secretary, WVEIS County Con...

Principals, School Secretary

Principals, Superintendents

Principals, WVEIS County Contact

School Secretary, Superintendents

School Secretary, WVEIS County Co...

Superintendents, WVEIS County Co...

Mean Diff. Crit. Diff P-Value

\begin{tabular}{|r|r|r|}
\hline-4.556 & 5.348 & .0942 \\
\hline-7.000 & 7.588 & .0702 \\
\hline 4.000 & 5.856 & .1786 \\
\hline-9.800 & 5.613 & .0008 \\
\hline 4.800 & 8.064 & .2407 \\
\hline-3.167 & 6.241 & .3169 \\
\hline-7.571 & 5.565 & .0081 \\
\hline-2.444 & 6.748 & .4744 \\
\hline 8.556 & 4.717 & .0005 \\
\hline-5.244 & 4.411 & .0202 \\
\hline 9.356 & 7.280 & .0122 \\
\hline 1.389 & 5.187 & .5968 \\
\hline-3.016 & 4.350 & .1723 \\
\hline 11.000 & 7.158 & .0029 \\
\hline-2.800 & 6.960 & .4270 \\
\hline 11.800 & 9.054 & .0111 \\
\hline 3.833 & 7.476 & .3118 \\
\hline-.571 & 6.921 & .8703 \\
\hline-13.800 & 5.015 & $<.0001$ \\
\hline .800 & 7.661 & .8364 \\
\hline-7.167 & 5.710 & .0144 \\
\hline-11.571 & 4.962 & $<.0001$ \\
\hline 14.600 & 7.476 & .0002 \\
\hline 6.633 & 5.460 & .0177 \\
\hline 2.229 & 4.672 & .3465 \\
\hline-7.967 & 7.959 & .0498 \\
\hline-12.371 & 7.440 & .0013 \\
\hline-4.405 & 5.411 & .1095 \\
\hline & & \\
\hline & $S$ \\
\hline$S$
\end{tabular}




\section{Stage 6 (Refocusing)}

Table I.19

\section{ANOVA Table for STAGE6}

\begin{tabular}{|c|c|c|c|c|c|c|c|}
\hline & $\mathrm{DF}$ & Sum of Squares & Mean Square & F-Value & P-Value & Lambda & Power \\
\hline Position & 7 & 1082.210 & 154.601 & 3.823 & .0009 & 26.758 & .980 \\
\hline Residual & 110 & 4448.874 & 40.444 & & & & \\
\hline
\end{tabular}

Table I.20

Means Table for STAGE 6

\section{Effect: Position}

Accountant

Central Office

Other

Other Secretary

Principals

School Secretary

Superintendents

WVEIS County Contact

\begin{tabular}{|r|r|r|r|} 
Count & \multicolumn{1}{c}{ Mean } & Std. Dev. & Std. Err. \\
\hline 11 & 7.455 & 7.891 & 2.379 \\
\hline 27 & 11.222 & 5.515 & 1.061 \\
\hline 6 & 10.833 & 4.916 & 2.007 \\
\hline 16 & 5.188 & 4.004 & 1.001 \\
\hline 20 & 14.050 & 6.403 & 1.432 \\
\hline 5 & 5.600 & 2.302 & 1.030 \\
\hline 12 & 10.750 & 6.107 & 1.763 \\
\hline 21 & 13.095 & 8.555 & 1.867 \\
\hline
\end{tabular}

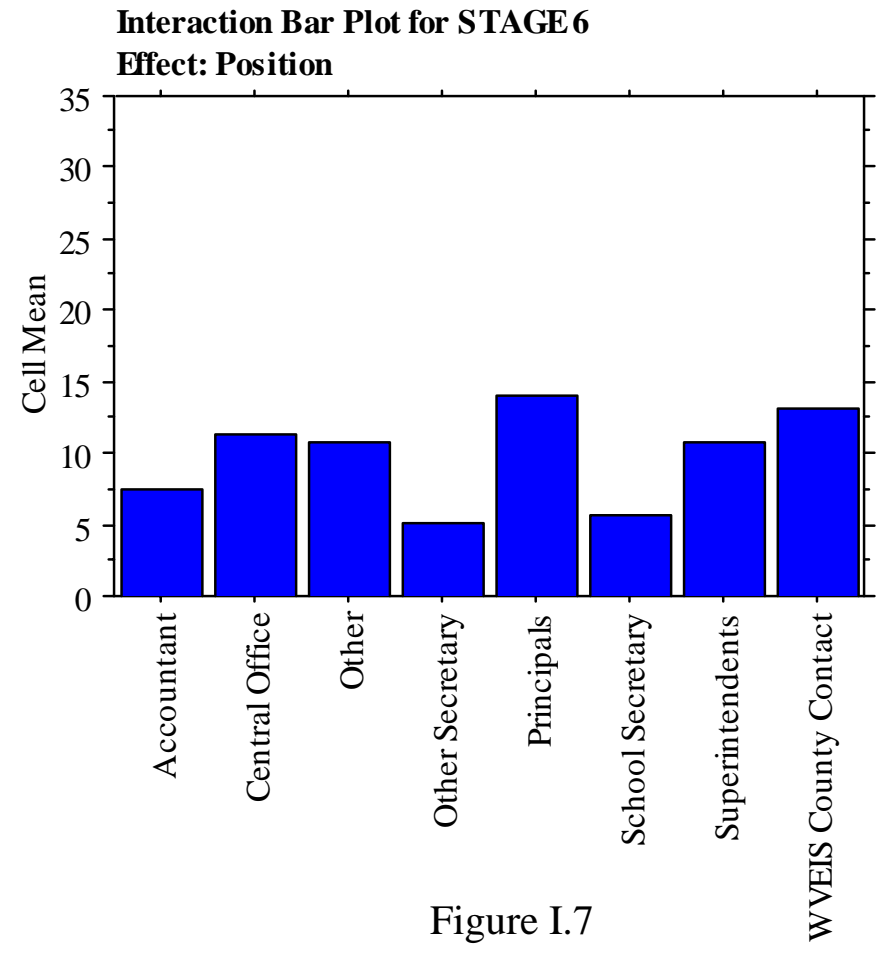




\section{Table I.21}

\section{Fisher's PLSD for STAGE 6}

\section{Effect: Position}

Significance Level: $5 \%$

Accountant, Central Office

Accountant, Other

Accountant, Other Secretary

Accountant, Principals

Accountant, School Secretary

Accountant, Superintendents

Accountant, W VEIS County Contact

Central Office, Other

Central Office, Other Secretary

Central Office, Principals

Central Office, School Secretary

Central Office, Superintendents

Central Office, WVEIS County Contact

Other, Other Secretary

Other, Principals

Other, School Secretary

Other, Superintendents

Other, WVEIS County Contact

Other Secretary, Principals

Other Secretary, School Secretary

Other Secretary, Superintendents

Other Secretary, WVEIS County Con...

Principals, School Secretary

Principals, Superintendents

Principals, WVEIS County Contact

School Secretary, Superintendents

School Secretary, WVEIS County Co...

Superintendents, WVEIS County Co...

\begin{tabular}{|c|c|c|}
\hline Mean Diff. & Crit. Diff & P-Value \\
\hline-3.768 & 4.508 & .1005 \\
\hline-3.379 & 6.396 & .2975 \\
\hline 2.267 & 4.936 & .3647 \\
\hline-6.595 & 4.731 & .0067 \\
\hline 1.855 & 6.798 & .5898 \\
\hline-3.295 & 5.261 & .2171 \\
\hline-5.641 & 4.691 & .0189 \\
\hline .389 & 5.688 & .8925 \\
\hline 6.035 & 3.976 & .0033 \\
\hline-2.828 & 3.718 & .1346 \\
\hline 5.622 & 6.136 & .0721 \\
\hline .472 & 4.373 & .8309 \\
\hline-1.873 & 3.667 & .3136 \\
\hline 5.646 & 6.033 & .0663 \\
\hline-3.217 & 5.866 & .2796 \\
\hline 5.233 & 7.632 & .1769 \\
\hline .083 & 6.302 & .9791 \\
\hline-2.262 & 5.834 & .4439 \\
\hline-8.863 & 4.227 & $<.0001$ \\
\hline-.412 & 6.457 & .8995 \\
\hline-5.563 & 4.813 & .0239 \\
\hline-7.908 & 4.182 & .0003 \\
\hline 8.450 & 6.302 & .0090 \\
\hline 3.300 & 4.602 & .1581 \\
\hline .955 & 3.938 & .6318 \\
\hline-5.150 & 6.709 & .1310 \\
\hline-7.495 & 6.272 & .0196 \\
\hline-2.345 & 4.561 & .3104 \\
\hline
\end{tabular}




\section{Subquestion 2}

Stage 0 (Awareness)
Table I.22
N=113
ANOVA Table for STAGE 0
\begin{tabular}{rr|r|r|r|r|r|r|} 
DF Sum of Squares & Mean Square & F-Value & P-Value Lambda & Power \\
ENROLLMENT & 4 & 92.504 & 23.126 & .590 & .6704 & 2.361 & .187 \\
Residual & 108 & 4231.249 & 39.178 & & & & \\
\cline { 2 - 8 }
\end{tabular}

Table I.23

\section{Means Table for STAGE 0}

\section{Effect: ENROLLMENT}

\begin{tabular}{l|r|r|r|r|}
\multicolumn{1}{c}{} & \multicolumn{1}{c}{ Count } & \multicolumn{1}{c}{ Mean } & \multicolumn{1}{c}{ Std. Dev. } & \multicolumn{1}{c}{ Std. Err. } \\
\cline { 2 - 5 } $0-2,000$ & 20 & 9.200 & 6.066 & 1.356 \\
\cline { 2 - 5 } $2,001-4,000$ & 15 & 8.200 & 4.411 & 1.139 \\
\cline { 2 - 5 } $4,001-6,000$ & 35 & 9.257 & 6.870 & 1.161 \\
\cline { 2 - 5 } $6,001-10,000$ & 16 & 9.500 & 5.978 & 1.494 \\
\cline { 2 - 5 } over 10,000 & 27 & 11.037 & 6.560 & 1.263 \\
\cline { 2 - 5 } & & & &
\end{tabular}

Interaction Bar Plot for STAGE0

Effect: ENROLLMENT

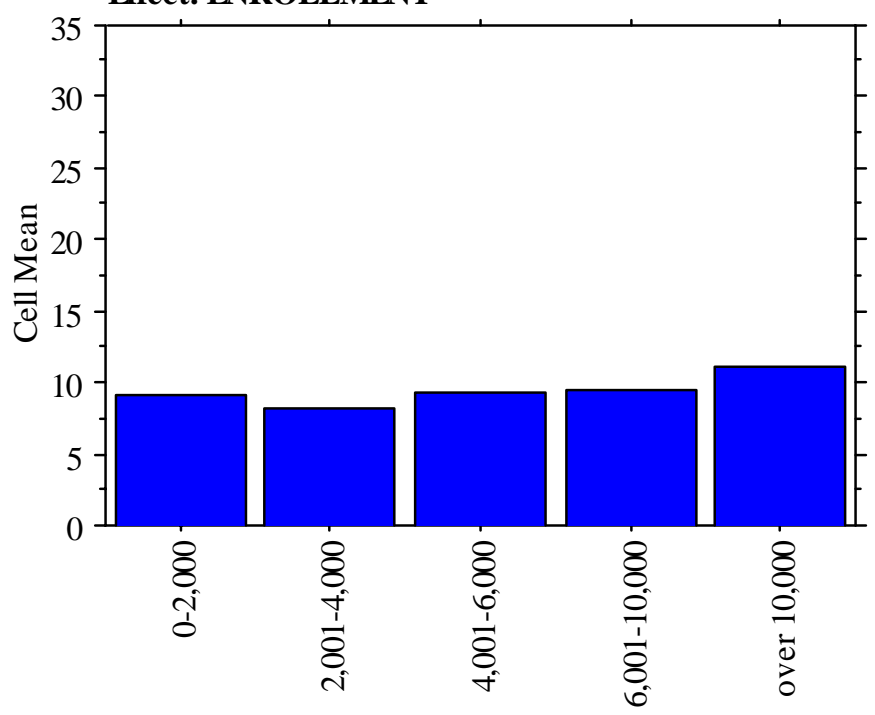

Figure I.9 
Table I.24

Fisher's PLSD for STAGE0

Effect: ENROLLMENT

Significance Level: $5 \%$

0-2,000, 2,001-4,000

0-2,000, 4,001-6,000

0-2,000, 6,001-10,000

0-2,000, over 10,000

2,001-4,000, 4,001-6,000

2,001-4,000, 6,001-10,000

$2,001-4,000$, over 10,000

4,001-6,000, 6,001-10,000

$4,001-6,000$, over 10,000

$6,001-10,000$, over 10,000

\begin{tabular}{|r|r|r|}
\multicolumn{1}{r|}{ Mean Diff. } & \multicolumn{1}{r|}{ Crit. Diff } & \multicolumn{1}{l}{ P-Value } \\
\hline 1.000 & 4.238 & .6409 \\
\hline-.057 & 3.478 & .9741 \\
\hline-.300 & 4.161 & .8866 \\
\hline-1.837 & 3.660 & .3220 \\
\hline-1.057 & 3.829 & .5853 \\
\hline-1.300 & 4.459 & .5645 \\
\hline-2.837 & 3.995 & .1622 \\
\hline-.243 & 3.744 & .8979 \\
\hline-1.780 & 3.178 & .2694 \\
\hline-1.537 & 3.914 & .4381 \\
\hline
\end{tabular}

\section{Stage 1 (Information)}

Table I.25

ANOVA Table for STAGE 1

\begin{tabular}{l|r|r|r|r|r|r|r|}
\multicolumn{1}{c}{} & \multicolumn{1}{c}{ DF } & Sum of Squares & \multicolumn{1}{c}{ Mean Square } & \multicolumn{1}{c}{ F-Value } & \multicolumn{1}{c}{ P-Value } & Lambda & Power \\
ENROLLMENT & 4 & 168.572 & 42.143 & .870 & .4846 & 3.480 & .263 \\
\cline { 2 - 9 } Residual & 108 & 5231.976 & 48.444 & & & & \\
\hline
\end{tabular}

Table I.26

Means Table for STAGE 1

Effect: ENROLLMENT

\begin{tabular}{l|r|r|r|r|}
\multicolumn{1}{c}{} & \multicolumn{1}{c}{ Count } & \multicolumn{1}{c}{ Mean } & \multicolumn{1}{c}{ Std. Dev. } & \multicolumn{1}{c}{ Std. Err. } \\
\cline { 2 - 5 } $0-2,000$ & 20 & 10.200 & 7.038 & 1.574 \\
\cline { 2 - 5 } $2,001-4,000$ & 15 & 9.467 & 6.947 & 1.794 \\
\cline { 2 - 5 } $4,001-6,000$ & 35 & 11.057 & 6.825 & 1.154 \\
\cline { 2 - 5 } $6,001-10,000$ & 16 & 11.375 & 7.108 & 1.777 \\
\cline { 2 - 5 } over 10,000 & 27 & 13.148 & 6.998 & 1.347 \\
\cline { 2 - 5 } & & &
\end{tabular}




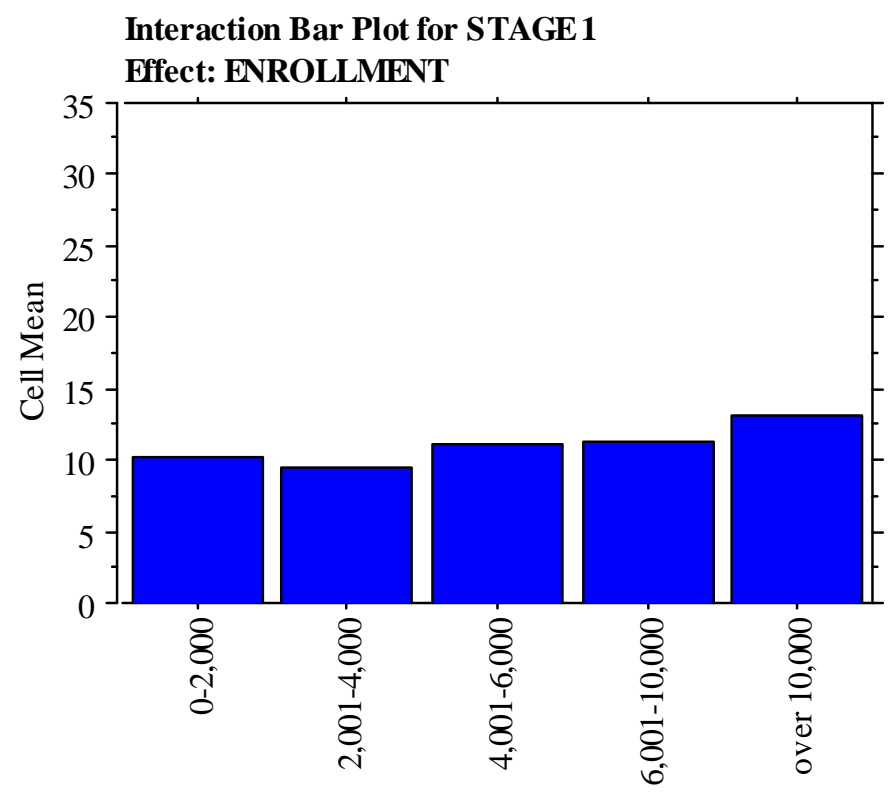

Figure I.10

Table I.27

Fisher's PLSD for STAGE 1

Effect: ENR OLLMENT

Significance Level: $5 \%$

0-2,000, 2,001-4,000
0-2,000, 4,001-6,000
0-2,000, 6,001-10,000
0-2,000, o ver 10,000
$2,001-4,000,4,001-6,000$
$2,001-4,000,6,001-10,000$
$2,001-4,000,0$ ver 10,000
$4,001-6,000,6,001-10,000$
$4,001-6,000,0$ ver 10,000
$6,001-10,000,0$ ver 10,000

\begin{tabular}{|r|r|r|}
\multicolumn{1}{r|}{ Mean Diff. } & Crit. Diff & \multicolumn{1}{c}{ P-Value } \\
\hline .733 & 4.712 & .7583 \\
\hline-.857 & 3.867 & .6613 \\
\hline-1.175 & 4.627 & .6158 \\
\hline-2.948 & 4.070 & .1540 \\
\hline-1.590 & 4.258 & .4606 \\
\hline-1.908 & 4.958 & .4472 \\
\hline-3.681 & 4.443 & .1034 \\
\hline-.318 & 4.163 & .8800 \\
\hline-2.091 & 3.534 & .2434 \\
\hline-1.773 & 4.353 & .4212 \\
\hline
\end{tabular}


Stage 2 (Personal)

ANOVA Table for STAGE2

Table I.28

\begin{tabular}{l|r|r|r|r|r|r|r|}
\multicolumn{1}{c}{ DF } & \multicolumn{1}{c}{ Sum of Squares } & Mean Square & \multicolumn{1}{c}{ F-Value } & \multicolumn{1}{c}{ P-Value } & Lambda & Power \\
ENROLLMENT & 4 & 96.008 & 24.002 & .369 & .8305 & 1.475 & .130 \\
\cline { 2 - 8 } \\
Residual & 108 & 7031.727 & 65.109 & & & & \\
\hline
\end{tabular}

Table I.29

Means Table for STAGE 2

Effect: ENROLLMENT

\begin{tabular}{l|r|r|r|r|}
\multicolumn{1}{c}{} & \multicolumn{1}{c}{ Count } & \multicolumn{1}{c}{ Mean } & \multicolumn{1}{c}{ Std. Dev. } & \multicolumn{1}{c}{ Std. Err. } \\
\cline { 2 - 5 } $0-2,000$ & 20 & 10.850 & 9.527 & 2.130 \\
\cline { 2 - 5 } $2,001-4,000$ & 15 & 12.867 & 9.156 & 2.364 \\
\cline { 2 - 5 } $4,001-6,000$ & 35 & 11.886 & 7.383 & 1.248 \\
\cline { 2 - 5 } 6,001-10,000 & 16 & 13.938 & 7.733 & 1.933 \\
\cline { 2 - 5 } over 10,000 & 27 & 11.963 & 7.293 & 1.404 \\
\cline { 2 - 5 } & & & &
\end{tabular}

Interaction Bar Plot for STAGE2

Effect: ENROLLMENT

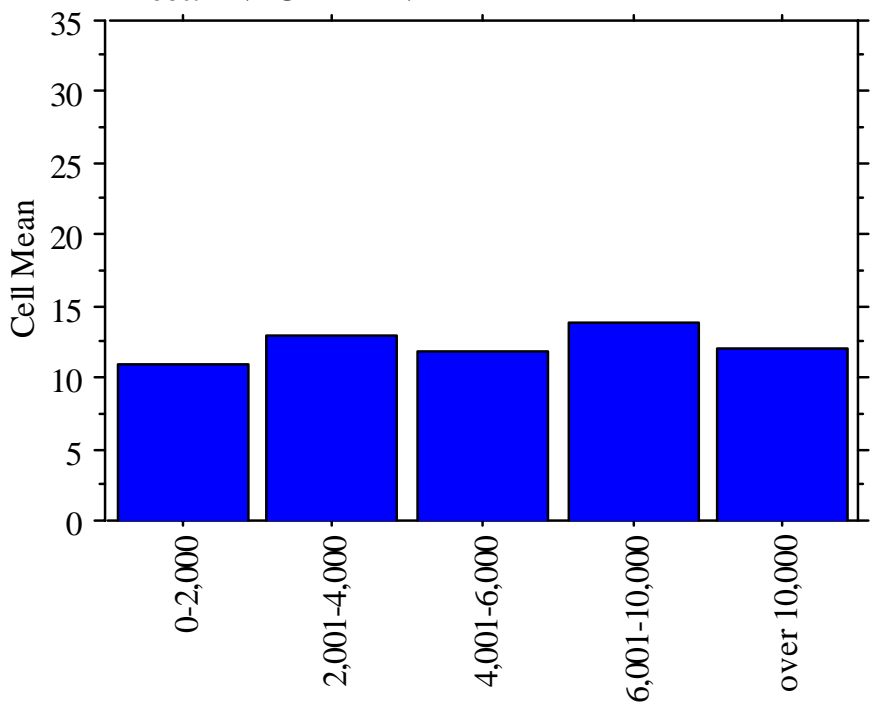

Figure I.11 


\section{Table I.30}

\begin{tabular}{|c|c|c|c|}
\hline \multicolumn{4}{|l|}{$\begin{array}{l}\text { Fisher's PLSD for STAG } \\
\text { Effect: ENROLLMENT } \\
\text { Significance Level: } 5 \%\end{array}$} \\
\hline $0-2,000,2,001-4,000$ & -2.017 & 5.463 & .4659 \\
\hline $0-2,000,4,001-6,000$ & -1.036 & 4.483 & 6479 \\
\hline $0-2,000,6,001-10,000$ & -3.088 & 5.365 & .2565 \\
\hline $0-2,000$, over 10,000 & -1.113 & 4.719 & .6411 \\
\hline $2,001-4,000,4,001-6,000$ & .981 & 4.936 & .6944 \\
\hline $2,001-4,000,6,001-10,000$ & -1.071 & 5.748 & .7127 \\
\hline $2,001-4,000$, over 10,000 & .904 & 5.151 & .7287 \\
\hline $4,001-6,000,6,001-10,000$ & -2.052 & 4.827 & .4013 \\
\hline $4,001-6,000$, over 10,000 & -.077 & 4.097 & .9703 \\
\hline $6,001-10,000$, over 10,000 & 1.975 & 5.046 & .4397 \\
\hline
\end{tabular}

\section{Stage 3 (Management)}

TableI.31

ANOVA Table for STAGE 3

\begin{tabular}{|c|c|c|c|c|c|c|c|}
\hline & DF & Sum of Squares & Mean Square & F-Value & P-Value & Lambda & Power \\
\hline \multirow{2}{*}{$\begin{array}{l}\text { ENROLLMENT } \\
\text { Residual }\end{array}$} & 4 & 317.501 & 79.375 & 1.805 & .1331 & 7.220 & .526 \\
\hline & 108 & 4749.047 & 43.973 & & & & \\
\hline
\end{tabular}

Table I.32

Means Table for STAGE 3
Effect: ENROLLMENT
\begin{tabular}{rr|r|r|r|} 
Count & \multicolumn{1}{c}{ Mean } & Std. Dev. & Std. Err. \\
\multirow{2}{*}{$0-2,000$} & 20 & 13.050 & 8.198 & 1.833 \\
\hline $2,001-4,000$ & 15 & 11.800 & 7.739 & 1.998 \\
\cline { 2 - 5 } $4,001-6,000$ & 35 & 9.543 & 5.305 & .897 \\
\cline { 2 - 5 } $6,001-10,000$ & 16 & 13.938 & 8.012 & 2.003 \\
\cline { 2 - 5 } over 10,000 & 27 & 10.185 & 5.241 & 1.009 \\
\cline { 2 - 5 }
\end{tabular}




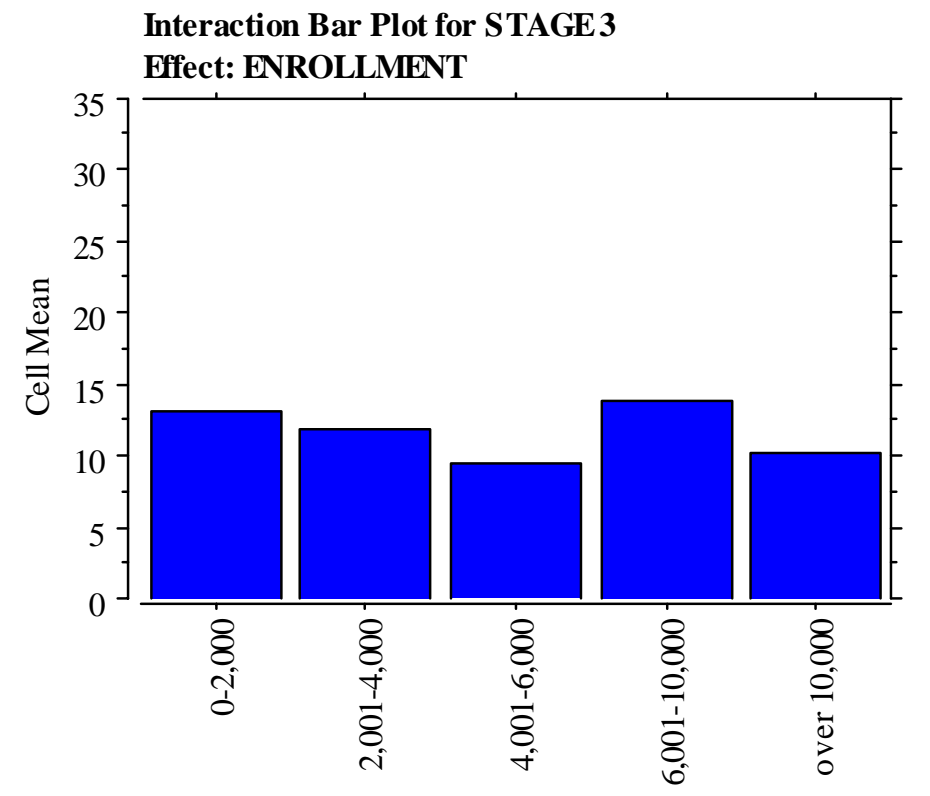

Figure I.12

Table I.33

Fisher's PLSD for STAGE 3

Effect: ENROLLMENT

Significance Level: $5 \%$

$0-2,000,2,001-4,000$
$0-2,000,4,001-6,000$
$0-2,000,6,001-10,000$
$0-2,000$, over 10,000
$2,001-4,000,4,001-6,000$
$2,001-4,000,6,001-10,000$
$2,001-4,000$, over 10,000
$4,001-6,000,6,001-10,000$
$4,001-6,000$, over 10,000
$6,001-10,000$, over 10,000

Mean Diff. Crit. Diff P-Value

\begin{tabular}{|r|r|r|}
\hline 1.250 & 4.490 & .5822 \\
\hline 3.507 & 3.684 & .0619 \\
\hline-.887 & 4.409 & .6907 \\
\hline 2.865 & 3.878 & .1460 \\
\hline 2.257 & 4.056 & .2725 \\
\hline-2.137 & 4.724 & .3718 \\
\hline 1.615 & 4.233 & .4512 \\
\hline-4.395 & 3.967 & .0302 \\
\hline-.642 & 3.367 & .7060 \\
\hline 3.752 & 4.147 & .0757 \\
\hline
\end{tabular}


Stage 4 (Consequences)

Table I.34

ANOVA Table for STAGE 4

\begin{tabular}{|c|c|c|c|c|c|c|c|}
\hline \multirow{3}{*}{$\begin{array}{l}\text { ENROLLMENT } \\
\text { Residual }\end{array}$} & DF & Sum of Squares & Mean Square & F-Value & P-Value & Lambda & Power \\
\hline & 4 & 459.796 & 114.949 & 2.471 & .0488 & 9.885 & 686 \\
\hline & 108 & 5023.426 & 46.513 & & & & \\
\hline
\end{tabular}

Table I.35

\section{Means Table for STAGE 4}

Effect: ENROLLMENT

\begin{tabular}{l|r|r|r|r|}
\multicolumn{1}{c}{} & \multicolumn{1}{c}{ Count } & \multicolumn{1}{c}{ Mean } & \multicolumn{1}{c}{ Std. Dev. } & \multicolumn{1}{c}{ Std. Err. } \\
\cline { 2 - 5 } $0-2,000$ & 20 & 7.950 & 6.802 & 1.521 \\
\cline { 2 - 5 } $2,001-4,000$ & 15 & 5.200 & 5.441 & 1.405 \\
\cline { 2 - 5 } $4,001-6,000$ & 35 & 4.829 & 4.860 & .821 \\
\cline { 2 - 5 } $6,001-10,000$ & 16 & 10.813 & 9.340 & 2.335 \\
\cline { 2 - 5 } over 10,000 & 27 & 6.444 & 7.890 & 1.518 \\
\cline { 2 - 5 } & & & &
\end{tabular}

Interaction Bar Plot for STAGE 4

Effect: ENROLLMENT

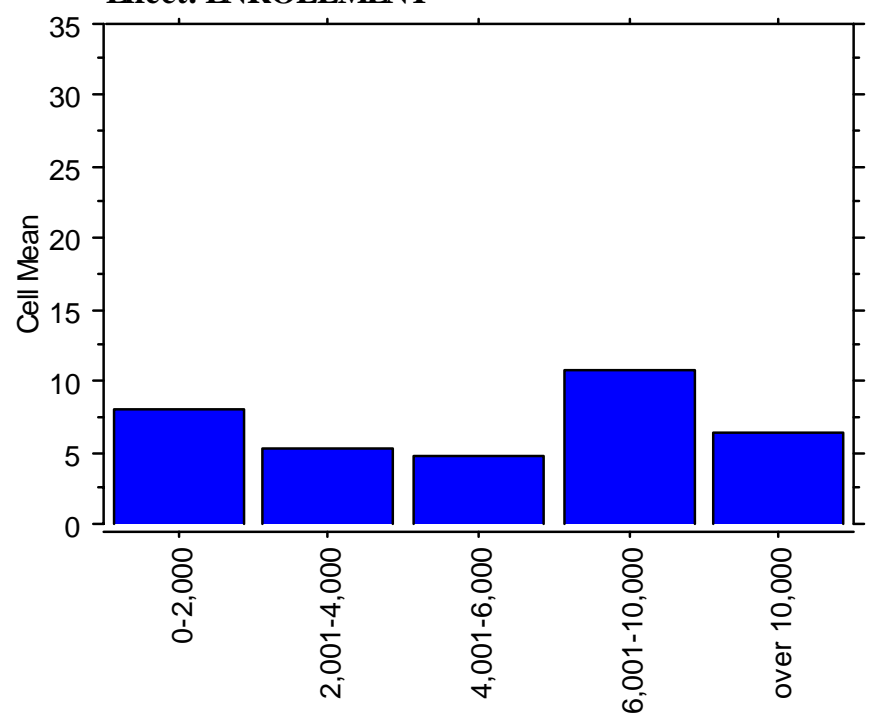

Figure I.13 


\section{Table I.36}

\begin{tabular}{|c|c|c|c|}
\hline \multicolumn{4}{|l|}{$\begin{array}{l}\text { Fisher's PLSD for STAG } \\
\text { Effect: ENROLLMENT }\end{array}$} \\
\hline $0-2,000,2,001-4,000$ & 2.750 & 4.617 & .2404 \\
\hline $0-2,000,4,001-6,000$ & 3.121 & 3.789 & .1054 \\
\hline $0-2,000,6,001-10,000$ & -2.862 & 4.534 & .2135 \\
\hline $0-2,000$, over 10,000 & 1.506 & 3.988 & .4559 \\
\hline $2,001-4,000,4,001-6,000$ & .371 & 4.172 & .8603 \\
\hline $2,001-4,000,6,001-10,000$ & -5.612 & 4.859 & .0240 \\
\hline $2,001-4,000$, over 10,000 & -1.244 & 4.353 & .5721 \\
\hline $4,001-6,000,6,001-10,000$ & -5.984 & 4.080 & .0044 \\
\hline $4,001-6,000$, over 10,000 & -1.616 & 3.463 & .3570 \\
\hline $6,001-10,000$, over 10,000 & 4.368 & 4.265 & .0448 \\
\hline
\end{tabular}

Stage 5 (Collaboration)

Table I.37

ANOVA Table for STAGE5

DF Sum of Squares Mean Square F-Value P-Value Lambda Power

\begin{tabular}{l|r|r|r|r|r|r|r|} 
ENROLLMENT & 4 & 200.975 & 50.244 & .657 & .6229 & 2.630 & .205 \\
\cline { 2 - 8 } Residual & 108 & 8252.989 & 76.417 & & & & \\
\hline
\end{tabular}

Table I.38

\begin{tabular}{|c|c|c|c|c|}
\hline \multicolumn{5}{|c|}{$\begin{array}{l}\text { Means Table for STAGE } 5 \\
\text { Effect: ENROLLMENT }\end{array}$} \\
\hline & Count & Mean & Std. Dev. & Std. Err. \\
\hline $0-2,000$ & 20 & 17.350 & 8.839 & 1.977 \\
\hline $2,001-4,000$ & 15 & 14.067 & 5.824 & 1.504 \\
\hline $4,001-6,000$ & 35 & 15.114 & 9.203 & 1.556 \\
\hline $6,001-10,000$ & 16 & 18.250 & 10.389 & 2.597 \\
\hline over 10,000 & 27 & 15.963 & 8.309 & 1.599 \\
\hline
\end{tabular}




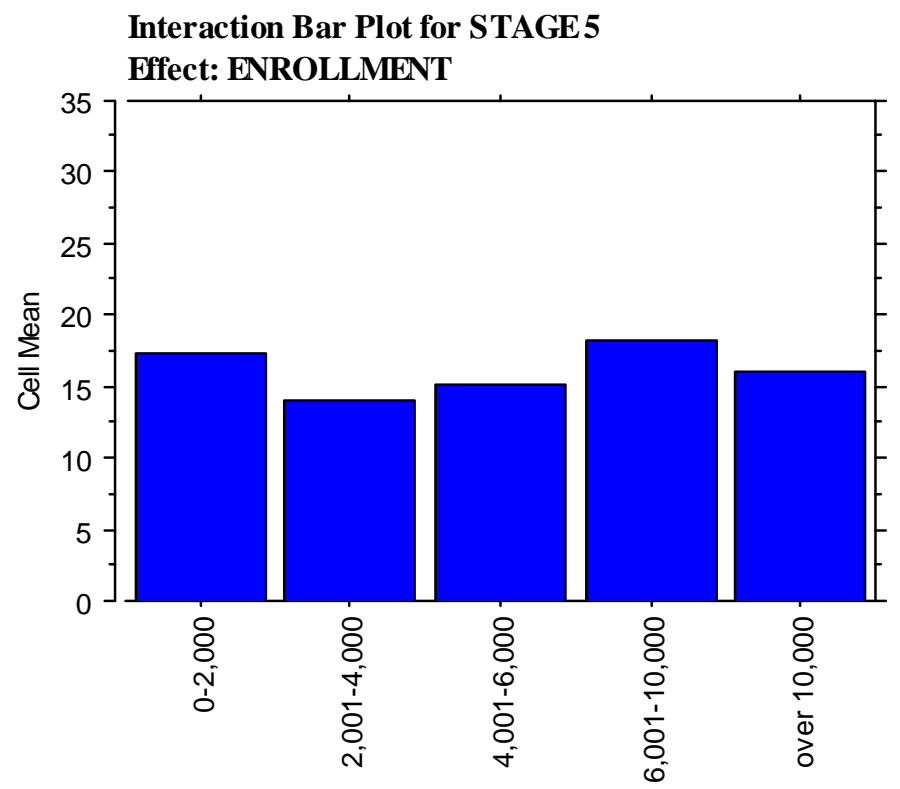

Figure I.14

Table I.39

Fisher's PLSD for STAGE5

Effect: ENROLLMENT

Significance Level: $5 \%$

0-2,000, 2,001-4,000

$0-2,000,4,001-6,000$

$0-2,000,6,001-10,000$

0-2,000, over 10,000

2,001-4,000, 4,001-6,000

2,001-4,000, 6,001-10,000

$2,001-4,000$, over 10,000

4,001-6,000, 6,001-10,000

4,001-6,000, over 10,000

$6,001-10,000$, over 10,000

Mean Diff. Crit. Diff P-Value

\begin{tabular}{|r|r|r|}
\hline 3.283 & 5.918 & .2739 \\
\hline 2.236 & 4.857 & .3636 \\
\hline-.900 & 5.812 & .7595 \\
\hline 1.387 & 5.112 & .5918 \\
\hline-1.048 & 5.347 & .6985 \\
\hline-4.183 & 6.227 & .1858 \\
\hline-1.896 & 5.580 & .5020 \\
\hline-3.136 & 5.229 & .2372 \\
\hline-.849 & 4.438 & .7054 \\
\hline 2.287 & 5.467 & .4088 \\
\hline
\end{tabular}


Stage 6 (Refocusing)

Table I.40

ANOVA Table for STAGE 6

Table 1.40

\begin{tabular}{|c|c|c|c|c|c|c|c|}
\hline \multirow{2}{*}{ ENROLLMENT } & DF & Sum of Squares & Mean Square & F-Value & P-Value & Lambda & Power \\
\hline & 4 & 146.239 & 36.560 & .736 & .5696 & 2.943 & .226 \\
\hline D. & 108 & 5367.036 & 49.695 & & & & \\
\hline
\end{tabular}

Table I.41

Means Table for STAGE 6

Effect: ENROLLMENT

\begin{tabular}{|c|c|c|c|c|}
\hline \multirow[b]{2}{*}{$0-2,00$} & Count & Mean & Std. Dev. & Std. Err. \\
\hline & 20 & 10.250 & 7.107 & 1.589 \\
\hline 2,001-4,000 & 15 & 9.067 & 6.123 & 1.581 \\
\hline \multirow{3}{*}{$\begin{array}{l}4,001-6,000 \\
6,001-10,000 \\
\text { over } 10,000\end{array}$} & 35 & 9.743 & 6.934 & 1.172 \\
\hline & 16 & 11.750 & 6.748 & 1.687 \\
\hline & 27 & 12.111 & 7.758 & 1.493 \\
\hline
\end{tabular}

Interaction Bar Plot for STAGE 6

Effect: ENROLLMENT

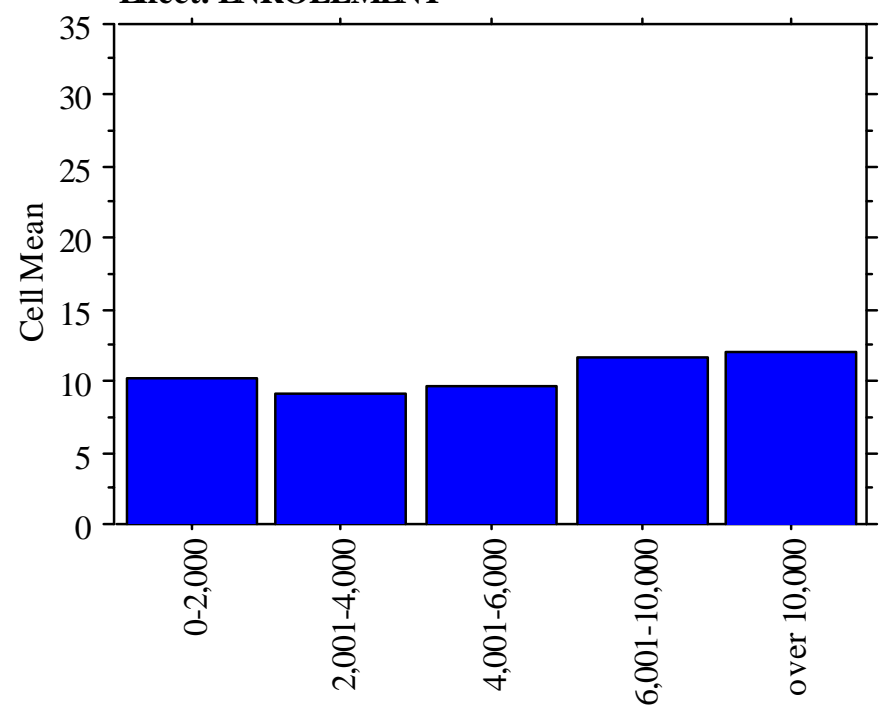

Figure I.15 


\section{Table I.42}

Fisher's PLSD for STAGE 6

Effect: ENROLLMENT

Significance Level: $5 \%$

0-2,000, 2,001-4,000

0-2,000, 4,001-6,000

$0-2,000,6,001-10,000$

$0-2,000$, over 10,000

2,001-4,000, 4,001-6,000

2,001-4,000, 6,001-10,000

$2,001-4,000$, over 10,000

4,001-6,000, 6,001-10,000

4,001-6,000, over 10,000

$6,001-10,000$, over 10,000

Mean Diff. Crit. Diff P-Value

\begin{tabular}{|r|r|r|}
\hline 1.183 & 4.773 & .6241 \\
\hline .507 & 3.917 & .7979 \\
\hline-1.500 & 4.687 & .5272 \\
\hline-1.861 & 4.122 & .3728 \\
\hline-.676 & 4.312 & .7565 \\
\hline-2.683 & 5.022 & .2919 \\
\hline-3.044 & 4.500 & .1827 \\
\hline-2.007 & 4.217 & .3475 \\
\hline-2.368 & 3.579 & .1924 \\
\hline-.361 & 4.408 & .8713 \\
\hline
\end{tabular}

\section{Subquestion 3 (Length in Years)}

Table I.43

$$
\mathrm{N}=115
$$

Stage 0 (Awareness)

ANOVA Table for STAGE 0

\begin{tabular}{|c|c|c|c|c|c|c|c|}
\hline \multirow{3}{*}{$\begin{array}{l}\text { WVEIS LENGTH } \\
\text { Residual }\end{array}$} & DF & Sum of Squares & Mean Square & F-Value & P-Value & Lambda & Power \\
\hline & 5 & 439.223 & 87.845 & 2.415 & .0406 & 12.073 & .747 \\
\hline & 109 & 3965.525 & 36.381 & & & & \\
\hline
\end{tabular}

Table I.44

\section{Means Table for STAGE 0 \\ Effect: WVEIS LENGTH}

\begin{tabular}{|c|c|c|c|c|}
\hline \multirow[b]{2}{*}{1 year or less } & Count & Mean & Std. Dev. & Std. Err. \\
\hline & 8 & 14.250 & 7.285 & 2.576 \\
\hline 1-2 years & 8 & 11.250 & 4.559 & 1.612 \\
\hline $2-3$ years & 19 & 9.421 & 5.601 & 1.285 \\
\hline \multirow{3}{*}{$\begin{array}{l}3-4 \text { years } \\
4-5 \text { years } \\
\text { greater than } 5 \text { years }\end{array}$} & 25 & 10.760 & 6.132 & 1.226 \\
\hline & 24 & 9.333 & 6.618 & 1.351 \\
\hline & 31 & 7.000 & 5.698 & 1.023 \\
\hline
\end{tabular}


Interaction Bar Plot for STAGE0

Effect: WVEIS LENGTH

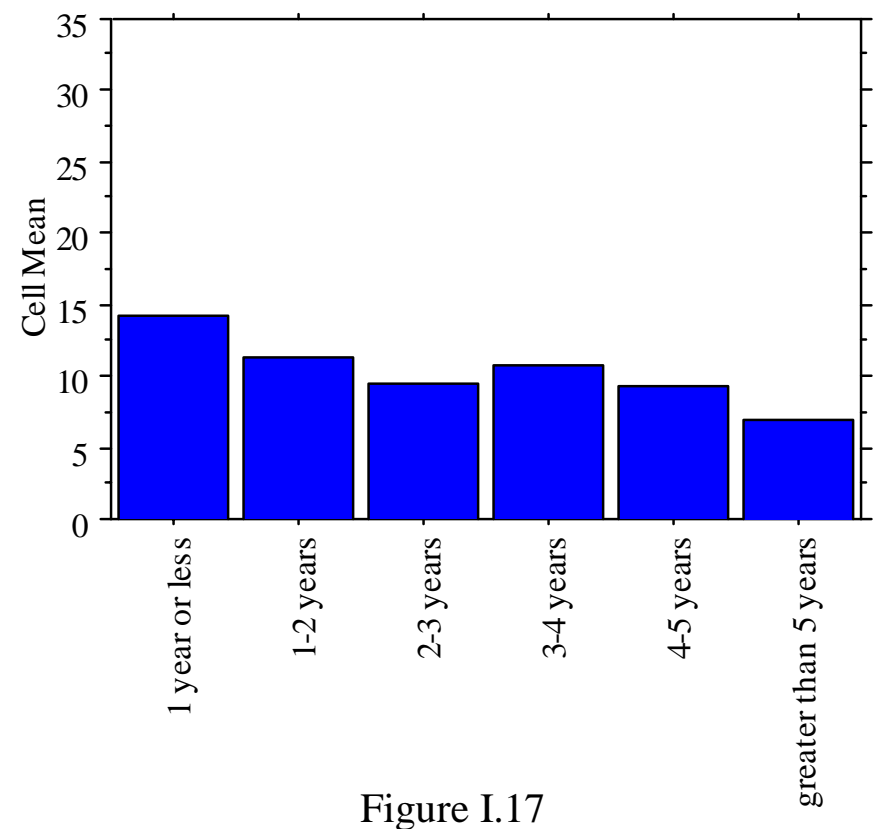

Table I.45

Fisher's PLSD for STAGE 0

Effect: WVEIS LENGTH

Significance Level: $5 \%$

1 year or less, 1-2 years

1 year or less, 2-3 years

1 year or less, 3-4 years

1 year or less, $4-5$ years

1 year or less, greater than 5 years

1-2 years, 2-3 years

1-2 years, $3-4$ years

1-2 years, $4-5$ years

1-2 years, greater than 5 years

2-3 years, 3-4 years

2-3 years, $4-5$ years

2-3 years, greater than 5 years

3-4 years, 4-5 years

3-4 years, greater than 5 years

4-5 years, greater than 5 years

\begin{tabular}{|r|r|r|}
\multicolumn{1}{r|}{ Mean Diff. } & \multicolumn{1}{r}{ Crit. Diff } & \multicolumn{1}{c}{ P-Value } \\
\hline 3.000 & 5.977 & .3221 \\
\hline 4.829 & 5.038 & .0601 \\
\hline 3.490 & 4.856 & .1572 \\
\hline 4.917 & 4.880 & .0484 \\
\hline 7.250 & 4.741 & .0030 \\
\hline 1.829 & 5.038 & .4734 \\
\hline .490 & 4.856 & .8419 \\
\hline 1.917 & 4.880 & .4380 \\
\hline 4.250 & 4.741 & .0784 \\
\hline-1.339 & 3.638 & .4673 \\
\hline .088 & 3.671 & .9623 \\
\hline 2.421 & 3.483 & .1711 \\
\hline 1.427 & 3.416 & .4097 \\
\hline 3.760 & 3.213 & .0223 \\
\hline 2.333 & 3.250 & .1576 \\
\hline
\end{tabular}

129 
Stage 1 (Information)

Table I.46

ANOVA Table for STAGE 1

\begin{tabular}{l|r|r|r|r|r|r|r|}
\multicolumn{1}{l}{} & \multicolumn{1}{c}{ DF } & \multicolumn{1}{c}{ Sum of Squares } & \multicolumn{1}{c}{ Mean Square } & \multicolumn{1}{c}{ F-Value } & \multicolumn{1}{c}{ P-Value } & Lambda & Power \\
WVEIS LENGTH & 5 & 737.936 & 147.587 & 3.435 & .0064 & 17.175 & .904 \\
\cline { 2 - 8 } Residual & 5 & 4683.247 & 42.966 & & & & \\
\hline
\end{tabular}

Table I.47

\begin{tabular}{|c|c|c|c|c|}
\hline \multicolumn{5}{|c|}{ Means Table for STAGE 1} \\
\hline & Count & Mean & Std. Dev. & Std. Err. \\
\hline \multirow{2}{*}{$\begin{array}{l}1 \text { year or less } \\
1-2 \text { years }\end{array}$} & 8 & 14.250 & 7.555 & 2.671 \\
\hline & 8 & 15.250 & 4.234 & 1.497 \\
\hline \multirow{4}{*}{$\begin{array}{l}\text { 2-3 years } \\
3-4 \text { years } \\
4-5 \text { years } \\
\text { greater than } 5 \text { years }\end{array}$} & 19 & 13.158 & 6.112 & 1.402 \\
\hline & 25 & 12.800 & 6.874 & 1.375 \\
\hline & 24 & 10.333 & 6.322 & 1.291 \\
\hline & 31 & 7.710 & 6.910 & 1.241 \\
\hline
\end{tabular}

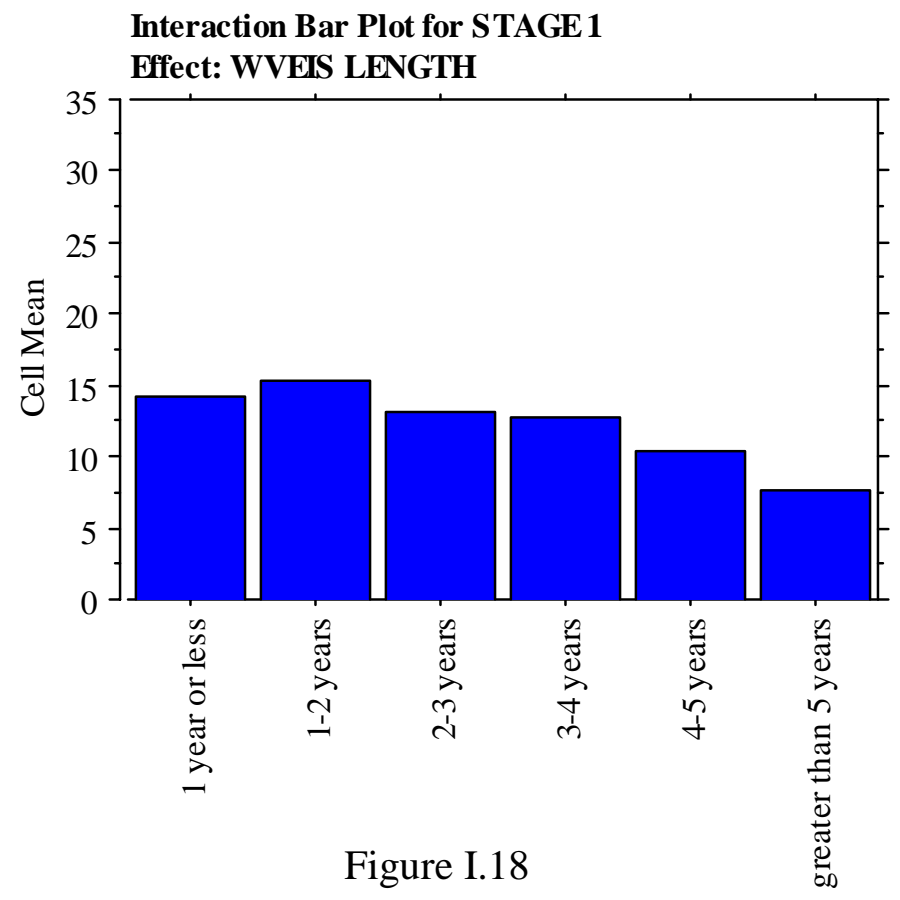




\section{Table I.48}

Fisher's PLSD for STAGE 1

Effect: WVEIS LENGTH

Significance Level: $5 \%$

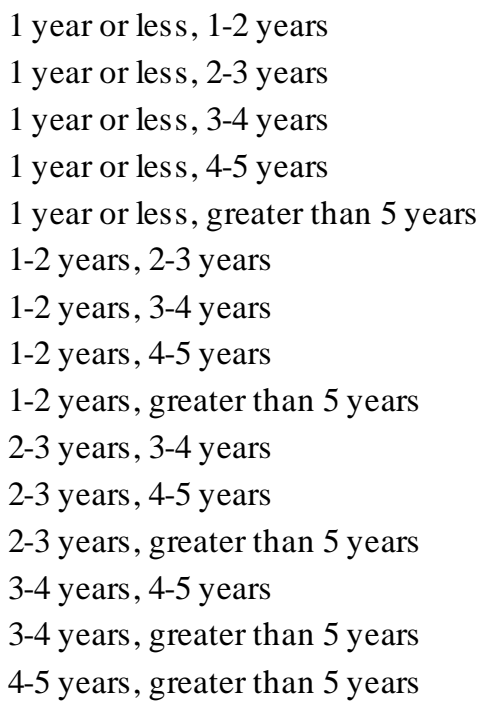

Mean Diff. Crit. Diff P-Value

\begin{tabular}{|r|r|r|}
\hline-1.000 & 6.496 & .7609 \\
\hline 1.092 & 5.475 & .6934 \\
\hline 1.450 & 5.277 & .5872 \\
\hline 3.917 & 5.304 & .1462 \\
\hline 6.540 & 5.152 & .0133 \\
\hline 2.092 & 5.475 & .4505 \\
\hline 2.450 & 5.277 & .3595 \\
\hline 4.917 & 5.304 & .0689 \\
\hline 7.540 & 5.152 & .0045 \\
\hline .358 & 3.954 & .8580 \\
\hline 2.825 & 3.989 & .1634 \\
\hline 5.448 & 3.785 & .0052 \\
\hline 2.467 & 3.713 & .1907 \\
\hline 5.090 & 3.492 & .0047 \\
\hline 2.624 & 3.532 & .1439 \\
\hline
\end{tabular}

Stage 2 (Personal)

Table I.49

ANOVA Table for STAGE 2

\begin{tabular}{|c|c|c|c|c|c|c|c|}
\hline \multirow{3}{*}{$\begin{array}{l}\text { WVEIS LENGTH } \\
\text { Residual }\end{array}$} & $\mathrm{DF}$ & Sum of Squares & Mean Square & F-Value & P-Value & Lambda & Power \\
\hline & 5 & 129.998 & 26.000 & .405 & .8446 & 2.024 & .151 \\
\hline & 109 & 7002.124 & 64.240 & & & & \\
\hline
\end{tabular}

Table I.50

Means Table for STAGE 2 Effect: WVEIS LENGTH

\begin{tabular}{|c|c|c|c|c|}
\hline \multirow{3}{*}{1 year or less } & Count & Mean & Std. Dev. & Std. Err. \\
\hline & 8 & 14.625 & 8.228 & 2.909 \\
\hline & 8 & 12.625 & 3.503 & 1.238 \\
\hline 2-3 years & 19 & 13.579 & 9.082 & 2.084 \\
\hline 3-4 years & 25 & 12.320 & 7.946 & 1.589 \\
\hline $4-5$ years & 24 & 11.125 & 7.914 & 1.615 \\
\hline greater than 5 years & 31 & 11.452 & 8.168 & 1.467 \\
\hline
\end{tabular}




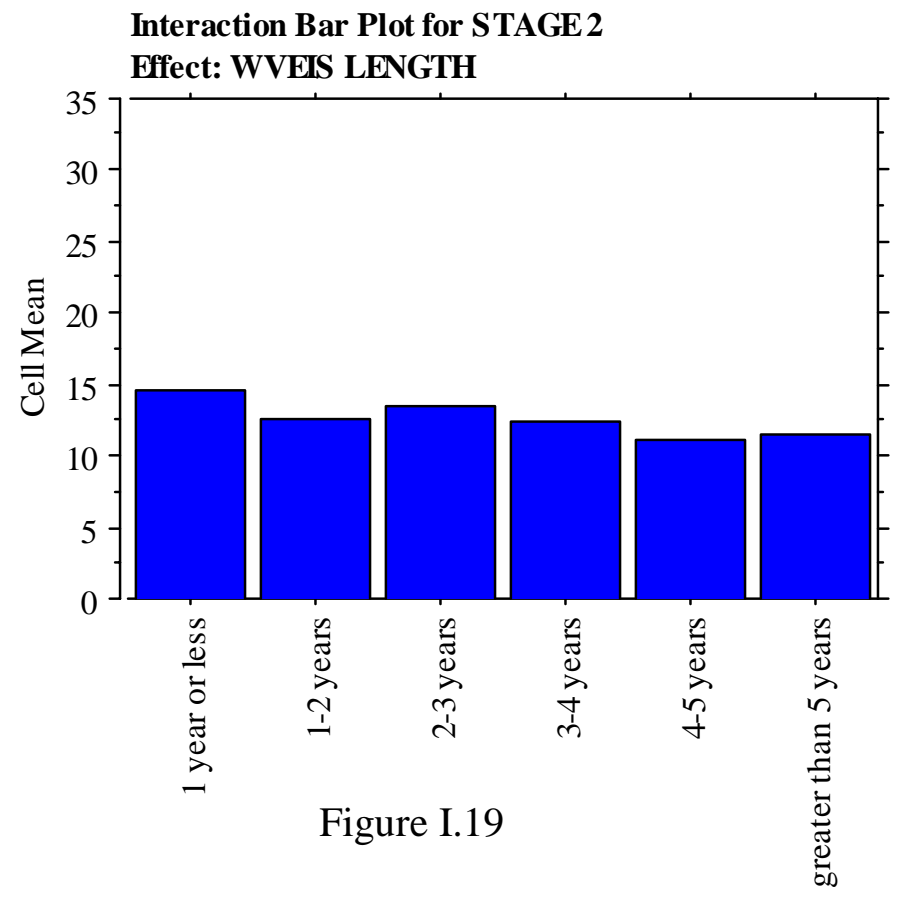

Table I.51

Fisher's PLSD for STAGE2

\section{Effect: WVEIS LENGTH}

\section{Significance Level: $5 \%$}

1 year or less, 1-2 years

1 year or less, 2-3 years

1 year or less, 3-4 years

1 year or less, 4-5 years

1 year or less, greater than 5 years

1-2 years, 2-3 years

1-2 years, 3-4 years

1-2 years, 4-5 years

1-2 years, greater than 5 years

2-3 years, 3-4 years

2-3 years, $4-5$ years

2-3 years, greater than 5 years

3-4 years, 4-5 years

3-4 years, greater than 5 years

4-5 years, greater than 5 years

\begin{tabular}{|r|r|r|}
\multicolumn{1}{r}{ Mean Diff. } & \multicolumn{1}{r|}{ Crit. Diff } & \multicolumn{1}{c}{ P-Value } \\
\hline 2.000 & 7.943 & .6187 \\
\hline 1.046 & 6.695 & .7574 \\
\hline 2.305 & 6.453 & .4805 \\
\hline 3.500 & 6.485 & .2871 \\
\hline 3.173 & 6.299 & .3203 \\
\hline-.954 & 6.695 & .7782 \\
\hline .305 & 6.453 & .9255 \\
\hline 1.500 & 6.485 & .6476 \\
\hline 1.173 & 6.299 & .7127 \\
\hline 1.259 & 4.835 & .6068 \\
\hline 2.454 & 4.878 & .3210 \\
\hline 2.127 & 4.628 & .3643 \\
\hline 1.195 & 4.540 & .6029 \\
\hline .868 & 4.270 & .6877 \\
\hline-.327 & 4.319 & .8811 \\
\hline
\end{tabular}


Stage 3 (Management)

Table I.52

ANOVA Table for STAGE 3

\begin{tabular}{l|r|r|r|r|r|r|r|}
\multicolumn{1}{l}{} & \multicolumn{1}{c}{ DF } & \multicolumn{1}{c}{ Sum of Squares } & \multicolumn{1}{c}{ Mean Square } & \multicolumn{1}{c}{ F-Value } & \multicolumn{1}{c}{ P-Value } & \multicolumn{1}{c}{ Lambda } & Power \\
\cline { 2 - 8 } WVEIS LENGTH & 5 & 80.692 & 16.138 & .347 & .8835 & 1.733 & .134 \\
\cline { 2 - 8 } Residual & 109 & 5075.430 & 46.564 & & & & \\
\cline { 2 - 8 }
\end{tabular}

Table I.53

Means Table for STAGE 3

Effect: WVEIS LENGTH

\begin{tabular}{l|r|r|r|r|}
\multicolumn{1}{l}{ 1 year or less } & \multicolumn{1}{c}{ Count } & \multicolumn{1}{c}{ Mean } & \multicolumn{1}{c}{ Std. Dev. } & \multicolumn{1}{c}{ Std. Err. } \\
\cline { 2 - 5 } $\begin{array}{l}\text { 1-2 years } \\
\text { 2-3 years }\end{array}$ & 8 & 13.125 & 8.576 & 3.032 \\
\cline { 2 - 5 } $\begin{array}{l}\text { 3-4 years } \\
\text { 4-5 years } \\
\text { greater than 5 years }\end{array}$ & 10.625 & 3.852 & 1.362 \\
\cline { 2 - 5 } & 19 & 10.421 & 6.185 & 1.419 \\
\cline { 2 - 5 } & 25 & 12.200 & 6.461 & 1.292 \\
\cline { 2 - 5 } & 24 & 11.250 & 7.029 & 1.435 \\
\cline { 2 - 5 } & 31 & 10.581 & 7.370 & 1.324 \\
\hline
\end{tabular}

Interaction Bar Plot for STAGE3

Effect: WVEIS LENGTH

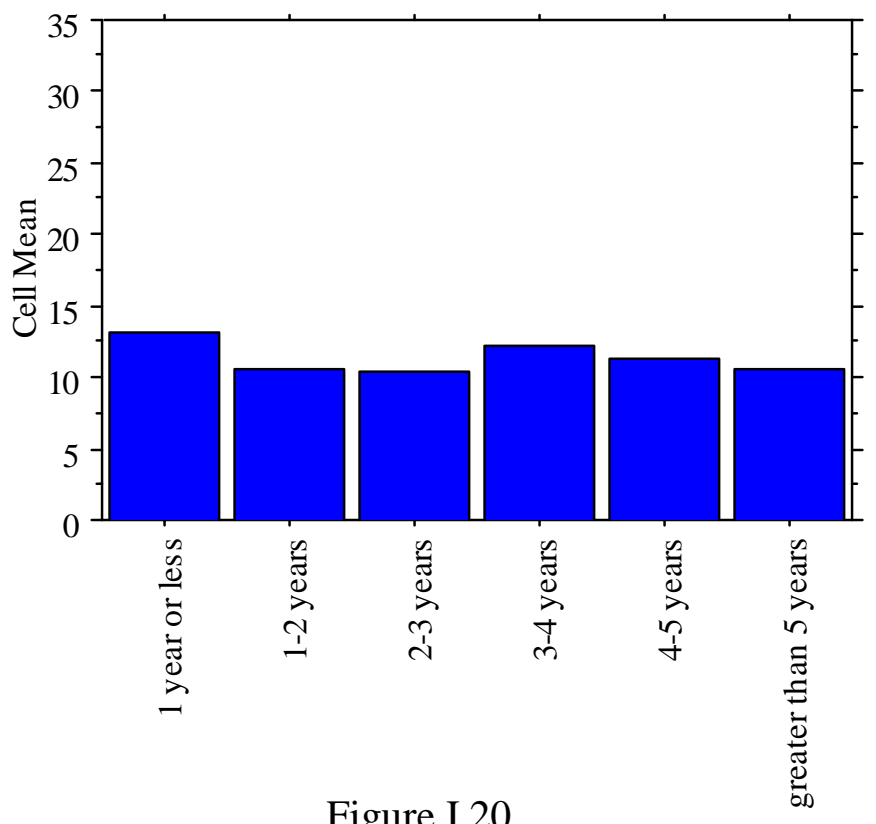

Figure I.20 


\section{Table I.54}

\section{Fisher's PLSD for STAGE3 \\ Effect: WVEIS LENGTH \\ Significance Level: $5 \%$}

1 year or less, 1-2 years

1 year or less, 2-3 years

1 year or less, 3-4 years

1 year or less, $4-5$ years

1 year or less, greater than 5 years

1-2 years, $2-3$ years

1-2 years, $3-4$ years

1-2 years, $4-5$ years

1-2 years, greater than 5 years

2-3 years, 3-4 years

2-3 years, $4-5$ years

2-3 years, greater than 5 years

3-4 years, 4-5 years

3-4 years, greater than 5 years

4-5 years, greater than 5 years

\begin{tabular}{|r|r|r|}
\multicolumn{1}{c}{ Mean Diff. } & \multicolumn{1}{c|}{ Crit. Diff } & P-Value \\
\hline 2.500 & 6.762 & .4653 \\
\hline 2.704 & 5.700 & .3492 \\
\hline .925 & 5.494 & .7392 \\
\hline 1.875 & 5.521 & .5023 \\
\hline 2.544 & 5.363 & .3492 \\
\hline .204 & 5.700 & .9436 \\
\hline-1.575 & 5.494 & .5711 \\
\hline-.625 & 5.521 & .8229 \\
\hline .044 & 5.363 & .9870 \\
\hline-1.779 & 4.116 & .3936 \\
\hline-.829 & 4.153 & .6932 \\
\hline-.160 & 3.940 & .9362 \\
\hline .950 & 3.865 & .6271 \\
\hline 1.619 & 3.635 & .3793 \\
\hline .669 & 3.677 & .7190 \\
\hline
\end{tabular}

Stage 4 (Consequences)

Table I.55

ANOVA Table for STAGE 4

\begin{tabular}{l|r|r|r|r|r|r|r|}
\multicolumn{1}{c}{} & \multicolumn{1}{c}{ DF } & Sum of Squares & Mean Square & \multicolumn{1}{c}{ F-Value } & \multicolumn{1}{c}{ P-Value } & Lambda & Power \\
WVEIS LENGTH & 5 & 624.429 & 124.886 & 2.639 & .0271 & 13.197 & .792 \\
\cline { 2 - 8 } Residual & 109 & 5157.362 & 47.315 & & & & \\
\hline
\end{tabular}


Table I.56

\section{Means Table for STAGE 4}

Effect: WVEIS LENGTH

\begin{tabular}{l|r|r|r|r|}
\multicolumn{1}{c}{ 1 year or less } & \multicolumn{1}{c}{ Count } & \multicolumn{1}{c}{ Mean } & \multicolumn{1}{c}{ Std. Dev. } & Std. Err. \\
\cline { 2 - 5 } 1-2 years & 8 & 13.125 & 12.900 & 4.561 \\
\hline 2-3 years & 8 & 4.625 & 4.207 & 1.487 \\
\hline 3-4 years & 19 & 4.421 & 4.312 & .989 \\
\hline 4-5 years & 25 & 5.640 & 5.656 & 1.131 \\
\hline greater than 5 years & 24 & 6.083 & 6.071 & 1.239 \\
\cline { 2 - 5 } & 31 & 8.710 & 7.997 & 1.436 \\
\cline { 2 - 5 } & & & &
\end{tabular}

Interaction Bar Plot for STAGE4

Effect: WVEIS LENGTH

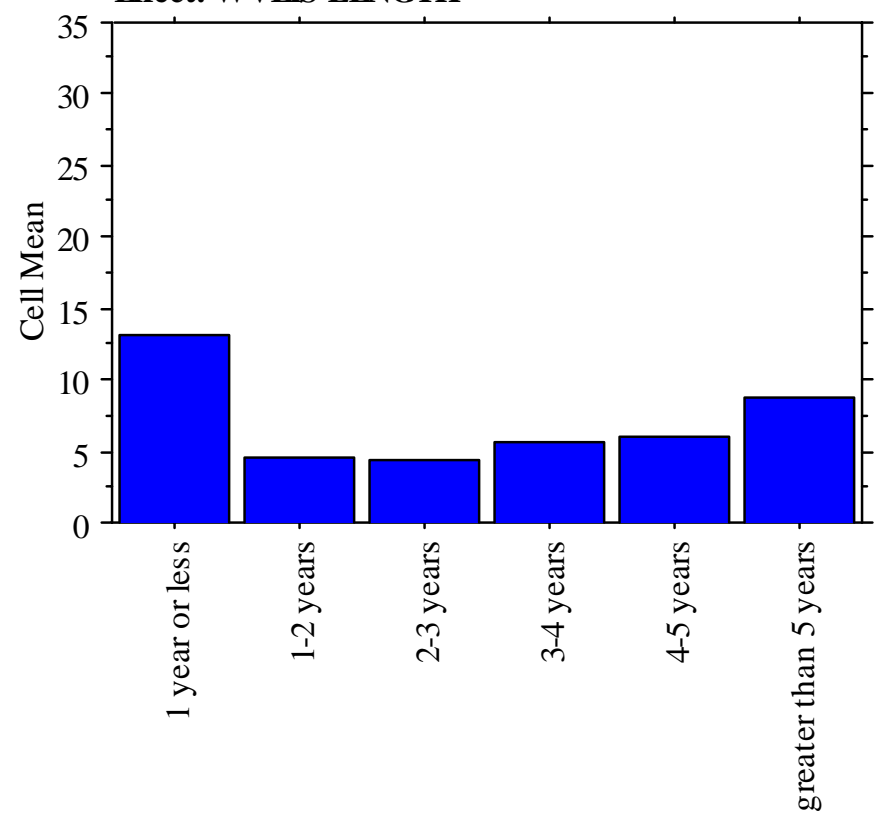

Figure I.21 


\section{Table I.57}

\section{Fisher's PLSD for STAGE 4 \\ Effect: WVEIS LENGTH \\ Significance Level: 5 \%}

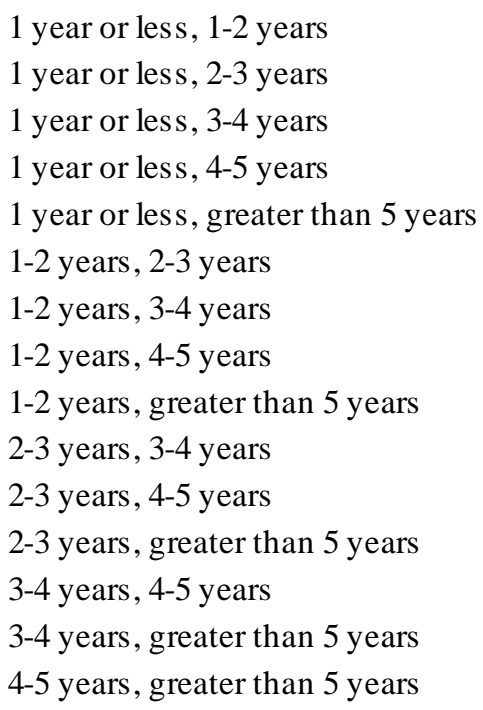

\begin{tabular}{|c|c|c|}
\hline Mean Diff. & Crit. Diff & P-Value \\
\hline 8.500 & 6.817 & .0150 \\
\hline 8.704 & 5.746 & .0033 \\
\hline 7.485 & 5.538 & .0085 \\
\hline 7.042 & 5.566 & .0136 \\
\hline 4.415 & 5.406 & .1084 \\
\hline .204 & 5.746 & .9440 \\
\hline-1.015 & 5.538 & .7171 \\
\hline-1.458 & 5.566 & .6046 \\
\hline-4.085 & 5.406 & .1372 \\
\hline-1.219 & 4.149 & .5616 \\
\hline-1.662 & 4.186 & .4330 \\
\hline-4.289 & 3.972 & .0346 \\
\hline-.443 & 3.896 & .8220 \\
\hline-3.070 & 3.665 & .0998 \\
\hline-2.626 & 3.707 & .1631 \\
\hline
\end{tabular}

Stage 5 (Collaboration)

Table I.58

ANOVA Table for STAGE 5

\begin{tabular}{l|r|r|r|r|r|r|r|}
\multicolumn{1}{l}{} & \multicolumn{1}{c}{ DF } & \multicolumn{1}{c}{ Sum of Squares } & \multicolumn{1}{c}{ Mean Square } & \multicolumn{1}{c}{ F-Value } & \multicolumn{1}{c}{ P-Value } & Lambda & Power \\
WVEIS LENGTH & 5 & 150.428 & 30.086 & .382 & .8600 & 1.911 & .144 \\
\cline { 2 - 8 } Residual & 5 & 8578.146 & 78.699 & & & & \\
\hline
\end{tabular}


Table I.59

Means Table for STAGE 5

Effect: WVEIS LENGTH

\begin{tabular}{l|r|r|r|r|}
\multicolumn{1}{l}{ 1 year or less } & \multicolumn{1}{c}{ Count } & \multicolumn{1}{c}{ Mean } & \multicolumn{1}{c}{ Std. Dev. } & Std. Err. \\
\cline { 2 - 5 } $\begin{array}{l}\text { 1-2 years } \\
\text { 2-3 years }\end{array}$ & 8 & 18.000 & 7.010 & 2.478 \\
\cline { 2 - 5 } 3-4 years & 8 & 15.625 & 6.116 & 2.162 \\
\cline { 2 - 5 } 4-5 years \\
greater than 5 years & 19 & 16.368 & 8.694 & 1.994 \\
\cline { 2 - 5 } & 25 & 14.120 & 8.724 & 1.745 \\
\cline { 2 - 5 } & 24 & 16.250 & 10.280 & 2.098 \\
\cline { 2 - 5 } & 31 & 16.903 & 8.859 & 1.591 \\
\hline
\end{tabular}

Interaction Bar Plot for STAGE5

Effect: WVEIS LENGTH

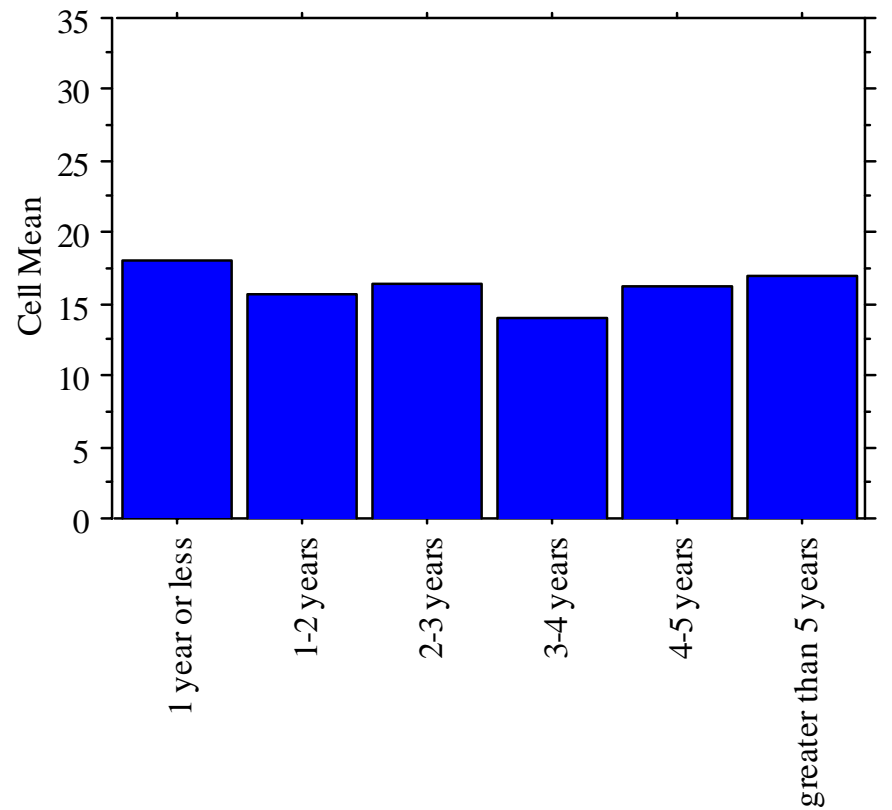

Figure I.22 


\section{Table I.60}

\section{Fisher's PLSD for STAGE 5 \\ Effect: WVEIS LENGTH \\ Significance Level: $5 \%$}

1 year or less, 1-2 years

1 year or less, 2-3 years

1 year or less, 3-4 years

1 year or less, 4-5 years

1 year or less, greater than 5 years

1-2 years, 2-3 years

1-2 years, $3-4$ years

1-2 years, 4-5 years

1-2 years, greater than 5 years

2-3 years, 3-4 years

2-3 years, 4-5 years

2-3 years, greater than 5 years

3-4 years, 4-5 years

3-4 years, greater than 5 years

4-5 years, greater than 5 years

\begin{tabular}{|r|r|r|}
\multicolumn{1}{r|}{ Mean Diff. } & \multicolumn{1}{r|}{ Crit. Diff } & \multicolumn{1}{c}{ P-Value } \\
\hline 2.375 & 8.791 & .5934 \\
\hline 1.632 & 7.410 & .6634 \\
\hline 3.880 & 7.142 & .2840 \\
\hline 1.750 & 7.178 & .6299 \\
\hline 1.097 & 6.972 & .7558 \\
\hline-.743 & 7.410 & .8428 \\
\hline 1.505 & 7.142 & .6770 \\
\hline-.625 & 7.178 & .8633 \\
\hline-1.278 & 6.972 & .7171 \\
\hline 2.248 & 5.351 & .4068 \\
\hline .118 & 5.399 & .9654 \\
\hline-.535 & 5.123 & .8365 \\
\hline-2.130 & 5.025 & .4026 \\
\hline-2.783 & 4.726 & .2457 \\
\hline-.653 & 4.781 & .7870 \\
\hline
\end{tabular}

Stage 6 (Refocusing)

Table I.61

ANOVA Table for STAGE6

\begin{tabular}{l|r|r|r|r|r|r|r|}
\multicolumn{1}{c}{ DF } & \multicolumn{1}{c}{ Sum of Squares } & \multicolumn{1}{c}{ Mean Square } & \multicolumn{1}{c}{ F-Value } & \multicolumn{1}{c}{ P-Value } & \multicolumn{2}{c}{ Lambda } & Power \\
WVEIS LENGTH & 5 & 229.442 & 45.888 & .955 & .4487 & 4.776 & .324 \\
\cline { 2 - 8 } Residual & 109 & 5236.645 & 48.043 & & & & \\
\hline
\end{tabular}


Table I.62

Means Table for STAGE 6

Effect: WVEIS LENGTH

\begin{tabular}{|c|c|c|c|c|}
\hline & Count & Mean & Std. Dev. & Std. Err. \\
\hline \multirow{2}{*}{$\begin{array}{l}1 \text { year or less } \\
1-2 \text { years }\end{array}$} & 8 & 12.375 & 7.782 & 2.751 \\
\hline & 8 & 10.250 & 3.770 & 1.333 \\
\hline \multirow{4}{*}{$\begin{array}{l}2-3 \text { years } \\
3-4 \text { years } \\
4-5 \text { years } \\
\text { greater than } 5 \text { years }\end{array}$} & 19 & 11.105 & 7.363 & 1.689 \\
\hline & 25 & 8.640 & 4.725 & .945 \\
\hline & 24 & 9.833 & 6.703 & 1.368 \\
\hline & 31 & 12.290 & 8.502 & 1.527 \\
\hline
\end{tabular}

Interaction Bar Plot for STAGE 6

Effect: WVEIS LENGTH

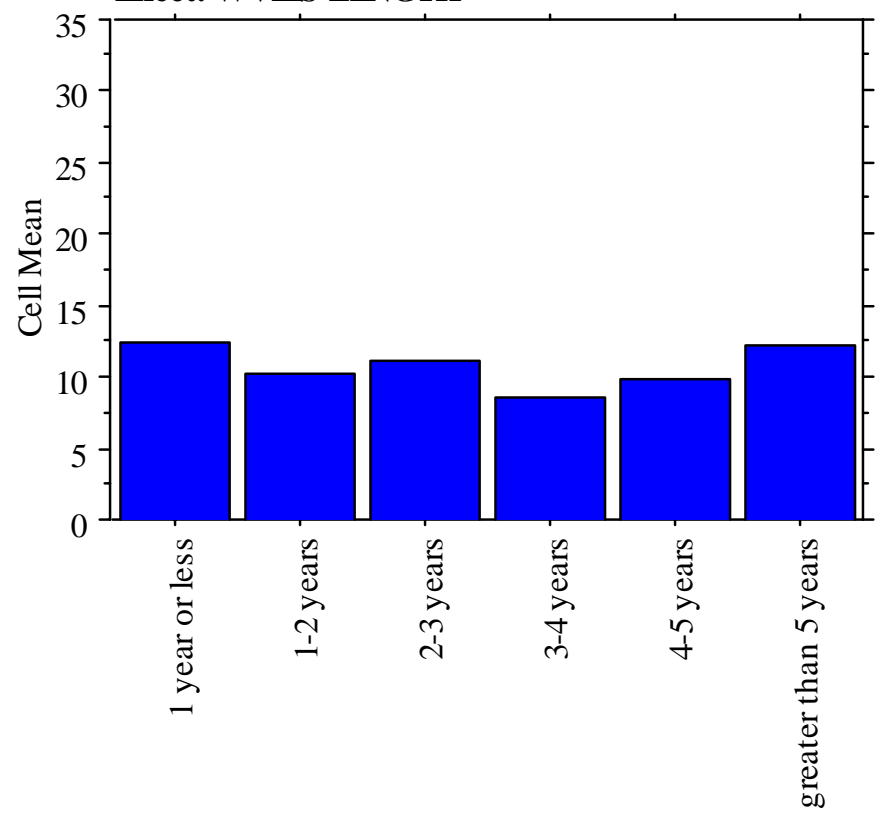

Figure I.23 


\section{Table I.63}

\begin{tabular}{|c|c|c|c|}
\hline $\begin{array}{l}\text { Fisher's PLSD for STAG } \\
\text { Effect: WVEIS LENGTH } \\
\text { Significance Level: } 5 \%\end{array}$ & Mean Diff. & Crit. Diff & P-Value \\
\hline \multirow{6}{*}{$\begin{array}{l}1 \text { year or less, } 1-2 \text { years } \\
1 \text { year or less, } 2-3 \text { years } \\
1 \text { year or less, } 3-4 \text { years } \\
1 \text { year or less, } 4-5 \text { years } \\
1 \text { year or less, greater than } 5 \text { years } \\
1-2 \text { years, } 2-3 \text { years }\end{array}$} & 2.125 & 6.869 & .5410 \\
\hline & 1.270 & 5.790 & .6647 \\
\hline & 3.735 & 5.580 & .1874 \\
\hline & 2.542 & 5.608 & .3711 \\
\hline & .085 & 5.448 & .9755 \\
\hline & -.855 & 5.790 & .7703 \\
\hline $1-2$ years, $3-4$ years & 1.610 & 5.580 & .5686 \\
\hline $1-2$ years, $4-5$ years & .417 & 5.608 & .8832 \\
\hline $1-2$ years, greater than 5 years & -2.040 & 5.448 & .4595 \\
\hline 2-3 years, $3-4$ years & 2.465 & 4.181 & .2451 \\
\hline 2-3 years, $4-5$ years & 1.272 & 4.219 & .5514 \\
\hline $2-3$ years, greater than 5 years & -1.185 & 4.003 & .5585 \\
\hline $3-4$ years, $4-5$ years & -1.193 & 3.926 & .5481 \\
\hline 3-4 years, greater than 5 years & -3.650 & 3.693 & .0526 \\
\hline $4-5$ years, greater than 5 years & -2.457 & 3.735 & .1951 \\
\hline
\end{tabular}

\section{Subquestion 3 (minutes)}

\section{Stage 0 (Awareness)}

$$
\mathrm{N}=113
$$

\section{Table I.64}

ANOVA Table for STAGE0

\begin{tabular}{|c|c|c|c|c|c|c|c|}
\hline & $\mathrm{DF}$ & Sum of Squares & Mean Square & F-Value & P-Value & Lambda & Power \\
\hline WVEIS TIME & 3 & 53.348 & 17.783 & .492 & .6884 & 1.477 & .145 \\
\hline Residual & 109 & 3937.785 & 36.126 & & & & \\
\hline
\end{tabular}


Table I.65

Means Table for STAGE 0

Effect: WVEIS TIME

\begin{tabular}{l|r|r|r|r|}
\multicolumn{1}{c}{} & \multicolumn{1}{c}{ Count } & \multicolumn{1}{c}{ Mean } & \multicolumn{1}{c}{ Std. Dev. } & \multicolumn{1}{c}{ Std. Err. } \\
\cline { 2 - 5 } Infrequent & 3 & 9.667 & 6.506 & 3.756 \\
\cline { 2 - 5 } Minimal & 18 & 10.278 & 6.027 & 1.421 \\
\cline { 2 - 5 } Regular & 23 & 9.826 & 5.069 & 1.057 \\
\cline { 2 - 5 } Steady & 69 & 8.623 & 6.266 & .754 \\
\cline { 2 - 5 }
\end{tabular}

Interaction Bar Plot for STAGE0

Effect: WVEIS TIME

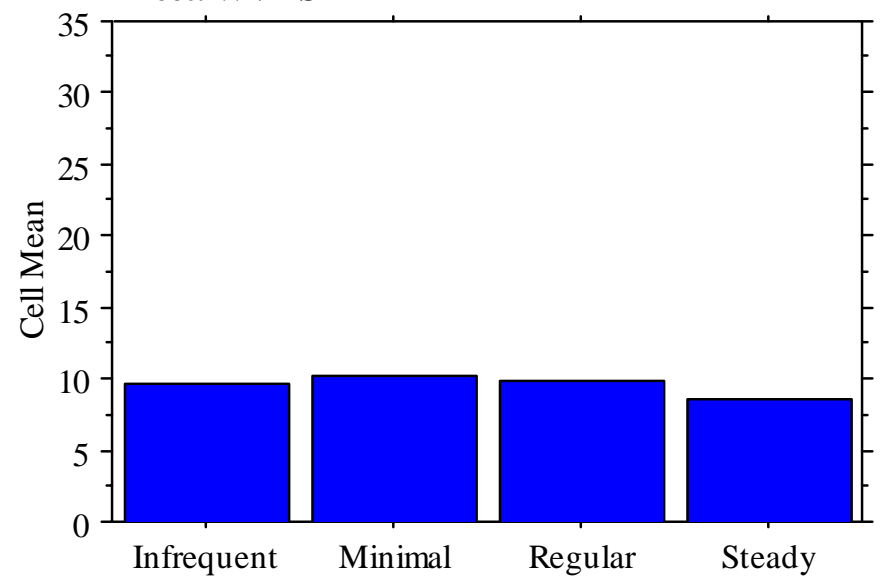

Figure I.24

Table I.66

Fisher's PLSD for STAGE0

Effect: WVEIS TIME

Significance Level: $5 \%$

\begin{tabular}{l|r|r|r|} 
& \multicolumn{1}{c}{ Mean Diff. } & \multicolumn{1}{c}{ Crit. Diff } & \multicolumn{1}{c}{ P-Value } \\
\cline { 2 - 4 } Infrequent, Minimal & -.611 & 7.429 & .8708 \\
\cline { 2 - 4 } Infrequent, Regular & -.159 & 7.313 & .9656 \\
\cline { 2 - 4 } Infrequent, Steady & 1.043 & 7.026 & .7690 \\
\cline { 2 - 4 } Minimal, Regular & .452 & 3.749 & .8117 \\
\cline { 2 - 4 } Minimal, Steady & 1.655 & 3.153 & .3006 \\
\cline { 2 - 4 } Regular, Steady & 1.203 & 2.868 & .4077 \\
\cline { 2 - 4 } & \multicolumn{3}{|c}{}
\end{tabular}


Stage 1 (Information)

Table I.67

ANOVA Table for STAGE 1

\begin{tabular}{l|r|r|r|r|r|r|r|}
\multicolumn{1}{c}{ DF } & \multicolumn{1}{c}{ Sum of Squares } & \multicolumn{1}{c}{ Mean Square } & \multicolumn{2}{c}{ F-Value } & \multicolumn{2}{c}{ P-Value } & \multicolumn{2}{c}{ Lambda } & Power \\
\cline { 2 - 8 } $\begin{array}{l}\text { WVEIS TIME } \\
\text { Residual }\end{array}$ & 227.066 & 75.689 & 1.650 & .1821 & 4.951 & .412 \\
\cline { 2 - 8 } & 109 & 4999.217 & 45.864 & & & & \\
\hline
\end{tabular}

Table I.68

Means Table for STAGE 1

Effect: WVEIS TIME

\begin{tabular}{|c|c|c|c|c|}
\hline & Count & Mean & Std. Dev. & Std. Err. \\
\hline Infrequent & 3 & 9.667 & 4.933 & 2.848 \\
\hline Minimal & 18 & 14.000 & 6.371 & 1.502 \\
\hline Regular & 23 & 11.217 & 6.660 & 1.389 \\
\hline Steady & 69 & 10.072 & 6.950 & .837 \\
\hline
\end{tabular}

Interaction Bar Plot for STAGE1

Effect: WVEIS TIME

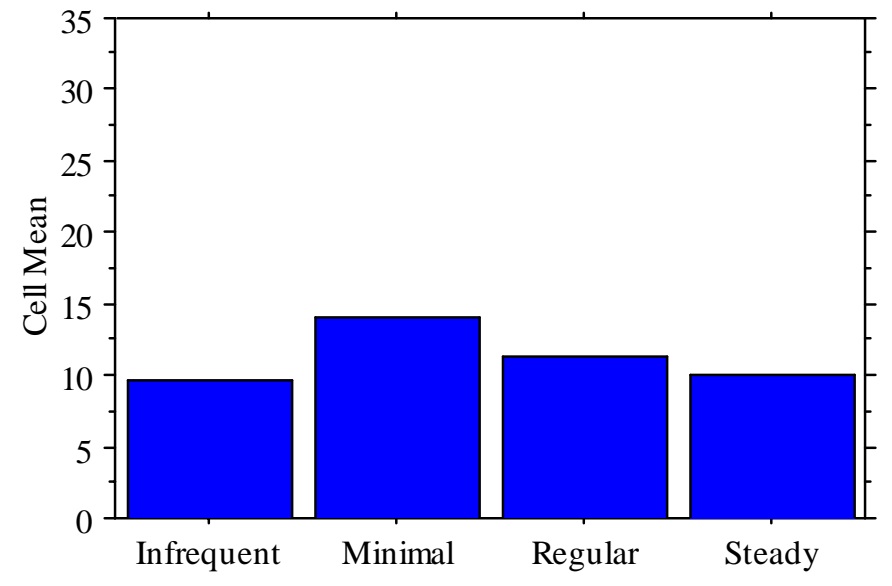

Figure I.25 


\section{Table I.69}

\begin{tabular}{|c|c|c|c|}
\hline \multicolumn{4}{|l|}{$\begin{array}{l}\text { Fisher's PLSD for ST } \\
\text { Effect: WVEIS TIME } \\
\text { Significance Level: } 5\end{array}$} \\
\hline & Mean Diff. & Crit. Diff & P-Value \\
\hline \multirow{2}{*}{$\begin{array}{l}\text { Infrequent, Minimal } \\
\text { Infrequent, Regular }\end{array}$} & -4.333 & 8.370 & .3071 \\
\hline & -1.551 & 8.239 & .7099 \\
\hline Infrequent, Steady & -.406 & 7.916 & .9193 \\
\hline Minimal, Regular & 2.783 & 4.224 & .1944 \\
\hline \multirow{2}{*}{$\begin{array}{l}\text { Minimal, Steady } \\
\text { Regular, Steady }\end{array}$} & 3.928 & 3.552 & .0306 \\
\hline & 1.145 & 3.232 & .4841 \\
\hline
\end{tabular}

Stage 2 (Personal)

Table I.70

ANOVA Table for STAGE 2

\begin{tabular}{|c|c|c|c|c|c|c|c|}
\hline & DF & Sum of Squares & Mean Square & F-Value & P-Value & Lambda & Power \\
\hline W VEIS T IME & 3 & 151.744 & 50.581 & .798 & .4976 & 2.394 & .212 \\
\hline Residual & 109 & 6909.176 & 63.387 & & & & \\
\hline
\end{tabular}

Table I.71

Means Table for STAGE 2

Effect: WVEIS TIME

\begin{tabular}{|c|c|c|c|c|}
\hline & Count & Mean & Std. Dev. & Std. Err. \\
\hline Infrequent & 3 & 8.333 & 8.021 & 4.631 \\
\hline Minimal & 18 & 13.944 & 7.158 & 1.687 \\
\hline Regular & 23 & 12.783 & 7.610 & 1.587 \\
\hline Steady & 69 & 11.348 & 8.257 & .994 \\
\hline
\end{tabular}




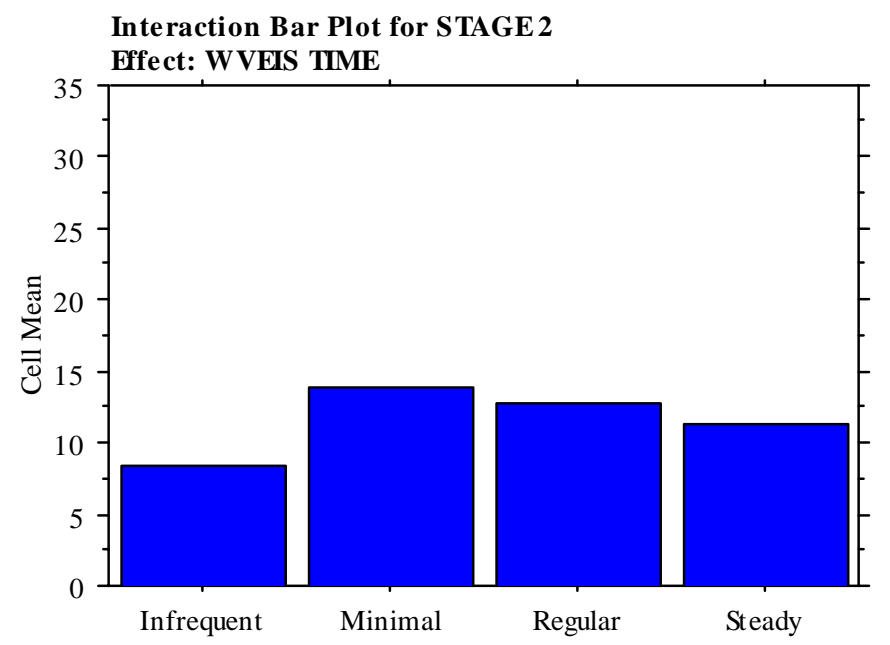

Figure I.26

Table I.72

Fisher's PLSD for STAGE 2

Effect: WVEIS TIME

Significance Level: $5 \%$

\begin{tabular}{l|r|r|r|}
\multicolumn{1}{c}{} & \multicolumn{1}{c}{ Mean Diff. } & \multicolumn{1}{c}{ Crit. Diff } & \multicolumn{1}{c}{ P-Value } \\
\cline { 2 - 4 } Infrequent, Minimal & -5.611 & 9.840 & .2609 \\
\cline { 2 - 4 } Infrequent, Regular & -4.449 & 9.686 & .3646 \\
\cline { 2 - 4 } Infrequent, Steady & -3.014 & 9.306 & .5222 \\
\cline { 2 - 4 } Minimal, Regular & 1.162 & 4.966 & .6438 \\
\cline { 2 - 4 } Minimal, Steady & 2.597 & 4.176 & .2205 \\
\cline { 2 - 4 } Regular, Steady & 1.435 & 3.799 & .4558 \\
\hline
\end{tabular}

Stage 3 (Management)

Table I.73

ANOVA Table for STAGE3

\begin{tabular}{|c|c|c|c|c|c|c|c|}
\hline \multirow{3}{*}{$\begin{array}{l}\text { WVEIS TIME } \\
\text { Residual }\end{array}$} & DF & Sum of Squares & Mean Square & F-Value & P-Value & Lambda & Power \\
\hline & 3 & 57.269 & 19.090 & .421 & .7383 & 1.263 & .130 \\
\hline & 109 & 4942.589 & 45.345 & & & & \\
\hline
\end{tabular}


Table I.74

Means Table for STAGE 3

Effect: WVEIS TIME

\begin{tabular}{|c|c|c|c|c|}
\hline & Count & Mean & Std. Dev. & Std. Err. \\
\hline \multirow{2}{*}{$\begin{array}{l}\text { Infrequent } \\
\text { Minimal }\end{array}$} & 3 & 10.667 & 8.622 & 4.978 \\
\hline & 18 & 11.778 & 5.082 & 1.198 \\
\hline Regular & 23 & 12.000 & 4.964 & 1.035 \\
\hline Steady & 69 & 10.420 & 7.488 & .901 \\
\hline
\end{tabular}

Interaction Bar Plot for STAGE3

Effect: WVEIS TIME

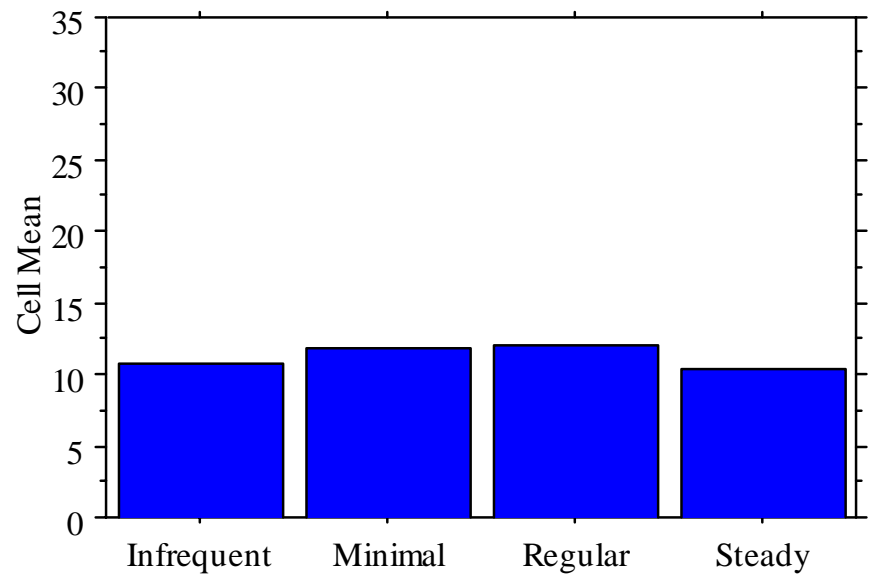

Figure I.27

Table I.75

Fisher's PLSD for STAGE3

Effect: WVEIS TIME

Significance Level: $5 \%$

\begin{tabular}{l|r|r|r|}
\multicolumn{1}{c}{} & \multicolumn{1}{c}{ Mean Diff. } & \multicolumn{1}{c}{ Crit. Diff } & \multicolumn{1}{c}{ P-Value } \\
\cline { 2 - 4 } Infrequent, Minimal & -1.111 & 8.323 & .7918 \\
\cline { 2 - 4 } Infrequent, Regular & -1.333 & 8.193 & .7476 \\
\cline { 2 - 4 } Infrequent, Steady & .246 & 7.871 & .9506 \\
\cline { 2 - 4 } Minimal, Regular & -.222 & 4.200 & .9167 \\
\cline { 2 - 4 } Minimal, Steady & 1.357 & 3.532 & .4479 \\
\cline { 2 - 4 } Regular, Steady & 1.580 & 3.213 & .3320 \\
\cline { 2 - 4 } & \multicolumn{3}{|c}{}
\end{tabular}


Stage 4 (Consequences)

Table I.76

ANOVA Table for STAGE4

\begin{tabular}{|c|c|c|c|c|c|c|c|}
\hline \multirow{3}{*}{$\begin{array}{l}\text { WVEIS TIME } \\
\text { Residual }\end{array}$} & DF & Sum of Squares & Mean Square & F-Value & P-Value & Lambda & Power \\
\hline & 3 & 125.613 & 41.871 & .837 & .4765 & 2.511 & .221 \\
\hline & 109 & 5453.662 & 50.034 & & & & \\
\hline
\end{tabular}

Table I.77

Means Table for STAGE 4

Effect: WVEIS TIME

\begin{tabular}{l|r|r|r|r|}
\multicolumn{1}{c}{} & \multicolumn{1}{c}{ Count } & \multicolumn{1}{c}{ Mean } & \multicolumn{1}{c}{ Std. Dev. } & \multicolumn{1}{c}{ Std. Err. } \\
\cline { 2 - 5 } Infrequent & 3 & 4.000 & 3.464 & 2.000 \\
\cline { 2 - 5 } Minimal & 18 & 8.778 & 7.377 & 1.739 \\
\cline { 2 - 5 } Regular & 23 & 6.783 & 5.265 & 1.098 \\
\cline { 2 - 5 } Steady & 69 & 6.072 & 7.568 & .911 \\
\cline { 2 - 5 } & & &
\end{tabular}

Interaction Bar Plot for STAGE4

Effect: WVEIS TIME

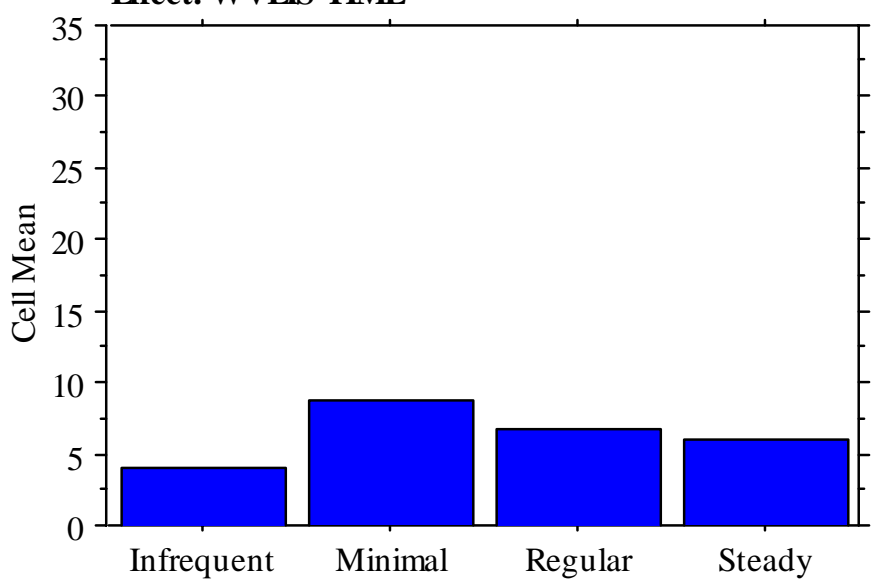

Figure I.28 


\section{Table I.78}

\begin{tabular}{|c|c|c|c|}
\hline \multicolumn{4}{|c|}{$\begin{array}{l}\text { Fisher's PLSD for STAGE } 4 \\
\text { Effect: WVEIS TIME } \\
\text { Significance Level: } 5 \%\end{array}$} \\
\hline \multirow{2}{*}{$\begin{array}{l}\text { Infrequent, Minimal } \\
\text { Infrequent, Regular }\end{array}$} & -4.778 & 8.743 & .2811 \\
\hline & -2.783 & 8.606 & .5230 \\
\hline Infrequent, Steady & -2.072 & 8.268 & .6203 \\
\hline Minimal, Regular & 1.995 & 4.412 & .3721 \\
\hline Minimal, Steady & 2.705 & 3.710 & .1513 \\
\hline Regular, Steady & .710 & 3.375 & .6775 \\
\hline
\end{tabular}

Stage 5 (Collaboration)

Table I.79

ANOVA Table for STAGE 5
\begin{tabular}{l|r|r|r|r|r|r|r|} 
DF Sum of Squares & \multicolumn{1}{c}{ Mean Square } & \multicolumn{2}{c}{ F-Value } & \multicolumn{1}{c}{ P-Value Lambda } & \multicolumn{2}{c}{ Power } \\
WVIS TIME & 3 & 153.852 & 51.284 & .671 & .5714 & 2.014 & .183 \\
\cline { 2 - 8 } Residual & 109 & 8325.652 & 76.382 & & & & \\
\hline
\end{tabular}

Table I.80

Means Table for STAGE 5

Effect: WVEIS TIME

\begin{tabular}{|c|c|c|c|c|}
\hline \multirow{3}{*}{$\begin{array}{l}\text { Infrequent } \\
\text { Minimal }\end{array}$} & Count & Mean & Std. Dev. & Std. Err. \\
\hline & 3 & 12.667 & 6.658 & 3.844 \\
\hline & 18 & 14.333 & 6.544 & 1.542 \\
\hline Regular & 23 & 17.739 & 8.905 & 1.857 \\
\hline Steady & 69 & 16.188 & 9.207 & 1.108 \\
\hline
\end{tabular}




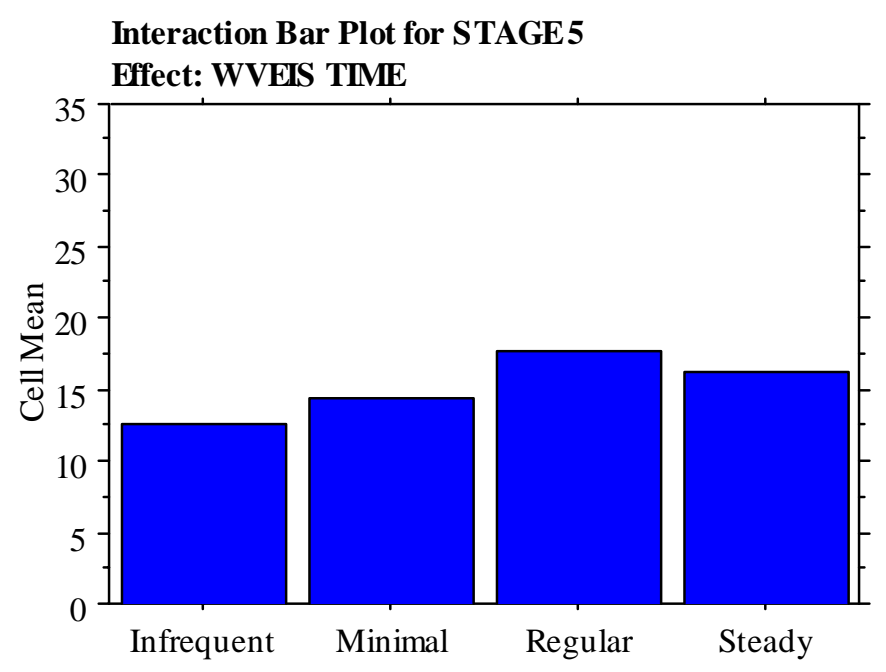

Figure I.29

Table I.81

Fisher's PLSD for STAGE 5

Effect: WVEIS TIME

Significance Level: $5 \%$

\begin{tabular}{l|r|r|r|} 
& \multicolumn{1}{c}{ Mean Diff. } & \multicolumn{1}{c}{ Crit. Diff } & \multicolumn{1}{c}{ P-Value } \\
\cline { 2 - 4 } Infrequent, Minimal & -1.667 & 10.802 & .7603 \\
\cline { 2 - 4 } Infrequent, Regular & -5.072 & 10.633 & .3465 \\
\cline { 2 - 4 } Infrequent, Steady & -3.522 & 10.216 & .4959 \\
\cline { 2 - 4 } Minimal, Regular & -3.406 & 5.451 & .2183 \\
\cline { 2 - 4 } Minimal, Steady & -1.855 & 4.584 & .4243 \\
\cline { 2 - 4 } Regular, Steady & 1.551 & 4.171 & .4627 \\
\cline { 2 - 4 } & & &
\end{tabular}

Stage 6 (Refocusing)

Table I.82

ANOVA Table for STAGE6

W VEIS TIME

DF Sum of Squares Mean Square F-Value P-Value Lambda Power

Residual

\begin{tabular}{|r|r|r|r|r|r|r|}
\hline 3 & 47.855 & 15.952 & .325 & .8071 & .976 & .110 \\
\hline 109 & 5346.676 & 49.052 & & & & \\
\hline
\end{tabular}




\section{Table I.83}

Means Table for STAGE 6

Effect: WVEIS TIME

\begin{tabular}{|c|c|c|c|c|}
\hline & Count & Mean & Std. Dev. & Std. Err. \\
\hline Infrequent & 3 & 9.333 & 6.429 & 3.712 \\
\hline Minimal & 18 & 10.222 & 6.093 & 1.436 \\
\hline Regular & 23 & 11.913 & 5.736 & 1.196 \\
\hline Steady & 69 & 10.449 & 7.582 & .913 \\
\hline
\end{tabular}

Interaction Bar Plot for ST AGE 6

Effect: WVEIS TIME

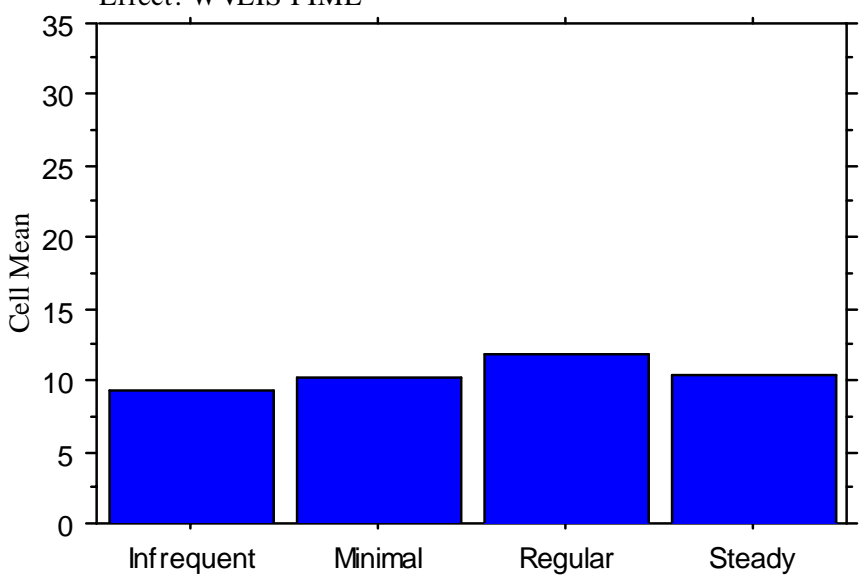

Figure I.30

Table I.84

\section{Fisher's PLSD for STAGE 6}

Effect: WVEIS TIME

Significance Level: $5 \%$

\begin{tabular}{|c|c|c|c|}
\hline & Mean Diff. & Crit. Diff & P-Value \\
\hline \multirow{2}{*}{$\begin{array}{l}\text { Infrequent, Minimal } \\
\text { Infrequent, Regular }\end{array}$} & -.889 & 8.656 & .8391 \\
\hline & -2.580 & 8.521 & .5497 \\
\hline Infrequent, Steady & -1.116 & 8.187 & .7875 \\
\hline Minimal, Regular & -1.691 & 4.368 & .4447 \\
\hline Minimal, Steady & -.227 & 3.674 & .9027 \\
\hline Regular, Steady & 1.464 & 3.342 & .3873 \\
\hline
\end{tabular}




\section{Subquestion 4}

Table I.85

$$
\begin{aligned}
& \mathrm{N}=117 \\
& \text { Pre-conference Survey }
\end{aligned}
$$

Stage 0 (Awareness)

\section{Unpaired t-test for STAGE 0 \\ Grouping Variable: DATA CONFERENCE}

Hypothesized Difference $=\mathbf{0}$ Mean Diff. DF $t$-Value P-Value

Attended, Did Not Attend

\begin{tabular}{l|l|l|l|}
-.299 & 115 & -.260 & .7953 \\
\hline
\end{tabular}

\section{Table I.86}

\section{Group Info for STAGE 0}

Grouping Variable: DATA CONFERENCE

Count Mean Variance Std. Dev. Std. Err

Attended

Did Not Attend

\begin{tabular}{|l|l|l|l|r|}
\hline 59 & 9.339 & 38.090 & 6.172 & .803 \\
\hline 58 & 9.638 & 39.217 & 6.262 & .822 \\
\hline
\end{tabular}

Table I.87

Stage 1 (Information)

Unpaired t-test for STAGE 1

Grouping Variable: DATA CONFERENCE

Hypothesized Difference $=0$

Attended, Did Not Attend

\begin{tabular}{|r|r|r|r|}
\multicolumn{1}{|c}{ Mean Diff. } & \multicolumn{1}{c}{ DF } & \multicolumn{1}{c}{ t-Value } & \multicolumn{1}{c}{ P-Value } \\
\hline-.361 & 115 & -.283 & .7781 \\
\hline
\end{tabular}

\section{Table I.88}

\section{Group Info for STAGE 1}

\begin{tabular}{|c|c|c|c|c|c|}
\hline & Count & Mean & Variance & Std. Dev. & Std. Err \\
\hline Attended & 59 & 10.966 & 46.068 & 6.787 & .884 \\
\hline Did Not Attend & 58 & 11.328 & 49.733 & 7.052 & .926 \\
\hline
\end{tabular}

Grouping Variable: DATA CONFERENCE 
Stage 2 (Personal)

Table I.89

Unpaired t-test for S TAGE 2

Grouping Variable: DATA CONFERENCE

Hypothesized Difference $=0$

Attended, Did Not Attend

Mean Diff. DF t-Value P-Value

\begin{tabular}{|l|l|l|l|}
\hline 2.118 & 115 & 1.455 & .1484 \\
\hline
\end{tabular}

Table I.90

Group Info for S TA GE 2

Grouping Variable: DATA CONFERENCE

A ttended

Did Not Attend

\begin{tabular}{|r|r|r|r|r|} 
Count & Mean & Variance & \multicolumn{1}{c}{ Std. Dev. } & Std. Err \\
\hline 59 & 13.169 & 69.454 & 8.334 & 1.085 \\
\hline 58 & 11.052 & 54.366 & 7.373 & .968 \\
\hline
\end{tabular}

Stage 3 (Management)

Table I.91

Unpaired t-test for STAGE 3

Grouping Variable: DATA CONFERENCE

Hypothesized Difference $=0$

Attended, Did Not Attend

Mean Diff. DF t-Value P-Value

\begin{tabular}{l|l|l|}
3.844 & 115 & 3.228 \\
\hline
\end{tabular}

.0016

Group Info for STAGE3 Table I.92

Grouping Variable: DATA CONFERENCE

Attended

Did Not Attend

\begin{tabular}{|r|r|r|r|r|} 
Count & \multicolumn{1}{c}{ Mean } & \multicolumn{1}{c}{ Variance } & \multicolumn{1}{c}{ Std. Dev. Std. Err } \\
\hline 59 & 13.051 & 50.601 & 7.113 & .926 \\
\hline 58 & 9.207 & 32.167 & 5.672 & .745 \\
\hline
\end{tabular}

Stage 4 (Consequences)

Table I.93

Unpaired t-test for STAGE 4

Grouping Variable: DATA CONFERENCE

Hypothesized Difference $=0$

Attended, Did Not Attend

\begin{tabular}{|r|r|r|r|} 
Mean Diff. & \multicolumn{1}{c}{ DF } & \multicolumn{1}{c}{ t-Value } & \multicolumn{1}{c}{ P-Value } \\
\hline 2.364 & 115 & 1.821 & .0712 \\
\hline
\end{tabular}

Group Info for STAGE 4 Table I.94 Grouping Variable: DATA CONFERENCE

\begin{tabular}{l|r|r|r|r|r|}
\multicolumn{1}{c}{} & \multicolumn{1}{c}{ Count } & \multicolumn{1}{c}{ Mean } & \multicolumn{1}{c}{ Variance } & \multicolumn{1}{c}{ Std. Dev. } & \multicolumn{1}{c}{ Std. Err } \\
\cline { 2 - 7 } Attended & 59 & 7.915 & 63.665 & 7.979 & 1.039 \\
\cline { 2 - 7 } Did Not Attend & 58 & 5.552 & 34.603 & 5.882 & .772 \\
\cline { 2 - 6 }
\end{tabular}


Stage 5 (Collaboration)

Table I.95

Unpaired t-test for STAGE 5

Grouping Variable: DATA CONFERENCE

Hypothesized Difference $=0$

Attended, Did Not Attend

Mean Diff. DF t-Value P-Value

Attended, Did Not Attend

\begin{tabular}{l|l|l|l|}
3.916 & 115 & 2.477 & .0147 \\
\hline
\end{tabular}

\section{Table I.96}

Group Info for STAGE 5

Grouping Variable: DATA CONFERENCE

\begin{tabular}{l|r|r|r|r|r|}
\multicolumn{1}{c}{ Attended } & \multicolumn{1}{c}{ Count } & \multicolumn{1}{c}{ Mean } & \multicolumn{1}{c}{ Variance } & \multicolumn{1}{c}{ Std. Dev. } & \multicolumn{1}{c}{ Std. Err } \\
\cline { 2 - 7 } Did Not Attend & 59 & 17.898 & 86.748 & 9.314 & 1.213 \\
\cline { 2 - 7 } & 58 & 13.983 & 59.140 & 7.690 & 1.010 \\
\hline
\end{tabular}

\section{Stage 6 (Refocusing)}

Table I.97

Unpaired t-test for STAGE 6

Grouping Variable: DATA CONFERENCE

Hypothesized Difference $=0$

\begin{tabular}{lr|r|r|r|} 
& \multicolumn{1}{c}{ Mean Diff. } & \multicolumn{1}{c}{ DF } & \multicolumn{1}{c}{ t-Value } & \multicolumn{1}{c}{ P-Value } \\
\cline { 2 - 5 } Attended, Did Not Attend & 2.897 & 115 & 2.311 & .0226 \\
\cline { 2 - 5 }
\end{tabular}

\section{Table I.98}

\section{Group Info for STAGE 6}

Grouping Variable: DATA CONFERENCE

\begin{tabular}{l|r|r|r|r|r|}
\multicolumn{1}{c}{ Attended } & \multicolumn{1}{c}{ Count } & \multicolumn{1}{c}{ Mean } & \multicolumn{1}{c}{ Variance } & \multicolumn{1}{c}{ Std. Dev. } & \multicolumn{1}{c}{ Std. Err } \\
\cline { 2 - 6 } Did Not Attend & 59 & 12.000 & 54.207 & 7.363 & .959 \\
\cline { 2 - 6 } & 58 & 9.103 & 37.568 & 6.129 & .805 \\
\hline
\end{tabular}

Paired t-test

Stage 3 (Management)

Table I.99

$$
\mathrm{N}=37
$$

Paired t-test

Hypothesized Difference $=0$

Stage 3 Attended Pre, Post

Mean Diff. DF t-Value P-Value


Table I.100

\section{Paired t-test \\ Hypothesized Difference $=\mathbf{0} \quad \mathrm{N}=35$}

Stage 3 Did Not Attend Pre, Stage 3 Did Not Attend Post

\begin{tabular}{|r|r|r|r|}
\multicolumn{1}{c}{ Mean Diff. } & \multicolumn{1}{c}{ DF } & \multicolumn{1}{c}{ t-Value } & \multicolumn{1}{c}{ P-Value } \\
\hline .400 & 34 & .433 & .6679 \\
\hline
\end{tabular}

Table I.101

$$
\mathrm{N}=37
$$

\section{Paired t-test}

Hypothesized Difference $=0$

Stage 5 Attended Pre, Stage 5 Attended Post

\begin{tabular}{|r|r|r|r|}
\multicolumn{1}{r|}{ Mean Diff. } & \multicolumn{1}{c}{ DF } & \multicolumn{1}{c}{ t-Value } & \multicolumn{1}{c}{ P-Value } \\
\hline .432 & 36 & .205 & .8390 \\
\hline
\end{tabular}

Table.I.102

$$
\mathrm{N}=35
$$

\section{Paired t-test}

\section{Hypothesized Difference $=0$}

\begin{tabular}{lr|r|r|r|} 
& \multicolumn{1}{r}{ Mean Diff. } & \multicolumn{1}{r}{ DF - Value } & P-Value \\
\cline { 2 - 5 } Stage 5 Did Not Attend Pre, Stage 5 Did Not Attend Post & 1.029 & 34 & .566 & .5752 \\
\hline
\end{tabular}

Table I.103

\section{Paired t-test$$
\mathrm{N}=37
$$ \\ Hypothesized Difference $=0$}

\begin{tabular}{|c|c|c|c|}
\hline Mean & $\mathrm{DF}$ & t-Value & P-Value \\
\hline 973 & 36 & .566 & .5752 \\
\hline
\end{tabular}

Stage 6 Attended Pre, Stage 6 Attended Post

Table I.104

\section{Paired t-test \\ Hypothesized Difference $=0$}

Stage 6 Did Not Attend Pre, Did Not Attend Post

\begin{tabular}{r|r|r|r|} 
Mean Diff. & \multicolumn{1}{c}{ DF } & \multicolumn{1}{c}{ t-Value } & \multicolumn{1}{c}{ P-Value } \\
\hline-.114 & 43 & -.080 & .9365 \\
\hline
\end{tabular}


Post-Conference Survey

$$
\begin{aligned}
& \mathrm{N}=72 \\
& \text { Stage } 0 \text { (Awareness) }
\end{aligned}
$$

Table I.105

$$
\mathrm{N}=72
$$

Unpaired t-test for STAGE 0

Grouping Variable: DATA CONFERENCE

Hypothesized Difference $=0$

\begin{tabular}{cr|r|r|r|}
\multicolumn{1}{c}{} & Mean Diff. & \multicolumn{1}{c}{ DF } & \multicolumn{1}{c}{-Value } & \multicolumn{1}{c}{ P-Value } \\
\cline { 2 - 5 } Attended, Did Not Attend & -1.923 & 70 & -1.802 & .0758 \\
\cline { 2 - 5 }
\end{tabular}

Table I.106

Group Info for STAGE 0

Grouping Variable: DATA CONFERENCE

\begin{tabular}{l|r|r|r|r|r|}
\multicolumn{1}{c}{ Count } & \multicolumn{1}{c}{ Mean } & \multicolumn{2}{c}{ Variance } & \multicolumn{1}{c}{ Std. Dev. } & \multicolumn{1}{c}{ Std. Err } \\
\cline { 2 - 7 } Attended & 37 & 6.649 & 11.401 & 3.377 & .555 \\
\cline { 2 - 7 } Did Not Attend & 35 & 8.571 & 30.076 & 5.484 & .927 \\
\cline { 2 - 7 }
\end{tabular}

Stage 1 (Information)

Table I.107

Unpaired t-test for STAGE 1

Grouping Variable: DATA CONFERENCE

Hypothesized Difference $=0$

\begin{tabular}{cr|r|r|r|} 
& \multicolumn{1}{c}{ Mean Diff. } & \multicolumn{1}{c}{ DF } & t-Value & \multicolumn{1}{c}{ P-Value } \\
\cline { 2 - 5 } Attended, Did Not Attend & .729 & 70 & .506 & .6145 \\
\cline { 2 - 5 }
\end{tabular}

Group Info for STAGE 1

\begin{tabular}{|c|c|c|c|c|c|}
\hline & Count & Mean & Variance & Std. Dev. & Std. Err \\
\hline Attended & 37 & 9.243 & 35.078 & 5.923 & .974 \\
\hline Did Not Attend & 35 & 8.514 & 39.728 & 6.303 & 1.065 \\
\hline
\end{tabular}

Table I.108

Grouping Variable: DATA CONFERENCE 
Stage 2 (Personal)

Table I.109

\section{Unpaired t-test for STAGE 2 \\ Grouping Variable: DATA CONFERENCE \\ Hypothesized Difference $=0$}

\begin{tabular}{cr|r|r|r|} 
& Mean Diff. & \multicolumn{1}{c}{ DF } & \multicolumn{1}{c}{ t-Value } & \multicolumn{1}{c}{ P-Value } \\
\cline { 2 - 5 } Attended, Did Not Attend & .068 & 70 & .040 & .9683 \\
\cline { 2 - 5 } & & &
\end{tabular}

Group Info for STAGE 2

Table I.110

Grouping Variable: DATA CONFERENCE

\begin{tabular}{l|r|r|r|r|r|}
\multicolumn{1}{c}{ Attended } & \multicolumn{1}{c}{ Count } & \multicolumn{1}{c}{ Mean } & \multicolumn{1}{c}{ Variance } & \multicolumn{1}{c}{ Std. Dev. } & \multicolumn{1}{c}{ Std. Err } \\
\cline { 2 - 7 } Did Not Attend & 37 & 9.811 & 50.158 & 7.082 & 1.164 \\
\cline { 2 - 7 } & 35 & 9.743 & 54.491 & 7.382 & 1.248 \\
\cline { 2 - 6 }
\end{tabular}

Stage 3 (Management)

Table I.111

Unpaired t-test for STAGE 3

Grouping Variable: DATA CONFERENCE

Hypothesized Difference $=0$

\begin{tabular}{cr|r|r|r|} 
& \multicolumn{1}{c}{ Mean Diff. } & \multicolumn{1}{c}{ DF } & t-Value & \multicolumn{1}{c}{ P-Value } \\
\cline { 2 - 5 } Attended, Did Not Attend & .970 & 70 & .607 & .5461 \\
\cline { 2 - 5 }
\end{tabular}

Table I.112

Group Info for STAGE 3

Grouping Variable: DATA CONFERENCE

\begin{tabular}{|c|c|c|c|c|c|}
\hline & Count & Mean & Variance & Std. Dev. & Std. Err \\
\hline Attended & 37 & 11.027 & 48.916 & 6.994 & 1.150 \\
\hline Did Not Attend & 35 & 10.057 & 42.879 & 6.548 & 1.107 \\
\hline
\end{tabular}


Stage 4 (Consequences)

Table I.113

Unpaired t-test for STAGE 4

Grouping Variable: DATA CONFERENCE

Hypothesized Difference $=0$

\begin{tabular}{lr|r|r|r|} 
& \multicolumn{1}{c}{ Mean Diff. } & \multicolumn{1}{c}{ DF } & \multicolumn{1}{c}{ t-Value } & \multicolumn{1}{c}{ P-Value } \\
\cline { 2 - 5 } Attended, Did Not Attend & -.033 & 70 & -.025 & .9801 \\
\cline { 2 - 5 }
\end{tabular}

Table I.114

Group Info for STAGE 4

Grouping Variable: DATA CONFERENCE

\begin{tabular}{l|r|r|r|r|r|}
\multicolumn{1}{c}{} & \multicolumn{2}{c}{ Count } & \multicolumn{1}{c}{ Mean } & \multicolumn{1}{c}{ Variance } & \multicolumn{1}{c}{ Std. Dev. } \\
\cline { 2 - 6 } Attended & 37 & 5.081 & 35.965 & 5.997 & .986 \\
\cline { 2 - 7 } Did Not Attend & 35 & 5.114 & 27.281 & 5.223 & .883 \\
\cline { 2 - 6 }
\end{tabular}

Stage 5 (Collaboration)

Table I.115

Unpaired t-test for STAGE 5

Grouping Variable: DATA CONFERENCE

Hypothesized Difference $=0$

\begin{tabular}{lr|r|r|r|} 
& \multicolumn{1}{c}{ Mean Diff. } & \multicolumn{1}{c}{ DF } & t-Value & P-Value \\
\cline { 2 - 5 } Attended, Did Not Attend & 3.755 & 70 & 1.749 & .0847 \\
\cline { 2 - 5 }
\end{tabular}

Table I.116

Group Info for STAGE 5

Grouping Variable: DATA CONFERENCE

\begin{tabular}{|c|c|c|c|c|c|}
\hline & Count & Mean & Variance & Std. Dev. & Std. Err \\
\hline Attended & 37 & 17.784 & 85.285 & 9.235 & 1.518 \\
\hline Did Not Attend & 35 & 14.029 & 80.382 & 8.966 & 1.515 \\
\hline
\end{tabular}




\section{Stage 6 (Refocusing)}

Table I.117

Unpaired t-test for STAGE 6

Grouping Variable: DATA CONFERENCE

Hypothesized Difference $=0$

\begin{tabular}{lr|r|r|r|} 
& \multicolumn{1}{c}{ Mean Diff. } & \multicolumn{1}{c}{ DF } & \multicolumn{1}{c}{ t-Value } & \multicolumn{1}{c}{ P-Value } \\
\cline { 2 - 5 } Attended, Did Not Attend & .019 & 70 & .012 & .9901 \\
\cline { 2 - 5 }
\end{tabular}

Table I.118

Group Info for STAGE 6

Grouping Variable: DATA CONFERENCE

\begin{tabular}{l|r|r|r|r|r|}
\multicolumn{1}{c}{ Count } & \multicolumn{1}{c}{ Mean } & \multicolumn{1}{c}{ Variance } & \multicolumn{1}{c}{ Std. Dev. } & \multicolumn{1}{c}{ Std. Err } \\
\cline { 2 - 7 } Attended & 37 & 10.162 & 45.640 & 6.756 & 1.111 \\
\cline { 2 - 7 } Did Not Attend & 35 & 10.143 & 41.185 & 6.418 & 1.085 \\
\cline { 2 - 6 }
\end{tabular}


Vitae

Toni Lynne DeVore

Toni Lynne DeVore attended Fairmont State College, receiving a Bachelor of Arts in Education in 1972. She began her teaching career at Washington Junior High School in 1972. In 1977, she received a Master of Education with emphasis in Earth Science from The University of Texas at Austin. She has been an adjunct instructor at Glenville State College. She is currently the Math/Science Supervisor for Wood County Schools in Parkersburg, WV. In 1999, she received her educational doctorate from West Virginia University.

She resides in Parkersburg, West Virginia with her husband Joseph Smith and daughter Sararose. 